\title{
Test Data for USEPR Severe Accident Code Validation
}

\author{
J. L. Rempe
}

May 2007

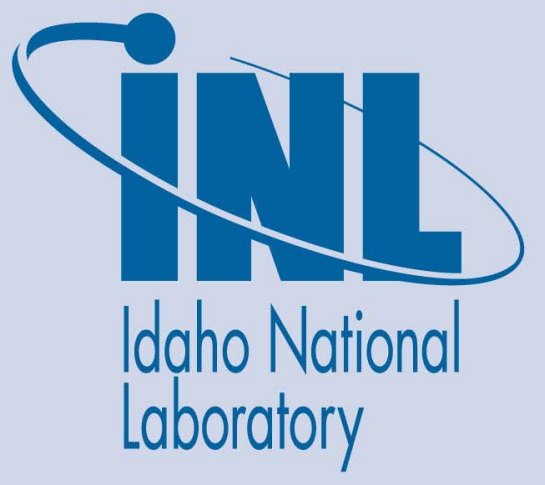

The INL is a U.S. Department of Energy National Laboratory operated by Battelle Energy Alliance 
INL/EXT-06-11326

Rev. 3

\title{
Test Data for USEPR Severe Accident Code Validation
}

\author{
J. L. Rempe
}

May 2007

\author{
Idaho National Laboratory \\ Idaho Falls, Idaho 83415 \\ www.inl.gov \\ Prepared for the \\ U.S. Department of Energy \\ Office of Nuclear Energy \\ Under DOE Idaho Operations Office \\ Contract DE-AC07-05ID14517
}


INEEL/EXT-06-11326 


\section{CONTENTS}

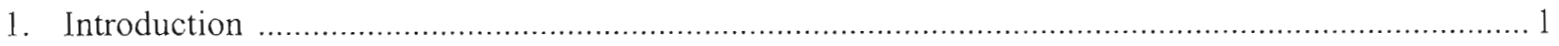

2. Fuel Heatup and Melt Progression …….............................................................................

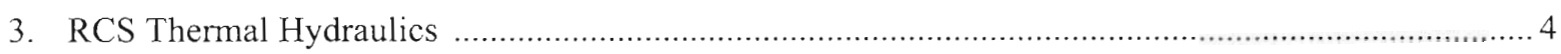

4. In-Vessel Molten Pool Formation and Heat Transfer ..................................................................... 7

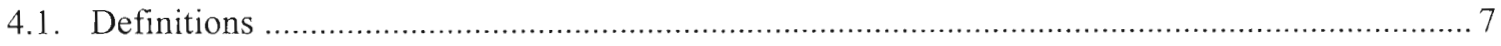

4.2. Typical Ranges for Heat Transfer Parameters .................................................................... 9

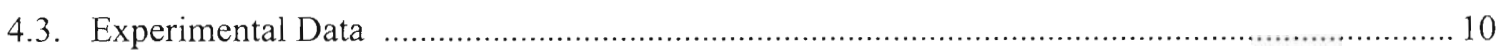

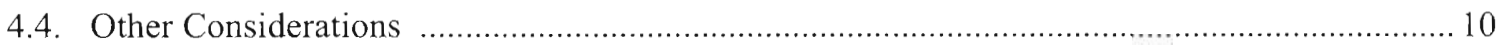

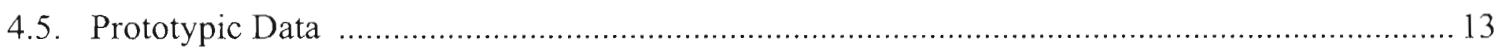

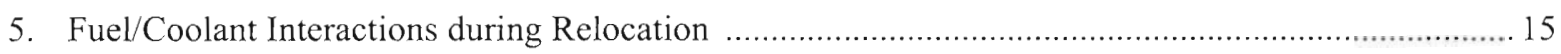

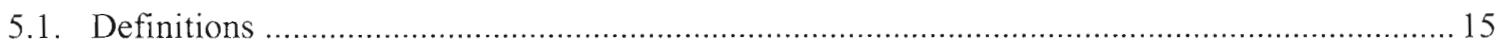

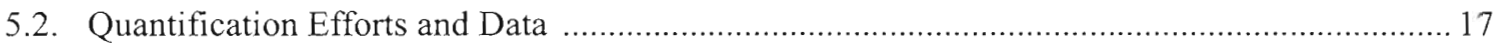

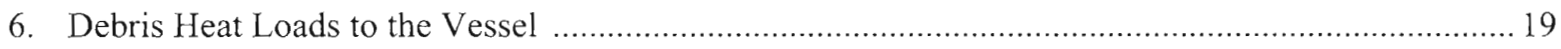

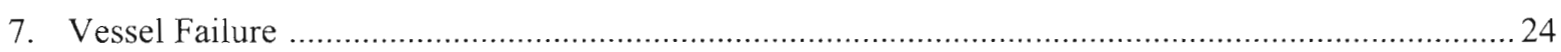

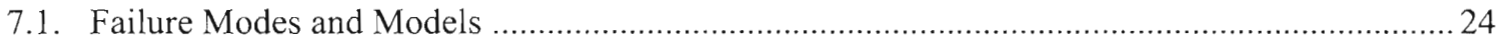

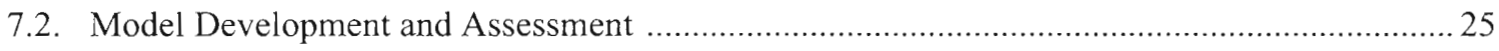

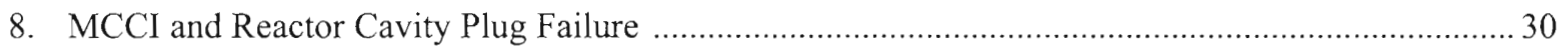

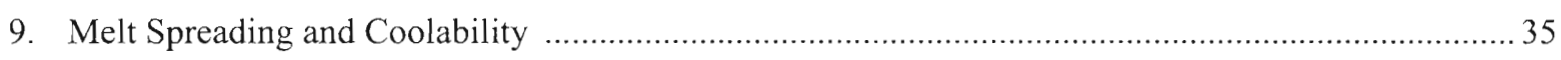

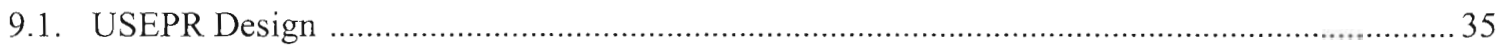

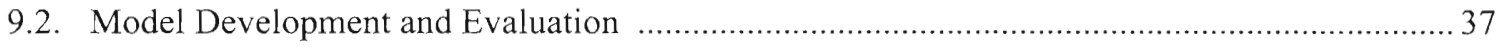

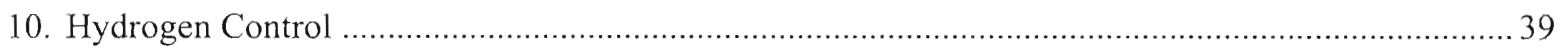

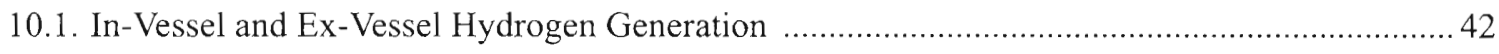

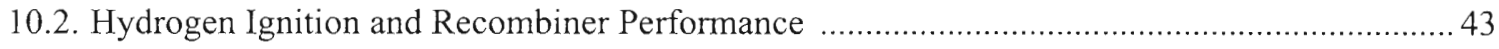

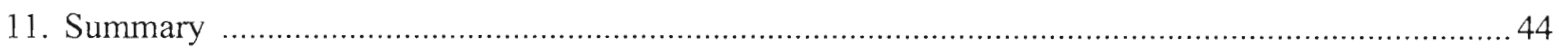

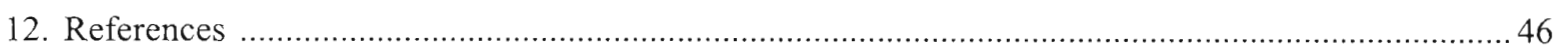


INEEL/EXT-06-11326 


\section{FIGURES}

1. SCDAP/RELAP5/MOD3.3 calculated collapsed liquid level in the reactor vessel. ........................5

2. Calculated and measured primary coolant system pressure. ..................................................... 6

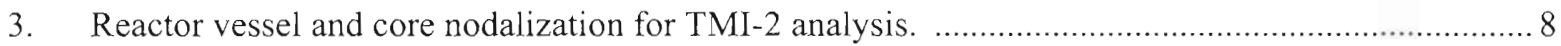

4. Lower head/corium configurations considered in AP600 review. ........................................... 12

5. Initial and final states of prototypic debris in the RASPLAV-AW-200-2 experimental section. ..... 14

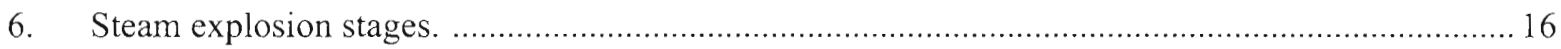

7. Geometry of steam explosion facilities testing with prototypic materials (not to scale). ............... 19

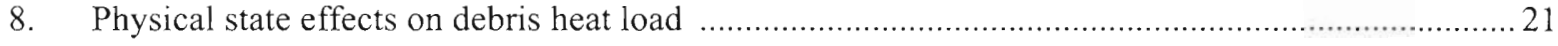

9. Possible geometries enhancing relocated debris coolability. .................................................... 21

10. Debris removed from FARO L-19 melt/water interaction test (Magallon, 1999) ........................22

11. ALPHA test results demonstrating impact of gap cooling. ............................................................ 23

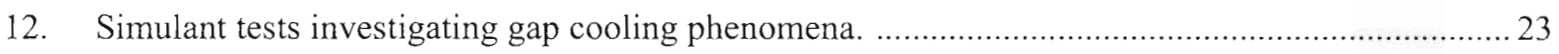

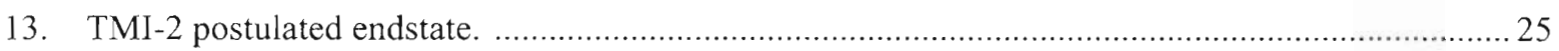

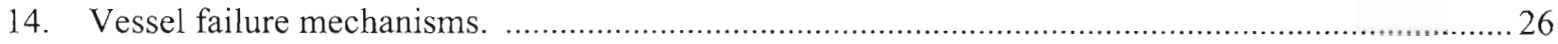

15. Location of nozzles and boat samples examined in the TMI-2 VIP. ......................................... 28

16. TMI-2 reactor pressure history indicated predicted timing of vessel failure. .................................. 29

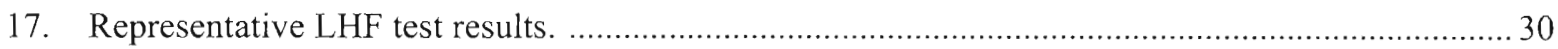

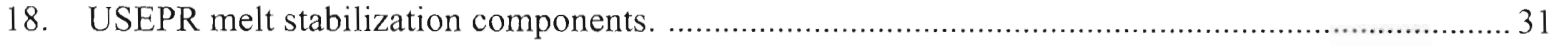

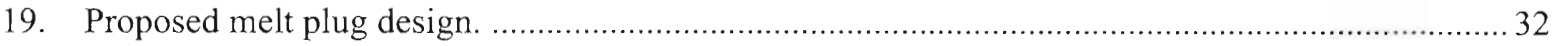

20. Preliminary design for melt plug support structure. …................................................................ 32

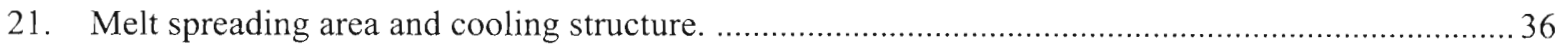

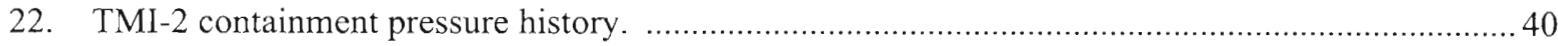

23. Flammability limits of hydrogen: air: steam mixtures. .......................................................... 41 


\section{TABLES}

1 Selected PWR-specific tests for early phase melt progression assessment. ........................ 3

2 Data for benchmarking PWR RCS pressure response. ................................................. 4

3 Ranges for variables used to estimate pool heat transfer parameters................................ 9

4 Natural convection studies for hemispherical and tori-spherical cavities......................... 11

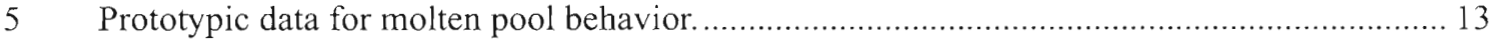

6 Steam explosion test facilities using prototypic materials. ........................................... 18

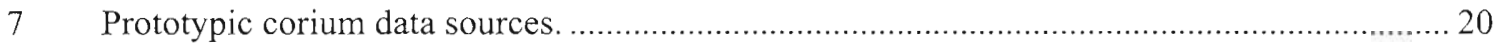

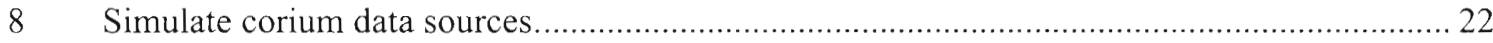

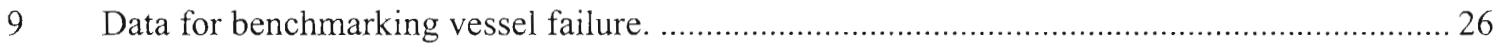

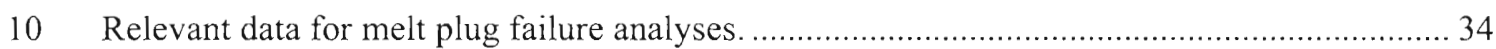

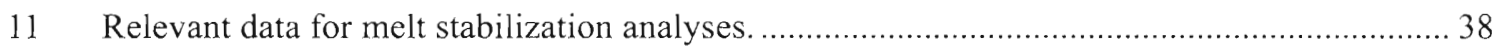

12 Relevant data sources for assessing ex-vessel hydrogen behavior.................................43

13 Summary recommendations for phenomena evaluated. .............................................45 


\section{Introduction}

The document identifies data that can be used for assessing various models embodied in severe accident analysis codes. Phenomena considered in this document, which were limited to those anticipated to be of interest in assessing severe accidents in the USEPR developed by AREVA, include:

- Fuel Heatup and Melt Progression (Section 2)

- Reactor Coolant System (RCS) Thermal Hydraulics (Section 3)

- In-Vessel Molten Pool Formation and Heat Transfer (Section 4)

- Fuel/Coolant Interactions during Relocation (Section 5)

- Debris Heat Loads to the Vessel (Section 6)

- Vessel Failure (Section 7)

- Molten Core Concrete Interaction (MCCI) and Reactor Cavity Plug Failure (Section 8)

- Melt Spreading and Coolability (Section 9)

- Hydrogen Control (Section 10)

As indicated above, each section of this report discusses one phenomenon of interest to the USEPR. Within each section, an effort is made to describe the phenomenon and identify what data are available modeling it. As noted in this document, models in US accident analysis codes (MAAP, MELCOR, and SCDAP/RELAP5) differ. Where possible, this report identifies previous assessments that illustrate the impact of modeling differences on predicting various phenomena. Section 11 summarizes recommendations regarding the status of data available for modeling USEPR severe accident phenomena.

\section{Fuel Heatup and Melt Progression}

Inadequate cooling of the core may lead to fuel heatup, dissolution due to component material interactions, and relocation. Analytical tools must be able to simulate the progression of damage to the reactor core. Models must be able to calculate the heatup, oxidation and meltdown of fuel rods and control rods, the ballooning and rupture of fuel rod cladding, the release of fission products from fuel rods, and the disintegration of fuel rods into porous debris and molten material. This section identifies representative sources of data available for evaluating the ability of analytical tools to simulate fuel heatup and melt progression and previous efforts to compare severe accident code models with this data.

Table 1 identifies representative test programs for benchmarking early phase PWR fuel heatup and melt progression phenomena. References 1 through 3 describe efforts to compare USdeveloped severe accident analysis codes to this data. These references typically describe the models used to simulate tests and phenomena listed in Table 1 and provide key references from which the data were obtained. These test programs provide time- and/or location-dependent data for evaluating early phase melt progression phenomena, such as fuel temperature, hydrogen production, cladding ballooning and rupture, and cladding oxidation fraction. In addition, Table 1 
identifies data for evaluation of initial key late phase melt progression phenomena, such as inpool molten pool formation, melt blockages, crust formation, and crust failure leading to melt relocation. Note that many of the tests listed in Table 1 considered the impact of cladding and control materials. In addition, tests were conducted in both inert gas (argon or helium) and steam conditions.

Because USEPR fuel is expected to be similar to PWR fuel used in previous benchmarking efforts, no additional data are needed to verify the ability of severe accident codes to model USEPR fuel heatup and melt progression. However, it is recommended that AREVA NP be knowledgeable of the differences among the various codes used to simulate key phenomena. 
Table 1. Selected PWR-specific tests for early phase melt progression assessment.

\begin{tabular}{|c|c|}
\hline Data - (Test Organization) & Phenomena \\
\hline \begin{tabular}{|l|l} 
Full Length High & I \\
Temperature Test 5 (FLHT- & c \\
5) (PNNL) & a
\end{tabular} & $\begin{array}{l}\text { Nuclear heatup of full-length PWR fuel assembly with gradual boiloff of } \\
\text { coolant. Measurements for rate of boiloff, fuel rod temperature and damage, } \\
\text { and } \mathrm{H}_{2} \text { production. SCDAP/RELAP5 analyses completed and documented. } \\
{[1]}\end{array}$ \\
\hline $\begin{array}{l}\text { Plasma Burst Facility } \\
\text { Severe Fuel Damage } \\
\text { Scoping Test (PBF SFD } \\
\text { ST) (INL) }\end{array}$ & $\begin{array}{l}\text { Nuclear heatup of PWR fuel assembly. Top of fuel assembly uncovered due } \\
\text { to coolant boiloff. Measurements for rate of boiloff, fuel rod temperature } \\
\text { and damage, and } \mathrm{H}_{2} \text { production. SCDAP/RELAP5 analyses completed and } \\
\text { documented. [1] }\end{array}$ \\
\hline PBF SFD 1-1 Test (INL) & $\begin{array}{l}\text { Nuclear heatup of PWR fuel assembly with steam flow. Measurements of } \\
\text { fuel rod temperatures and damage and } \mathrm{H}_{2} \text { production. SCDAP/RELAP5 } \\
\text { analyses completed and documented. [1] }\end{array}$ \\
\hline PBF SFD 1-4 Test (INL) & $\begin{array}{l}\text { Nuclear heatup of PWR fuel assembly with steam and argon flow. } \\
\text { Measurements of fuel rod temperatures and damage and } \mathrm{H}_{2} \text { production. } \\
\text { MAAP and SCDAP/RELAP5 analyses completed and documented. }[1,2]\end{array}$ \\
\hline PHEBUS FPT0 (CEA) & $\begin{array}{l}\text { Nuclear heatup of PWR fuel assembly with steam flow. Measurements of } \\
\text { fuel rod temperatures and damage and } \mathrm{H}_{2} \text { production. SCDAP/RELAP5 } \\
\text { analyses completed and documented. [1] }\end{array}$ \\
\hline PHEBUS B9+ (CEA) & $\begin{array}{l}\text { Nuclear heating of PWR fuel assembly with steam flow until assembly hot, } \\
\text { then He flow to represent the situation of extreme steam starvation. } \\
\text { Measurements of fuel rod temperature and damage and } \mathrm{H}_{2} \text { production. } \\
\text { MELCOR and SCDAP/RELAP5 analyses completed and documented. [1, } \\
\text { 3] }\end{array}$ \\
\hline CORA-5 (FzK) & $\begin{array}{l}\text { PWR fuel assembly with electrical heater rods.SCDAP/RELAP5 analyses } \\
\text { completed and documented. [1] }\end{array}$ \\
\hline CORA-7 (FzK) & $\begin{array}{l}\text { PWR fuel assembly with electrical heater rods with steam and argon flow. } \\
\text { Measurements of fuel rod temperatures and damage and } \mathrm{H}_{2} \text { production. } \\
\text { MAAP and SCDAP/RELAP5 analyses completed and documented. }[1,2]\end{array}$ \\
\hline CORA-13 (FzK) & $\begin{array}{l}\text { PWR fuel assembly with electrical heater rods and steam and argon flow, } \\
\text { followed by rapid reflood of hot assembly. Measurements of fuel rod } \\
\text { temperatures and damage and } \mathrm{H}_{2} \text { production. MAAP, MELCOR, and } \\
\text { SCDAP/RELAP5 analyses completed and documented. }[1,2,3]\end{array}$ \\
\hline
\end{tabular}




\section{RCS Thermal Hydraulics}

The temperature, pressure, and mass of coolant are key boundary conditions for evaluating the core's thermal response. Models must be able to simulate the overall RCS thermalhydraulics, the performance of RCS components, the effects of blockage associated with core damage, control system interactions, reactor kinetics, and transport of noncondensable gases.

Several sources of information are available for benchmarking the transient system pressure response predicted by severe accident codes. Table 2 identifies representative test program data used to benchmark the ability of various severe accident codes for predicting the pressure response of PWRs and advanced PWRs. In addition, Table 2 cites several references for predicting natural circulation within the vessel. Such data have been used to benchmark SCDAP/RELAP5 models for predicting natural circulation flows that can cause induced piping failures in PWR steam generator tubes, surge lines, and hot leg piping.

Table 2. Data for benchmarking PWR RCS pressure response.

\begin{tabular}{|l|l|}
\hline \multicolumn{1}{|c|}{ Data Source (Ref) } & \multicolumn{1}{c|}{ Phenomena/ Insights } \\
\hline $\begin{array}{l}\text { Three Mile Island - Unit 2 } \\
\text { (TMI-2) Accident [5-9] }\end{array}$ & $\begin{array}{l}\text { Measurements of transient system pressure, heatup of reactor system } \\
\text { piping, and reactor core endstate. Indirect measurement of } \mathrm{H}_{2} \\
\text { production. MAAP, MELCOR, and SCDAP/RELAP5 analyses } \\
\text { completed and documented. [1,2, 3, and 10] }\end{array}$ \\
ROSA [11] & $\begin{array}{l}\text { Used to predict the AP600 RCS pressure response due to a large break } \\
\text { Loss of Coolant Accident (LOCA). SCDAP/RELAP5 analyses } \\
\text { completed and documented. [12,13] } \\
\text { Used to predict the RCS pressure response due to small and large } \\
\text { break LOCAs, fuel degradation., and fission product release MAAP, } \\
\text { MELCOR, and SCDAP/RELAP5 analyses completed and } \\
\text { documented. [1, 16, and 17] }\end{array}$ \\
Westinghouse [18,19] & $\begin{array}{l}\text { Used to validate MAAP, MELCOR, and SCDAP/RELAP5 in-vessel } \\
\text { natural circulation flowrates.[2, 21, 22, 23] }\end{array}$ \\
University of Maryland [20] & $\begin{array}{l}\text { Used to validate SCDAP/RELAP in-vessel natural circulation } \\
\text { flowrates. [21,22] }\end{array}$ \\
\hline
\end{tabular}

One benchmark often used to test the ability of a severe accident analysis code to simulate RCS thermal hydraulics is the TMI-2 accident depressurization. Considerable effort (e.g., see References 5 through 9) has been expended to characterize the required boundary conditions for calculating key TMI-2 RCS thermal hydraulic parameters (e.g., pressure history and water level in the vessel and pressurizer). However, there is still considerable uncertainty in several boundary conditions that influence the primary coolant system pressure. Typically, analysts divide the accident into four distinct phases. Phase $1(0-100 \mathrm{~min})$ is a small-break LOCA through the stuckopen pilot-operated relief valve (PORV). One or more reactor coolant pumps (RCPs) operated continuously during Phase 1 of the accident, thereby providing adequate core cooling. Phase 2 
(100 - $174 \mathrm{~min}$ ) is a continuation of a small break LOCA without the RCPs. Core uncovery, heatup, and initial melting occurred during Phase 2. Phase 3 (174- $200 \mathrm{~min}$ ) begins with a restart of RCP 2B. Approximately $30 \mathrm{~m}^{3}$ of coolant was injected into the reactor vessel in less than one minute, cooling the peripheral fuel assemblies and forming an upper core debris bed with significant zircaloy oxidation. Heatup of the degraded core region, with the formation and growth of a pool of molten material, continued during Phase 3. Phase 4 (200-300 min) begins with the initiation of high pressure injection (HPI). The central region of the partially molten core material was not coolable by HPI even through the water level reached the level of the hot legs by 207 min. Between 224 and $226 \mathrm{~min}$, the crust encasing and supporting the molten core region is believed to have failed, allowing molten material to relocate to the lower plenum.

Reference 1 describes the SCDAP/RELAP5/MOD3.3 model used to simulate the TMI-2 event. Figure 1 plots the SCDAP/RELAP5 MOD3.3 calculated collapsed liquid level in the reactor vessel as a function of time. A temporary core uncovery was calculated to begin at 80 minutes, and the long term uncovery was calculated to begin at 106 minutes. After 106 minutes, the core continued to uncover until the 2-B pump activation at 174 minutes. The collapsed liquid level was calculated to be $0.3 \mathrm{~m}$ above the bottom of the reactor core just before activation of the 2-B pump. After activation of the 2-B pump, the water level was calculated to rise $3.0 \mathrm{~m}$. At 200 minutes, HPIS activation was predicted, which led to reflooding of the entire reactor core with water in 10 minutes.

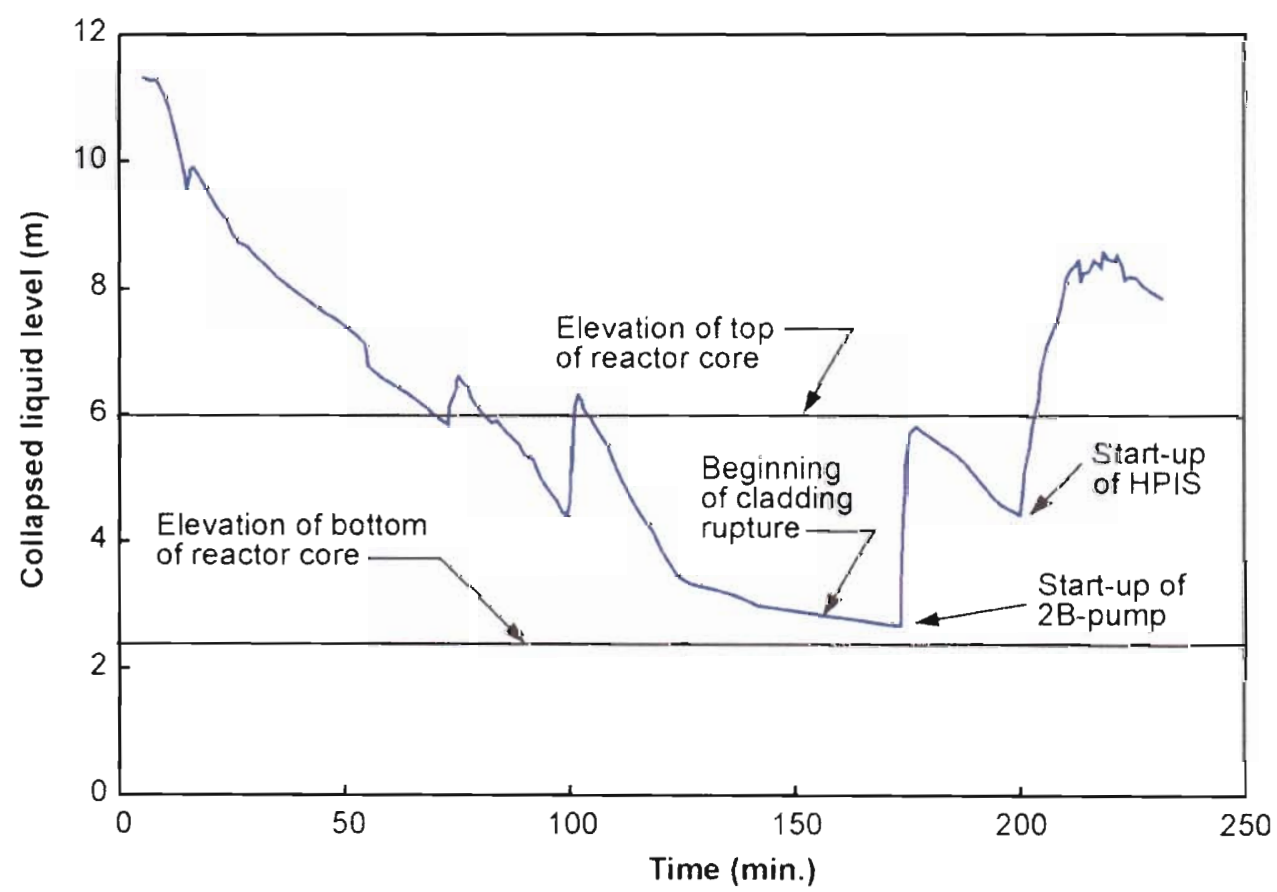

Figure 1. SCDAP/RELAP5/MOD3.3 calculated collapsed liquid level in the reactor vessel.

Figure 2 compares the ability of versions of MELCOR, SCDAP/RELAP5, and MAAP to simulate the TMI-2 accident primary system pressure. ${ }^{1,3,10}$ As shown in Figure 2, calculated 
primary coolant system pressures agree well with measured data for early time periods (up to 125 minutes). In the period of 125 minutes to start-up of the $2 \mathrm{~B}$-pump at 174 minutes, the pressures calculated by both versions of SCDAP/RELAP5 were somewhat less than the measured pressure. The coolant system pressure was calculated to increase about $7 \mathrm{MPa}$ after start-up of the 2-B pump. This calculated increase in pressure was in general agreement with the measured pressure increase of $6.3 \mathrm{MPa}$. The increase in pressure was calculated to be due to steam generated by pumping water into the hot reactor core and by heatup of the reactor core due to accelerated oxidation of fuel rod cladding. In the period between 174 minutes and activation of HPIS at 200 minutes, the pressure was calculated and measured to gradually decrease a few MPa. After activation of the HPIS, the pressure was calculated and measured to increase a few MPa. As indicated in Figure 2, SCDAP/RELAP5 and MELCOR models are more closely simulating TMI2 data in more recent versions, but discrepancies still exist in predicting RCS pressure at later time periods.

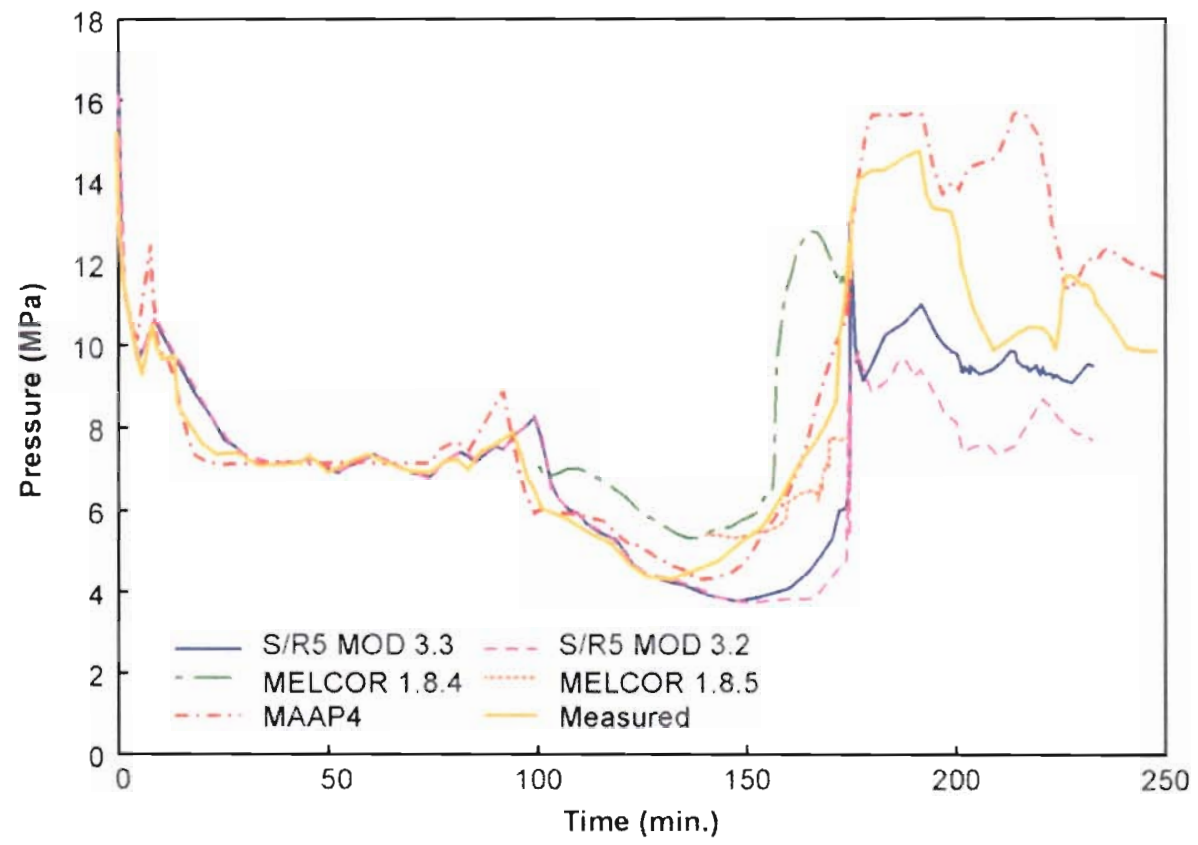

Figure 2. Calculated and measured primary coolant system pressure.

Differences in code predictions are attributed to differences in modeling detail, model assumptions (e.g., depressurization correlations), and uncertainties in boundary conditions. To illustrate the differences in modeling detail, compare the RELAP5 and MELCOR nodalization schemes for modeling the TMI-2 reactor vessel and core shown in Figure 3. The more detailed SCDAP/RELAP5 model allows simulation of phenomena that can't be predicted with the MELCOR model. For example, the upper plenum is divided into five parallel regions that are connected laterally by crossflow junctions. This arrangement allows for the development of invessel natural circulation under appropriate conditions. Depressurization model assumptions also 
differ in these codes. In SCDAP/RELAP5, depressurization is simulated using the Ransom/Trapp critical flow model; whereas depressurization in MELCOR is simulated using a two phase critical flow model with user-supplied discharge coefficients. Last, as noted above, there is still a large degree of uncertainty in boundary conditions that influence the pressure of the primary coolant system, such as uncertainties in makeup flow rate, performance of the $2 \mathrm{~B}$-pump, flow rate through the PORV and time of closure. In addition, there are differences in modeling assumptions invoked by these codes.

Because its response should be similar to that of other PWRs, no additional data are needed to verify that severe accident codes adequately model USEPR transient system thermal hydraulic response. However, it is recommended that AREVA NP be cognizant of the limited capabilities of MAAP and MELCOR to model key phenomena affecting vessel response, such as natural circulation.

\section{In-Vessel Molten Poo! Formation and Heat Transfer}

If molten pools form in the core or the lower head after relocation, analytical tools must be able to simulate the heat loads from these molten pools. This section identifies selected sources of data available for evaluating the ability of analytical tools to estimate the heat transfer from such pools for homogenous and stratified melt configurations. In addition, this section identifies some of the key issues associated with modeling such pools.

\subsection{Definitions}

For steady-state heat transfer, data are usually correlated in terms of the surface-averaged Nusselt number, $\mathrm{Nu}$, a modified Rayleigh number, $\mathrm{Ra}$, and the fluid Prandtl number, $\mathrm{Pr}$, which are defined by

$$
\begin{aligned}
& N u=\frac{h L}{k}=\frac{q^{\prime \prime}}{\frac{k}{L} \Delta T}=\frac{q^{\prime \prime} L}{k \Delta T} \\
& R a=\frac{g \beta q^{\prime \prime \prime} L^{5}}{\alpha v k} \\
& \operatorname{Pr}=\frac{v}{\alpha}
\end{aligned}
$$

where

$k=$ thermal conductivity $(\mathrm{W} / \mathrm{m}-\mathrm{K})$

$h=$ average heat transfer coefficient $\left(\mathrm{W} / \mathrm{m}^{2}-\mathrm{K}\right)$

$L=$ a characteristic length; in a hemispherical geometry, the radius (m)

$\mathrm{g}=$ acceleration due to gravity $\left(\mathrm{m} / \mathrm{s}^{2}\right)$ 


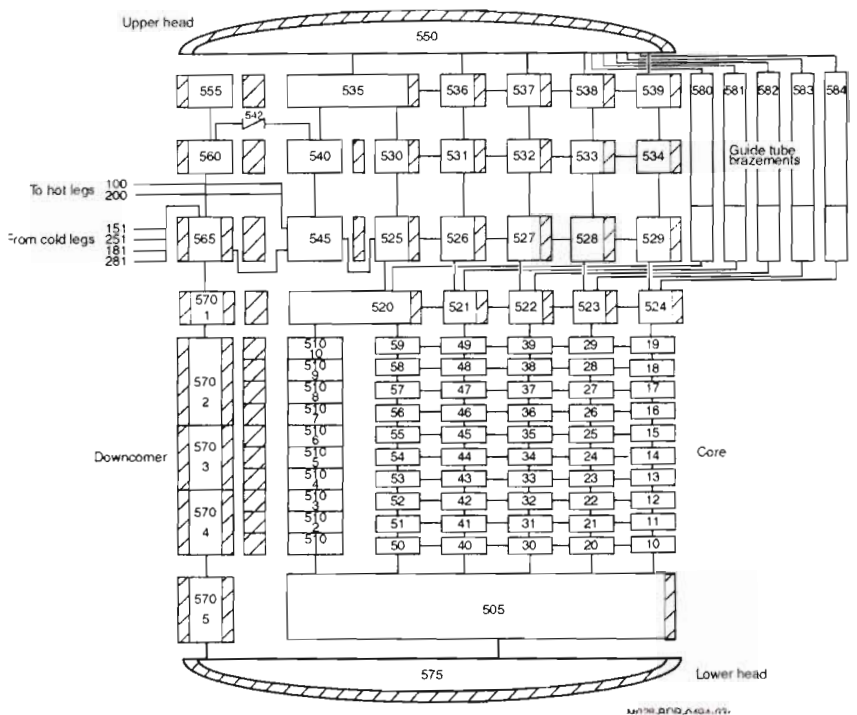

(a) SCDAP/RELAP5

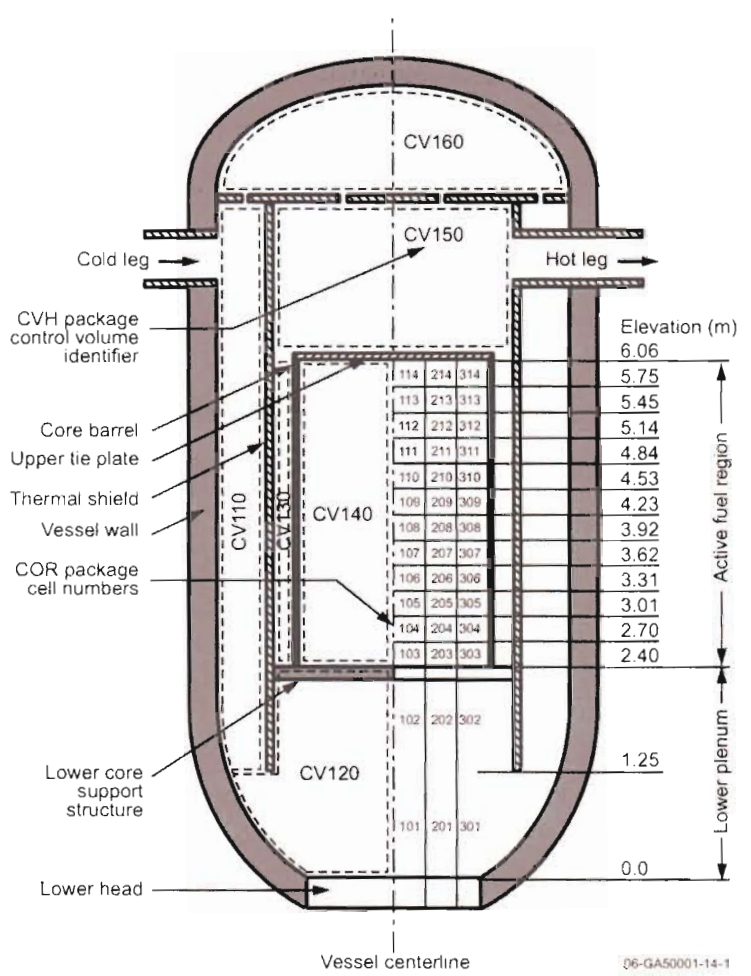

(b) MELCOR

Figure 3. Reactor vessel and core nodalization for TMI-2 analysis.

$$
\begin{array}{ll}
\beta= & \text { volumetric coefficient of thermal expansion }\left(\mathrm{K} / \mathrm{m}^{3}\right) \\
\alpha= & \text { thermal diffusivity of the fluid in the pool }\left(\mathrm{m}^{2} / \mathrm{s}\right)
\end{array}
$$




$$
\begin{array}{lll}
v & = & \text { kinematic viscosity of the fluid in the pool }\left(\mathrm{m}^{2} / \mathrm{s}\right) \\
q^{\prime \prime \prime} & = & \text { volumetric heat generation rate within the pool }\left(\mathrm{W} / \mathrm{m}^{3}\right) \\
q^{\prime \prime} & = & \text { heat flux from the pool }\left(\mathrm{W} / \mathrm{m}^{2}\right) \\
\Delta T= & \text { difference between pool peak temperature and pool melting temperature }(\mathrm{K}) .
\end{array}
$$

As discussed in Reference 4, references differ in their definition of the Rayleigh number. In this study, consistent definitions for the Rayleigh number are used for each geometry, and correlations were modified (as needed) to reflect the above-defined Rayleigh number.

\subsection{Typical Ranges for Heat Transfer Parameters}

The applicability of previous experimental work can be assessed by comparing the range of conditions over which the data were obtained to the range of conditions expected during a severe accident. Representative ranges for several dimensionless groups were quantified in Reference 4 using representative upper and lower input values and results from a representative SCDAP/RELAP5/MOD3.1 calculation. Table 3 lists values estimated in Reference 4. Note that

\begin{tabular}{|c|c|c|c|}
\hline Parameter/ & \multicolumn{3}{|c|}{ Condition } \\
\hline & $\begin{array}{c}\text { Ceramic material } \\
\left(\mathrm{UO}_{2} \text { molten at } \sim 3200 \mathrm{~K}\right)\end{array}$ & $\begin{array}{c}\text { Metallic material } \\
\text { (SS-304 molten at } \sim 1700 \mathrm{~K} \text { ) }\end{array}$ & $\begin{array}{c}80 \mathrm{wt}^{\circ} \% \mathrm{UO}_{2} / 20 \mathrm{wt} \% \mathrm{ZrO}_{2} \\
(\text { molten at } \sim 2900 \mathrm{~K} \text { ) }\end{array}$ \\
\hline$\rho \mathrm{kg} / \mathrm{m}^{3}$ & 8,400 & 7,250 & 9,300 \\
\hline$c_{p}, \mathrm{~J} / \mathrm{kg}-\mathrm{K}$ & 500 & 560 & 650 \\
\hline$k, \mathrm{~W} / \mathrm{m}-\mathrm{K}$ & 3.8 & 38 & 3.8 \\
\hline$\beta, \mathrm{K}^{-1}$ & $1.6 \times 10^{-4}$ & $3.5 \times 10^{-4}$ & $7.1 \times 10^{-5}$ \\
\hline$\alpha, \mathrm{m}^{2} / \mathrm{s}$ & $9.0 \times 10^{-7}$ & $9.4 \times 10^{-6}$ & $6.2 \times 10^{-7}$ \\
\hline$v, \mathrm{~m}^{2} / \mathrm{s}$ & $5.4 \times 10^{-7}$ & $3.2 \times 10^{-7}$ & $4.8 \times 10^{-7}$ \\
\hline \multirow[t]{2}{*}{$\operatorname{Pr}$} & $6.0 \times 10^{-1}$ & $3.0 \times 10^{-2}$ & $8.0 \times 10^{-1}$ \\
\hline & \multicolumn{3}{|c|}{ Lower bound/upper bound } \\
\hline$q^{\prime \prime \prime}, \mathrm{W} / \mathrm{m}^{3}$ & \multicolumn{3}{|c|}{$1.0 \times 10^{5} / 2.0 \times 10^{6}$} \\
\hline$L, \mathrm{~m}($ core $)$ & \multicolumn{3}{|c|}{$1.0 / 2.4$} \\
\hline$L, \mathrm{~m}$ (vessel) & \multicolumn{3}{|c|}{$1.0 / 2.8$} \\
\hline
\end{tabular}
values were evaluated at different temperatures, approximately $100^{\circ} \mathrm{C}$ above the liquidus temperatures for each melt composition.

Table 3. Ranges for variables used to estimate pool heat transfer parameters. 
As documented in Reference 4, Table 3 values were obtained by considering a range of debris conditions and reactor designs. A range of debris compositions (primarily oxide to primarily metallic) were considered in estimating values for debris thermal properties. Volumetric heat generation rates were quantified using results from previous calculations. Pool characteristic lengths were quantified considering pool sizes possible in the core and in the vessel lower plenum (i.e., upper bounds for the pool radius were based on core and vessel radii).

Using the values in Table 3, Rayleigh numbers for pools in the core region and in the lower head of the vessel are estimated to range from $10^{12}$ to $10^{17}$. Debris Prandtl numbers are estimated to range from 0.03 to 0.8 . This range of parameters is considerably different than the range for which most natural circulation heat transfer data for fluids with internal heating were obtained.

\subsection{Experimental Data}

Reference 4 reviews several experimental and numerical investigations performed to investigate heat transfer from molten pools with volumetric heat sources. In addition to original references reporting natural convection investigations, information in previous reviews (e.g., References 24 through 28) were considered. As noted in Reference 4, data were primarily obtained for single component pools experiencing steady-state natural convection. Both flat and curved geometries were studied for two-and three-dimensional test cavities. In addition, various "fixed" boundary conditions, such as adiabatic and constant temperature conditions, were investigated. The studies are limited in the fluid Prandtl number and Rayleigh number ranges considered. For example, experimental investigations typically use conducting aqueous solutions with a Prandtl number of approximately 7 , which is considerably higher than the 0.03 to 0.8 range estimated for fluids in severe accident molten pools; and Rayleigh numbers in the experimental investigations reviewed are less than $10^{15}$, which is considerably less than the $10^{17}$ upper limit estimated for severe accident molten pools. Table 4 identifies several simulant studies that were conducted in hemispherical and torispherical test geometries for development or verification of models for predicting natural convection from a molten pool with volumetric heat sources.

\subsection{Other Considerations}

As noted in Reference 4, there are also several phenomena that impact heat transfer from a molten pool that aren't currently considered in many severe accident models, such as vapor transport, transient natural convection behavior prior to the time period when steady-state natural convection is established, and stratified layers (although SCDAP/RELAP5-3D ${ }^{\mathcal{C}}$, MAAP, and MELCOR have now implemented limited cases with stratified layers in recent years, the user must preselect which stratified layer configuration to assume). 
Table 4. Natural convection studies for hemispherical and tori-spherical cavities.

\begin{tabular}{|c|c|c|c|}
\hline Geometry & Correlation $^{\mathrm{a}}$ & Conditions & Reference \\
\hline$T=$ constant & $\begin{array}{c}N u_{u}=0.3 R a^{0.23} \\
N u_{d}=0.54 R a^{0.18}\left(\frac{H}{R}\right)^{0.26}\end{array}$ & $\begin{array}{c}10^{7}<R a<5 \times 10^{10} ; \operatorname{Pr}=7 \\
0.3<H / R<1.0\end{array}$ & $\begin{array}{l}\text { Mayinger, Jahn, } \\
\text { Reineke, Steinbrenner } \\
{[29,30,31]}\end{array}$ \\
\hline$=$ constant & $\begin{array}{c}N u_{u}=0.345 R a^{0.233} \\
N u_{s}=0.85 R a^{0.19} \\
N u_{d}=0.54 R a^{0.18}\left(\frac{H}{R}\right)^{0.26}\end{array}$ & $\begin{array}{c}10^{14}<R a<5 \times 10^{15} ; \mathrm{Pr}=7 \\
3.4<H / R<5.6\end{array}$ & $\begin{array}{l}\text { Kymalainen, Tuomisto, } \\
\text { Hongisto, Theofanous } \\
{[32]^{b}}\end{array}$ \\
\hline constant & $\begin{array}{l}N u_{u}=0.4 R a^{0.2} \\
N u_{d}=0.55 R a^{0.2}\end{array}$ & $\begin{array}{c}7 \times 10^{6}<R a<5 \times 10^{14} ; \mathrm{Pr}=7 \\
H / R=1.0\end{array}$ & $\begin{array}{l}\text { Mayinger, Jahn, } \\
\text { Reineke, Steinbrenner } \\
{[29,30,31]}\end{array}$ \\
\hline & $N u_{d}=0.55 R a^{0.15}\left(\frac{H}{R}\right)^{1.1}$ & $\begin{array}{c}2 \times 10^{10}<R a<4 \times 10^{11} \\
\sim 3<\operatorname{Pr}<7 ; 0.5<H / R<1.0\end{array}$ & $\begin{array}{l}\text { Gabor, Cassulo, Ellison } \\
{[33]}\end{array}$ \\
\hline & $N u_{d}=0.55 R a^{0.2}$ & $\begin{array}{c}10^{10}<\operatorname{Ra}<4 \times 10^{13} \\
15<\operatorname{Pr}<16 ; 0.4<H / R<1.0\end{array}$ & Frantz and Dhir $[34]^{\mathrm{c}}$ \\
\hline & $N u_{d}=0.54 R a^{0.2}\left(\frac{H}{R}\right)^{0.25}$ & $\begin{array}{c}10^{11}<R a<10^{14} \\
15<\operatorname{Pr}<16 ; 0.26<H / R<1.0\end{array}$ & Asfia and Dhir $[35]^{\mathrm{d}}$ \\
\hline \multirow{4}{*}{$\mathrm{H}$} & $N u_{u}=2.086 R a^{0.127}$ & $\begin{array}{c}9 \times 10^{7}<R a<1 \times 10^{10} \\
2.1<\operatorname{Pr}<5.9 ; H / R=0.22^{\mathrm{e}}\end{array}$ & \multirow[t]{4}{*}{ Min and Kulacki $[36]^{f}$} \\
\hline & $N u_{u}=2.320 R a^{0.125}$ & $\begin{array}{c}3 \times 10^{8}<R a<3 \times 10^{13} ; \\
2.7<\operatorname{Pr}<7 ; 0.30<H / R<0.32\end{array}$ & \\
\hline & $N u_{u}=1.091 R a^{0.166}$ & $\begin{array}{c}4 \times 10^{10}<R a<1 \times 10^{13} \\
2.3<\operatorname{Pr}<6.8 ; H / R=0.81\end{array}$ & \\
\hline & $N u_{u}=0.280 R a^{0.227}$ & $\begin{array}{c}6 \times 10^{11}<R a<2 \times 10^{14} \\
1.9<\operatorname{Pr}<5.8 ; 1.37<H / R<1.41\end{array}$ & \\
\hline
\end{tabular}
a. In most cases, the Nusselt and Rayleigh numbers are defined as $N u=\frac{h R}{k}$ and $R a=\frac{g \beta q^{\prime \prime \prime} R^{5}}{\alpha \nu k}$. Subscripts are
defined as $u$ : upward; d: downward; and s: sideways.

b. For downward heat transfer, the Nusselt and Rayleigh numbers are defined as $N u=\frac{h H_{c}}{k}$ and $R a=\frac{g \beta q^{m \prime \prime} H_{c}^{5}}{\alpha \vee k}$.

c. Upper surface of pool in these experiments was exposed to air.

d. Three types of pool upper surface boundary conditions were tested: a free surface, a rigid insulated surface, and a rigid cooled surface.

e. The pool height was below the junction between the curved bottom and the cylindrical sidewall.

f. The Nusselt and Rayleigh numbers are defined as $N u=\frac{h H}{k}$ and $R a=\frac{g \beta q^{\prime \prime \prime} H^{5}}{\alpha v k}$. 
In the AP600 design certification effort, the NRC-sponsored review raised several questions about the "bounding" debris configuration assumed by Westinghouse. This bounding endstate assumes that a molten ceramic pool lies beneath a metallic layer (see the UCSB FIBS configuration shown in Figure 4a). The ceramic pool was assumed to contain oxide core components (mainly $\mathrm{UO}_{2}$ and $\mathrm{ZrO}_{2}$ ), and turbulent steady-state natural convection associated with volumetric heat sources was assumed to govern heat transfer. The molten pool experienced sufficient cooling that it was surrounded by thin crusts imposing uniform temperature boundary conditions at the outer pool surface. The thin metallic layer was heated from below and cooled from above and along the side. The side boundary temperature was assumed to be fixed at the metallic layer liquidus temperature. In the NRC's review, it was noted that this assumed bounding state may not necessarily be the most bounding or plausible debris configuration. In fact, several other alternate configurations were identified that may be more challenging than the UCSB FIBS configuration (see Configurations A, B, and C shown in Figure 4b). ${ }^{37}$

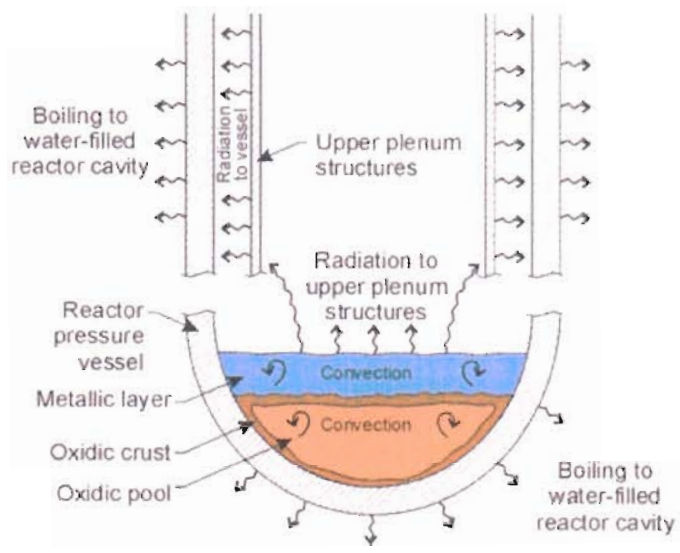

(a) UCSB FIBS:

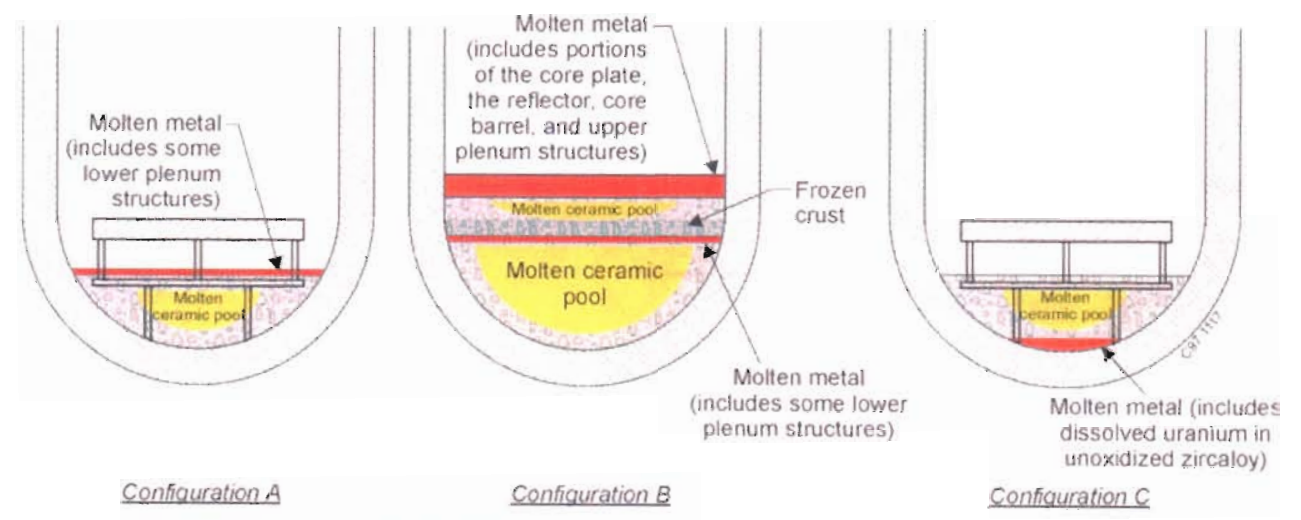

(b) INEEL alternate debris configurations.

Figure 4. Lower head/corium configurations considered in AP600 review. 
- Configuration $A$ is similar to the UCSB FIBS, but evaluated at an earlier time period, before all the metallic and ceramic materials relocate. Based on SCDAP/RELAP5 AP600 calculations results, Configuration A contains a large ceramic pool ( $\sim 50 \%$ of the core inventory) with a small metallic component (unoxidized zircaloy and stainless steel). Calculations suggesting that this configuration could persist for more than an hour indicate that it is appropriate to consider this intermediate configuration as a "quasi-steady" state.

- Configuration B is based on additional results from the SCDAP/RELAP5 calculations that formed the basis for Configuration A. At a time after Configuration A develops,

SCDAP/RELAP5 predicts that an additional $35 \%$ of the core materials relocate to form a second molten pool. The metallic layer from the first relocation would be heated from below by the molten pool and above by the overlying pool and crust.

- Configuration $C$ represents a case where a more dense U-Zr metallic layer sinks below the ceramic pool. If this configuration forms, it presents a unique challenge to vessel integrity because heat sources within the lower metallic layer are focused toward the bottom of the vessel (angles near the bottom center of the vessel).

Many assumptions differed between the NRC-sponsored review and the UCSB analyses. For example, the NRC-sponsored review assumed that chemistry impacted fission product distribution; whereas the UCSB study assumed that all fission products were retained in the ceramic layer. In fact, variations between the INL and UCSB assumptions led to significantly lower margins being predicted for the FIBS configuration (see Reference 37).

\subsection{Prototypic Data}

Since 1994, the NEA-OECD has sponsored a collaborative project on severe accidents that is conducted at the RRC KI. ${ }^{38}$ The RASPLAV and MASCA programs (see Table 5) used a host of small, intermediate, and large-scale facilities in which prototypic and simulant materials were tested to investigate molten pool heat transfer. Facilities were used to investigate a range of corium compositions, a range of oxidation levels, and the impact of contaminants in the corium.

Table 5. Prototypic data for molten pool behavior.

\begin{tabular}{|l|l|}
\hline \multicolumn{1}{|c|}{ Data Source } & \multicolumn{1}{c|}{ Phenomena/ Insights } \\
\hline RASPLAV [38,39] & $\begin{array}{l}\text { Prototypic material data for predicting stratification and natural convection of } \\
\text { relocated molten corium materials. } \\
\text { MASCA [39] }\end{array}$ \\
$\begin{array}{l}\text { Prototypic material data for predicting stratification, natural convection, and } \\
\text { fission product distribution of relocated molten corium materials. }\end{array}$ \\
\hline
\end{tabular}

Experimental data from the RASPLAV tests support the Figure 4 Configuration C endstate in which a heavier metallic layer with a higher uranium content forms due to density stratification. Post-test examinations in several of the larger-scale RASPLAV tests (with up to $200 \mathrm{~kg}$ of corium) indicated that the initially homogeneous melt pool had become stratified into two layers of unequal density. Figure 5 compares the initial configuration and the final endstate for the RASPLAV-AW-200-2 test. Investigations indicate that over $70 \%$ of the corium became molten 
during this test. Examinations revealed that the upper layer of the resolidified corium was lighter in color and more porous. Post-test examinations showed that the melt pool, initially of a homogenous composition and density, stratified into two layers of unequal density. The lower layer contained a denser material that was richer in $\mathrm{UO}_{2}$, while the upper lighter layer was richer in $\mathrm{Zr}$ and $\mathrm{ZrO}_{2}$. Investigations suggested that a small amount of carbon (from the graphite bricks surrounding the corium materials) was responsible for the observed stratification. Recognizing that small amounts of carbon actually exist in some reactor cores (due to control materials or burnable poisons), RASPLAV data raised concerns about the potential for the chemical composition of relocating materials to affect the thermal-hydraulic behavior of a corium pool. If the stratification observed in the RASPLAV tests occurs in a molten corium pool, it would alter the downward heat flux to the vessel. In addition, RASPLAV data raised concerns that fission products distributed in the relocated materials may tend to segregate in various layers due to chemical composition. For example, metallic fission products segregating in thin metallic layers could result in higher heat fluxes to the wall adjacent to these metallic layers. The RASPLAV AW 200 tests identified the need to better quantify the impact of melt segregation on heat fluxes to the vessel wall.
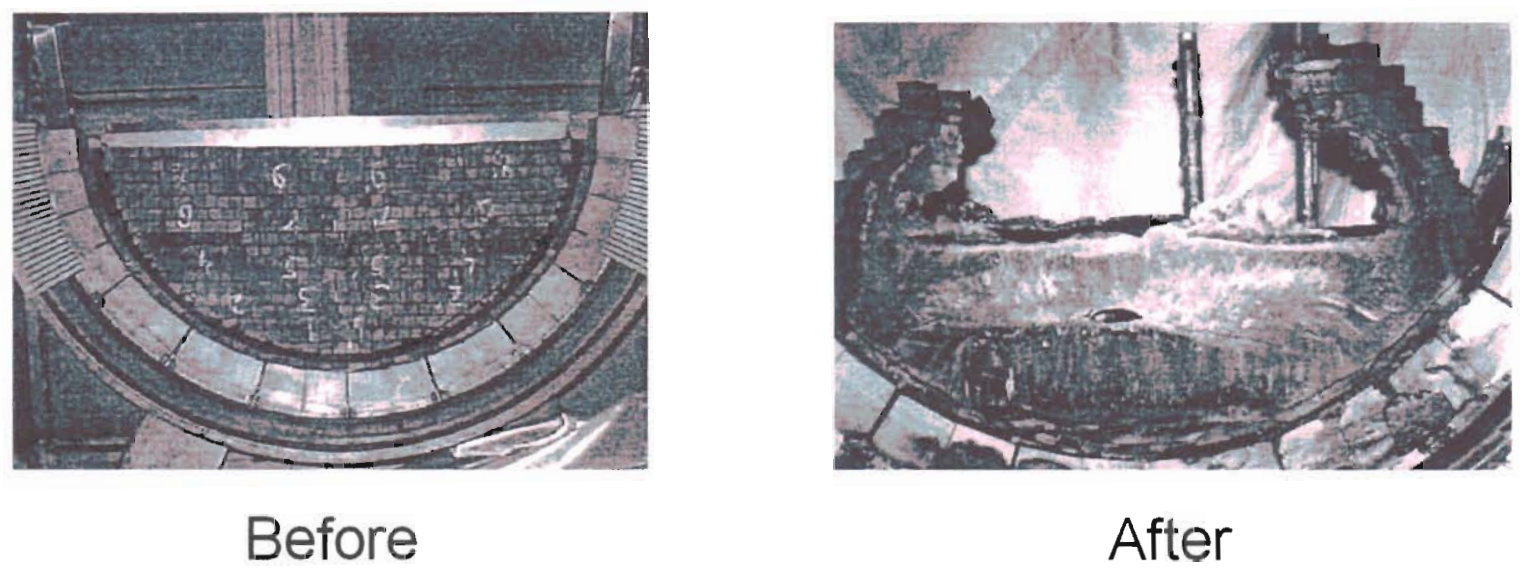

Figure 5. Initial and final states of prototypic debris in the RASPLAV-AW-200-2 experimental section.

Results from RAPLAV and MASCA prototypic tests suggest that severe accident analysis should consider the following key insights:

- Corium Endstate Configuration - As noted in Reference 39, MASCA and RASPLAV test data suggest that it is possible for melt to stratify, but tests have not conclusively shown which stratification endstates are more likely.

- Prototypic Test Data are Needed in Oxidizing Conditions - For example, it is not clear that it is possible to ignore the potential for unoxidized zircaloy and uranium to exist as molten metal beneath an oxide layer.

- Decay Heat Distribution - Test results indicate that fission products will reside with like chemical species.

- Design Specific Features - Experimental data clearly indicate that other factors, such as lower head penetrations, insulation design, etc., impact vessel heat removal. 
As discussed in Reference 39, several aspects of RASPLAV and MASCA test conditions differ from predicted LWR accident conditions:

- Typically, steam is predicted to be present in the reactor vessel and water is predicted to be present in the lower head. Hence, there is the potential for materials to oxidize; whereas all RASPLAV and MASCA tests were conducted in an inert environment.

- The materials become molten prior to relocation in LWR accident scenarios. In these test facilities, the materials are usually heated in place without relocation. In some tests, corium materials become molten prior to the time that steel is added.

Confidence in the applicability of RASPLAV and MASCA test results could be increased if tests were repeated in an oxidizing (especially a steam) environment and if more prototypic heating scenarios were experimentally simulated (e.g., that included melt relocation).

\section{Fuel/Coolant Interactions during Relocation}

Considerable research has been expended to assess the potential for and effects of steam explosions due to the rapid energy transfer between relocating core materials and water in the reactor vessel. This section identifies the phenomena of interest and previous efforts to assess the potential for an in-vessel steam explosion. As discussed in Section 9, the USEPR includes several design measures that preclude ex-vessel steam explosions, such as an initially dry pit and dry spreading area, the addition of silica-rich sacrificial material into the melt before ex-vessel flooding, and the controlled addition of water to the top of the melt after spreading (which experimental data have shown to not lead to a steam explosion). Hence, ex-vessel steam explosions are not discussed in this report.

\subsection{Definitions}

Steam explosions occur when heat is transferred from the melt to water in a very short time scale $(\sim 1 \mathrm{msec}$.). The major stages of a steam explosion (as depicted in Figure 6 ) are:

- Initial coarse mixing of melt and water during which heat transfer is generally characterized by stable film boiling;

- Triggering that causes local destabilization of film boiling and local fragmentation of melt into small drops, on the order of 0.01 to $0.1 \mathrm{~mm}$ in diameter;

- Explosion propagation of the region of rapid heat transfer through the coarse mixture, and expansion driven by steam at high pressure.

Coarse mixing results in some melt quenching with associated steam and hydrogen production. During mixing, some of the molten drops may spontaneously fragment into much smaller drops, on the order of 0.01 to $0.1 \mathrm{~mm}$ in diameter. This localized fragmentation or triggering event may be produced by natural oscillation in the vapor film about the drop leading to fuel-coolant contact, or it may be induced by shock waves from falling objects, contact of the fuel with the bottom surface, entrance of the fuel into a region of colder water, or by turbulence generated in part of the 


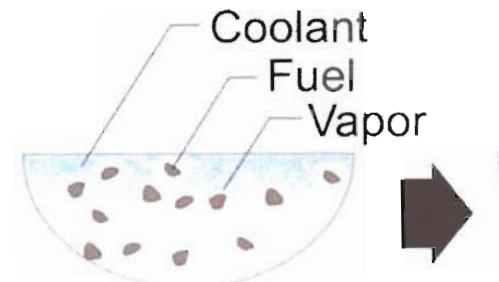

Mixing

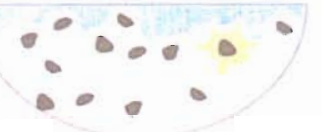

Trigger

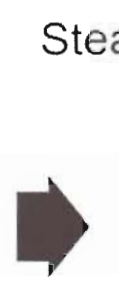

Propagation

06-GA50001-14-6

Figure 6. Steam explosion stages.

mixing region. If the fragmentation is rapid enough, local shock waves can be produced, which can cause neighboring drops to fragment. If such a chain reaction escalates, a steam explosion can result. In the absence of a triggering event, only a nonexplosive FCI may occur.

Research indicates that the probability and magnitude of steam explosions depend on various initial and boundary conditions, including:

- Mass, compositions, and temperature of the molten material,

- Water mass, depth, and temperature,

- Vessel geometry, degree of confinement, and the presence and nature of flow restrictions and other structures,

- fuel-coolant contact mode (e.g., pouring, melt entry velocity, pour diameter, extent of mixing)

- Ambient pressure, and

- Timing and strength of any external triggers that might be present.

Steam explosions can occur for a variety of high-temperature molten materials including uranium and its oxides. Spontaneous (no external trigger) steam explosions have been observed for aluminum, iron, tin, and associated oxides in all possible contact models including melt pours, stratified water over melt, and reflooding. High ambient pressure and low water subcooling have been shown to reduce the probability of spontaneous steam explosions at experimental scales; however, explosions can still occur if the necessary triggers are available.

Experimentally measured conversion ratios (the work done divided by the thermal energy available) range from zero to values approaching the thermodynamic limit. Explosion pressures have been measured over the range of tens of bars to 2 kilobars. If unoxidized zirconium is present, mixing of this metal at high temperatures with water in the lower plenum would promote rapid oxidation (and increase the amount of energy released during FCIs). It is estimated that if $1 \%$ of the Zr typically contained in a PWR core were oxidized during in-vessel FCIs, an additional $1.3 \mathrm{GJ}$ would be released (which is approximately $1 \%$ of the energy that would be transferred from the core to the RCS coolant from all of the $\mathrm{UO}_{2}$ in a PWR core). Calculations indicate that a 1 to $1.5 \mathrm{GJ}$ steam explosion could fail the vessel lower head. 
In assessing the impact of an in-vessel FCI, three alternative scenarios can be postulated:

- No steam explosion, but violent boiling;

- One or more relative low-yield steam explosions and nonexplosive quenching;

- A large steam explosion involving a significant fraction of the melt, triggered spontaneously or by a low-yield steam explosion.

Because of the resulting disruption (and possible dispersal) of internal structures and residual core materials, the occurrence of even a relatively low-yield steam explosion could significantly alter subsequent damage progression in a severe accident.

\subsection{Quantification Efforts and Data}

Energetically, it is possible that a large in-vessel steam explosion could cause a breach of the reactor vessel or a breach of the reactor vessel that generates containment-failing missiles [e.g., the alpha mode of containment failure that was initially identified in the Reactor Safety Study (RSS), also known as WASH- $1400^{40}$ ]. Either event would completely alter the course of the accident by causing the immediate ejection of fuel and fission products from the reactor vessel. The second possibility would essentially lead to simultaneous venting of the containment.

There have been several efforts to use "experts" to quantify the likelihood of an energetic steam explosion that fails the vessel and leads to an alpha mode containment failure. In the first effort, the RSS, experts estimated the alpha failure probability to be 0.01 (given that a core melt accident occurs), although experts also acknowledged that the uncertainty in this failure probability was large by assigning a pessimistic, upper bound estimate of 0.1 . Since the RSS, several small and intermediate scale tests were completed (see reviews of these tests in References 41 through 43). Analytical models developed using data from these tests predicted conversion ratios less than $5.3 \%$ and masses of actively participating molten corium less than $5000 \mathrm{~kg}$. Such small masses yielded alpha mode failure probabilities of 0.0001 or less. However, in the first NRC-sponsored Steam Explosion Review Group (SERG-1), ${ }^{44}$ the experts provided an upper bound failure probability estimate of 0.1 (for high pressure events) and an upper bound failure probability of 1.0 (for low pressure events). Mean value estimates for alpha mode failure probabilities (given that a core melt accident occurs) range from 0.001 (for high pressure events) to 0.01 (for low pressure events).

Since the SERG-1 evaluation, additional FCI research was conducted to further reduce uncertainties and improve the technical basis for alpha mode failure estimates given by the experts. ${ }^{45}$ One major insight gained from these experiments was that steam voiding around hot debris particles causes the mixing region to be depleted of water, in part due to vaporization associated with rapid melt-to-coolant heat transfer and, in part due to displacement of remaining water mass away from the interfacial region. Tests indicate that depletion is even more pronounced in cases with adjacent simultaneous pours, as occurred through multiple holes in the TMI-2 elliptical flow distributor. 
In June 1995, the NRC convened the SERG-2 workshop ${ }^{46}$ to reassess the alpha mode failure issue and to evaluate the current understanding of other FCI issues of potential risk significance. At this workshop, nine of the eleven SERG-2 experts concluded that the probability of an alpha mode failure was very low (e.g., $10^{-3}$ or smaller). These experts based their judgements primarily on data indicating that there are limits to the mixing that may occur during FCIs. Experts agreed that there was still much uncertainty in the triggering process (and hence, experts invoked conservative estimates with respect to triggering processes). For cases where data were obtained using prototypic reactor melts interacting with saturated or subcooled water at ambient pressure $(0.1 \mathrm{MPa})$, only one or two cases exhibited weak steam explosions and then, only when an external trigger was used. At higher pressures, data indicate that an explosion is difficult to trigger.

Table 6 summarizes parameters of several facilities using prototypic materials to investigate steam explosions. Although the geometry and size of these test facilities differ (see Figure 7), each contains the same functional components:

- A melt generator or furnace

- A release vessel

- An interaction chamber or sections, and

- A plate or "melt catcher"

With respect to geometry, the TROI, KRYTOS, and FARO facilities are of similar size, pressure capacity, and capability with respect to prototypic materials testing.

Table 6. Steam explosion test facilities using prototypic materials.

\begin{tabular}{|c|c|c|c|c|c|c|}
\hline \multirow[b]{2}{*}{ Facility } & \multirow[b]{2}{*}{ Phenomena / Insights } & \multicolumn{5}{|c|}{ Geometry/Test Parameters } \\
\hline & & $\begin{array}{l}\text { Section } \\
\text { Diameter, } \\
\text { mm }\end{array}$ & $\begin{array}{l}\text { Melt Jet } \\
\text { Diameter, } \\
\text { mm }\end{array}$ & $\begin{array}{c}\text { Water } \\
\text { Depth, m }\end{array}$ & $\begin{array}{l}\text { System } \\
\text { Pressure, } \\
\text { MPa }\end{array}$ & $\begin{array}{c}\text { Melt } \\
\text { Composition } \\
\text { and Mass, kg }\end{array}$ \\
\hline $\begin{array}{l}\text { Fuel Melt And } \\
\text { Release Oven } \\
(\text { FARO) - }[47,48, \\
49]\end{array}$ & $\begin{array}{l}\text { Integral test investigating } \\
\text { premixing, quenching, } \\
\text { propagation, and FCI } \\
\text { energetics. }\end{array}$ & $47-700$ & 100 & $0.1-5.0$ & $0.1-5.0$ & $\begin{array}{l}\mathrm{UO}_{2}-\mathrm{ZrO}_{2}(\mathrm{w} \\
\text { and } \mathrm{w} / \mathrm{o} \mathrm{Zr} \text { and } \\
\mathrm{SS}) ; 18-250 \mathrm{~kg}\end{array}$ \\
\hline KROTOS $[50,51]$ & $\begin{array}{l}\text { Smaller scale tests } \\
\text { investigating premixing, } \\
\text { quenching, propagation, } \\
\text { and FCI energetics }\end{array}$ & $95-200$ & $30-50$ & 1.0 & $0.1-1.0$ & $\begin{array}{l}\mathrm{UO}_{2}-\mathrm{ZrO}_{2} \\
1.4-10.0 \mathrm{~kg}\end{array}$ \\
\hline $\begin{array}{l}\text { Test for Real } \\
\text { cOrium Interaction } \\
\text { (TROI) - }[52,53,54]\end{array}$ & $\begin{array}{l}\text { Integral tests } \\
\text { investigating premixing, } \\
\text { quenching, propagation, } \\
\text { and FCI energetics }\end{array}$ & 600 & $\sim 38-50$ & 0.67 & 0.1 to 2.0 & $\begin{array}{l}\mathrm{ZrO}_{2} \text { and } \mathrm{UO}_{2-} \\
\mathrm{ZrO}_{2} ; 5 \text { to } 13.7 \\
\mathrm{~kg}\end{array}$ \\
\hline
\end{tabular}

Reference 1 presents results comparing SCDAP/RELAP5/MOD3.3 calculations with the FARO Test L-08. As documented in Reference 1, the SCDAP/RELAP5/MOD3.3 results for the 


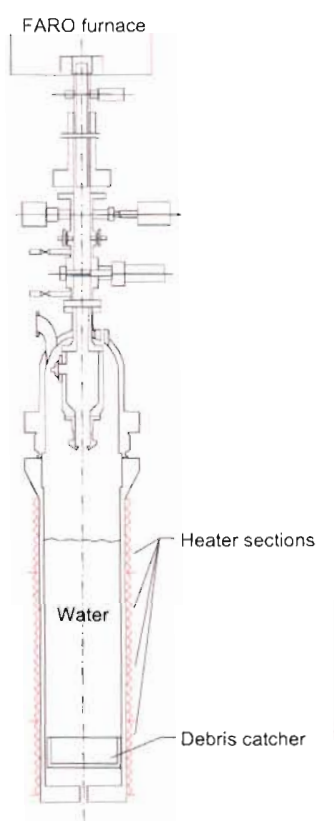

FARO

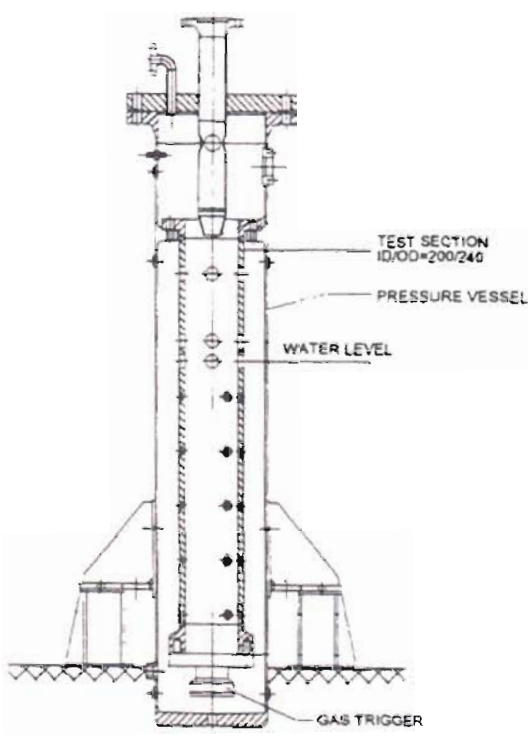

KRYTOS

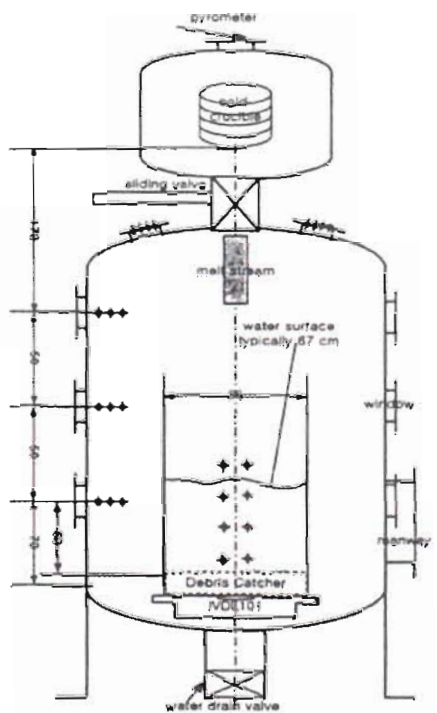

TROI

Figure 7. Geometry of steam explosion facilities testing with prototypic materials (not to scale).

pressure in the FARO vessel were similar to the measured data, but significant discrepancies were observed in predictions for the fragmented particle size. These differences were attributed to uncertainty in the value selected for the interfacial tension between $\mathrm{UO}_{2}$ and $\mathrm{ZrO}_{2}$ in contact with the water and steam.

In summary, no additional data are needed to simulate USEPR fuel/coolant interactions. The existing data are deemed sufficient to demonstrate that the potential for an energetic in-vessel steam explosion is negligible.

\section{Debris Heat Loads to the Vessel}

As discussed in Section 4, the heat load from relocated debris to the vessel is impacted by molten pool heat transfer and any stratification that may occur. In addition, the heat load from relocated debris is impacted by the physical form of the debris and the contact between the debris and the vessel. Figure 8 shows three possible endstates that vary in physical form. The endstate shown in Figure 8(a), a coherent mass beneath a fragmented rubble bed, is consistent with results 
inferred from post-accident evaluations of the relocated material in the TMI-2 vessel. (Wolf and Rempe, $1993^{55}$ ). Experimental data (e.g., Mayinger, 1976; ${ }^{29} \mathrm{Jahn}$ and Reineke, $1974 ;{ }^{30}$ Asfia and Dhir, 1994; ${ }^{35}$ Theofanous, et al., $1996^{56}$ ) show that the heat flux from a homogeneous molten pool is proportional to its height and the decay heat associated with the material in the pool.

Several prototypic material data sources provide insights about debris morphology and heat transfer. As indicated in Table 7, characteristic parameters of these data sources vary considerably.

Table 7. Prototypic corium data sources.

\begin{tabular}{|c|c|c|c|c|c|}
\hline \multirow{2}{*}{ Program } & \multirow{2}{*}{ Insight } & \multicolumn{3}{|c|}{ Materials } & \multirow{2}{*}{ Pressure } \\
\hline & & Debris & Vessel & Coolant & \\
\hline $\begin{array}{l}\text { RRC/OECD } \\
\text { RASPLAV and } \\
\text { MASCA - }[38,39]\end{array}$ & $\begin{array}{l}\text { Natural convection heat } \\
\text { fluxes, corium stratification }\end{array}$ & $\begin{array}{l}\mathrm{UO}_{2}, \mathrm{ZrO}_{2}, \mathrm{Zr}, \mathrm{C} \\
\mathrm{FeO}, \mathrm{LaO} ; \text { up to } 200 \\
\mathrm{~kg}\end{array}$ & $\begin{array}{l}\text { W/Ta protected by } \\
\text { graphite in slice geometry }\end{array}$ & None & $\begin{array}{l}\text { Low } \\
(0.1 \mathrm{MPa})\end{array}$ \\
\hline $\begin{array}{l}\text { JRC/ISPRA Fuel Melt } \\
\text { And Release Oven } \\
\text { (FARO) - }[47,48,49]\end{array}$ & $\begin{array}{l}\text { Melt/water interactions, } \\
\text { debris cooling, morphology, } \\
\text { interactions with structures }\end{array}$ & $\begin{array}{l}\mathrm{UO}_{2}, \mathrm{ZrO}_{2}, \mathrm{Zr} ; 18- \\
250 \mathrm{~kg}\end{array}$ & SS flat plate & Water & $\begin{array}{l}\text { High } \\
(0.5 \text { to } 5 \\
\mathrm{MPa})\end{array}$ \\
\hline $\begin{array}{l}\text { KAERI Test for Real } \\
\text { cOrium Interaction } \\
(\mathrm{TROI})-[52,53,54]\end{array}$ & $\begin{array}{l}\text { Melt/water interactions, } \\
\text { debris morphology }\end{array}$ & $\begin{array}{l}\mathrm{ZrO}_{2} \text { and } \mathrm{UO}_{2-}^{-} \\
\mathrm{ZrO}_{2} ; 5 \text { to } 13.7 \mathrm{~kg}\end{array}$ & $\begin{array}{l}\text { SS "debris catcher" above } \\
\text { the hemispherical vessel } \\
\text { lower head. }\end{array}$ & Water & $\begin{array}{l}\text { High } \\
(0.1 \text { to } 2.0 \\
\text { MPa })\end{array}$ \\
\hline $\begin{array}{l}\text { OECD TMI- } 2 \text { Vessel } \\
\text { Investigation Program - } \\
{[55]}\end{array}$ & $\begin{array}{l}\text { Debris cooling, morphology, } \\
\text { and interactions with } \\
\text { structures }\end{array}$ & $\begin{array}{l}\mathrm{UO}_{2}, \mathrm{ZrO}_{2}, \mathrm{Zr} \\
\mathrm{FeO}_{2}, \mathrm{Ag}, \mathrm{SS} \text {; up to } \\
20,000 \mathrm{~kg} \text { relocated. }\end{array}$ & $\begin{array}{l}\text { SS-lined carbon steel } \\
\text { vessel w penetrations }\end{array}$ & Water & $\begin{array}{l}\text { High } \\
(3-15 \mathrm{MPa})\end{array}$ \\
\hline
\end{tabular}

Experimental evidence from the FARO and TROI tests ${ }^{48,49,53}$ support the observed TMI2 configuration with fragmented material above a cohesive mass. Clearly, the heat flux from either a fragmented rubble bed or a rubble bed above a molten pool [Figures 8(b) and (c)] is lower than the heat flux from relocated material that remains a molten pool.

Another factor shown to influence the heat load to the vessel is associated with the presence of a gap between the relocated debris and the vessel and the presence of cracks within the relocated debris (see Figure 9). Evidence from the OECD-sponsored analyses to evaluate the "Margin-to-Failure" of the TMI-2 vesse ${ }^{57}$ suggests that the heat load from relocated debris was significantly reduced due to cooling between the narrow gap that formed between the relocated debris and the vessel (see Section 7). This hypothesis was later supported by data and observations from tests conducted with prototypic and simulant materials.

For example, photos of debris from the FARO L-19 test (see Figure 10$)^{48}$ show that the prototypic material $\left(\mathrm{UO}_{2}-\mathrm{ZrO}_{2}\right)$ used in these melt -water interaction tests contained furrows and cracks and had an uneven contact surface with test plate onto which material relocated. As noted by Magallon, ${ }^{49}$ the channeling structure of the cake in contact with the bottom plate is the "rule and seems to confirm the hypothesis of a 'gap' as one of the main contributors to cooling the bottom head during the TMI-2 accident." 
(a) Molten pool

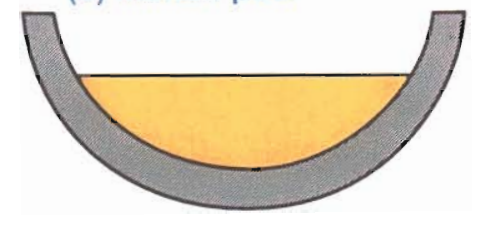

(b) Fragmented rubble

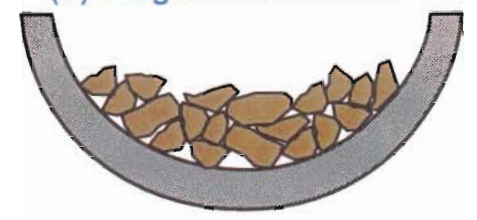

(c) Molten pool beneath fragmented rubble

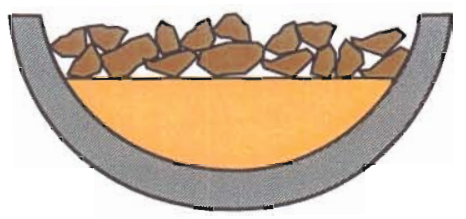

Figure 8. Physical state effects on debris heat load

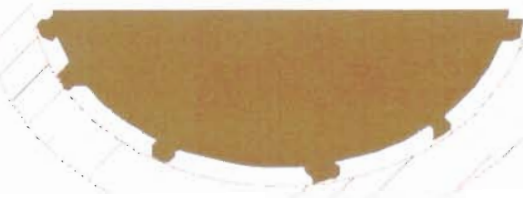

(a) Debris-to-vessel gap with intermittent contact

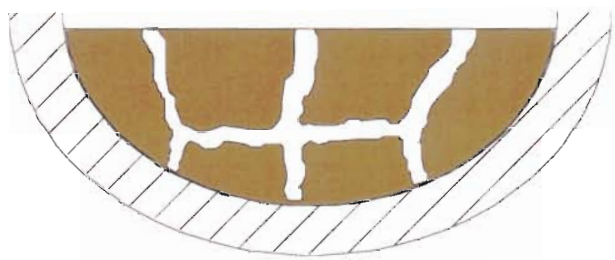

(b) Cracks within solidified debris

Figure 9. Possible geometries enhancing relocated debris coolability.

A significant number of tests with simulant material were conducted to investigate debris cooling, including the Korea Atomic Energy Research Institute (KAERI) SONATA-IV LAVA tests, ${ }^{58}$ the Japan Atomic Energy Research Institute (JAPAN) ALPHA tests, ${ }^{59}$ the Fauske and Associates Incorporated (FAI) tests ${ }^{60}$ and the Royal Institute of Technology FOREVER tests. ${ }^{61,62}$ These tests use a simulant material (iron-alumina thermite) or $\mathrm{CaO}+\mathrm{B}_{2} \mathrm{O}_{3}$, for the molten corium and focused on measuring "gap" cooling phenomena in a hemispherical vessel. Table 8 and Figure 11 compare the designs of these facilities. Typically, the facilities are $\sim 1 / 10$ th scale (vessel diameters range from 0.25 to $0.50 \mathrm{~m}$ and test melt masses ranged from 30 to $50 \mathrm{~kg}$ ), and they include some sort of furnace to melt the simulant before it is poured into a water-filled hemispherical vessel. 


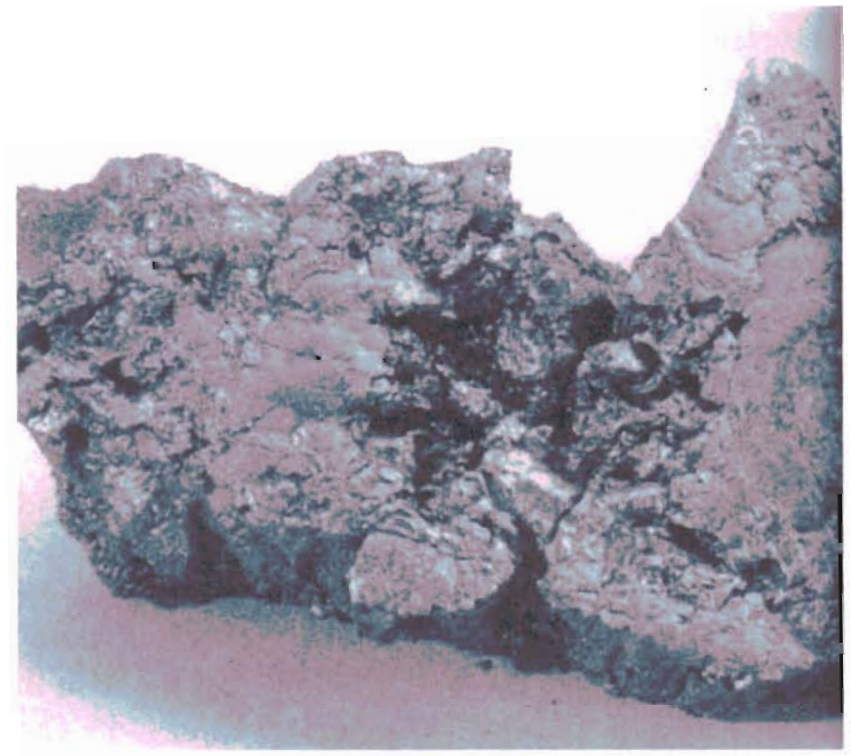

Figure 10. Debris removed from FARO L-19 melt/water interaction test (Magallon, 1999)

Table 8. Simulate corium data sources.

\begin{tabular}{|c|c|c|c|c|c|}
\hline \multirow{2}{*}{$\begin{array}{c}\text { Facility } \\
\text { (Organization/ } \\
\text { Country) }\end{array}$} & \multirow{2}{*}{$\begin{array}{l}\text { Phenomena } \\
\text { Investigated }\end{array}$} & \multicolumn{3}{|c|}{ Materials } & \multirow{2}{*}{ Pressure } \\
\hline & & Debris & Vessel & Coolant & \\
\hline $\begin{array}{l}\text { SONATA IV - } \\
\text { LAVA } \\
\text { KAERI/Korea - } \\
{[58]}\end{array}$ & Gap & $\begin{array}{l}\mathrm{Al}_{2} \mathrm{O}_{3} \\
\mathrm{w} \text { and } \mathrm{w} / \mathrm{O} \mathrm{Fe}\end{array}$ & $\begin{array}{l}\text { Carbon steel; some } \\
\text { tests w. penetrations }\end{array}$ & None & $\begin{array}{l}\quad \leq 2 \mathrm{MPa} \text { for } \\
\text { initial tests, } \Delta \mathrm{P}_{\text {ves }} \\
=1.8 \mathrm{MPa}\end{array}$ \\
\hline $\begin{array}{l}\text { ALPHA } \\
\text { JAERI/Japan - } \\
{[59]}\end{array}$ & $\begin{array}{l}\text { Gap, Crack, } \\
\text { and Enhanced } \\
\text { Area }\end{array}$ & $\mathrm{Al}_{2} \mathrm{O}_{3}$ & $\begin{array}{l}\text { SS-lined carbon steel } \\
\text { vessel. }\end{array}$ & Water & $\begin{array}{l}\quad \leq 1.6 \mathrm{MPa} \text { for } \\
\text { initial tests, } \Delta \mathrm{P}_{\mathrm{ves}} \\
=0 \mathrm{MPa}\end{array}$ \\
\hline $\begin{array}{l}\text { In-Vessel } \\
\text { Cooling } \\
\text { Experiment } \\
\text { FAI/USA - }[60]\end{array}$ & Gap & $\begin{array}{l}\mathrm{Al}_{2} \mathrm{O}_{3} \\
\mathrm{w} \text { and } \mathrm{w} / \mathrm{o} \mathrm{Fe}\end{array}$ & $\begin{array}{l}\text { Carbon steel w and } \\
\text { w/o insulation; some } \\
\text { tests w penetrations }\end{array}$ & $\begin{array}{l}\text { Water. Some } \\
\text { tests w/o } \\
\text { water. }\end{array}$ & $\begin{array}{c}\sim 3.1 \mathrm{MPa} \\
\Delta \mathrm{P}_{\mathrm{ves}}=3 \mathrm{MPa}\end{array}$ \\
\hline $\begin{array}{l}\text { FOREVER } \\
\text { RIT/Sweden - } \\
{[61,62]}\end{array}$ & Gap & $\begin{array}{l}\mathrm{CaO}-\mathrm{B}_{2} \mathrm{O}_{3} \text { or } \mathrm{CaO}- \\
\mathrm{WO}_{3} \text { w electrical } \\
\text { heating for } \mathrm{q}^{\prime \prime}=1 \\
\mathrm{MW} / \mathrm{m}^{3}\end{array}$ & $\begin{array}{l}\text { Carbon steel; some } \\
\text { tests w. penetrations }\end{array}$ & $\begin{array}{l}\text { Water. Some } \\
\text { tests w/o } \\
\text { water }\end{array}$ & $\begin{array}{c}\leq 4 \mathrm{MPa} \\
\Delta \mathrm{P}_{\mathrm{ves}}=2 \mathrm{MPa}\end{array}$ \\
\hline
\end{tabular}

Data obtained from many of these simulant corium tests exceeds that possible by conduction alone. Figure 12 contains representative data obtained from one of the ALPHA tests. The TV3 thermocouple is at the base of the vessel and reached the highest temperatures. The solid curve with red dots represents the predicted thermal response of the vessel if only conduction 


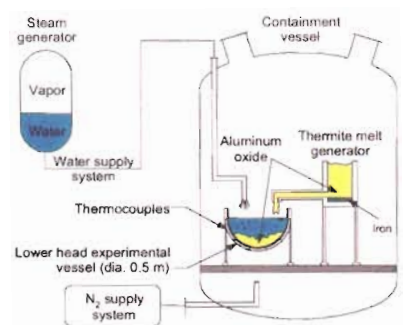

$\sim 1 / 10$ th scale JAERI ALPHA tests measure crack and gap formation and surface area enhancement

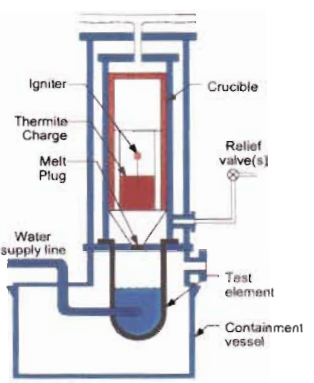

$\sim 1 / 10$ th scale FAI in-vessel tests include insulation and penetrations

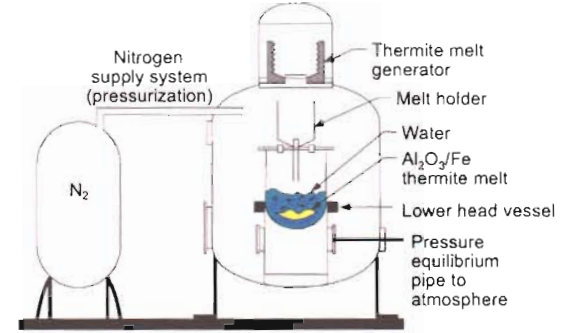

1/10th scale KAERI SONATA-IV LAVA tests measure debris-to-vessel gap formation

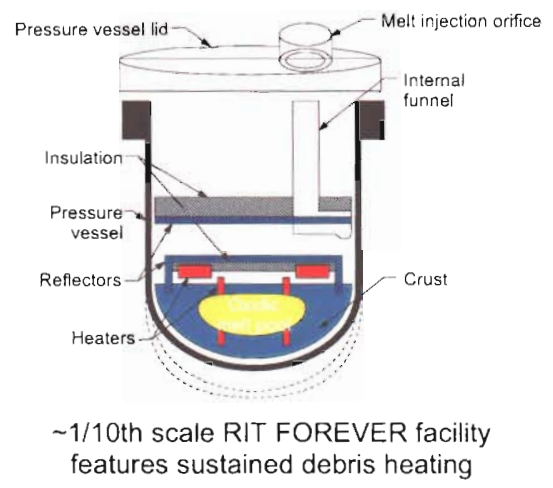

"Facilities not to scale

Figure 11. Simulant tests investigating gap cooling phenomena.

were present. Clearly, additional cooling occurred that decreased peak values and caused more rapid quenching of the vessel temperatures. However, the resolution of data from these tests was insufficient to quantify the "intermittent" debris-to-vessel contact or develop detailed models for simulating a narrow gap boiling curve.

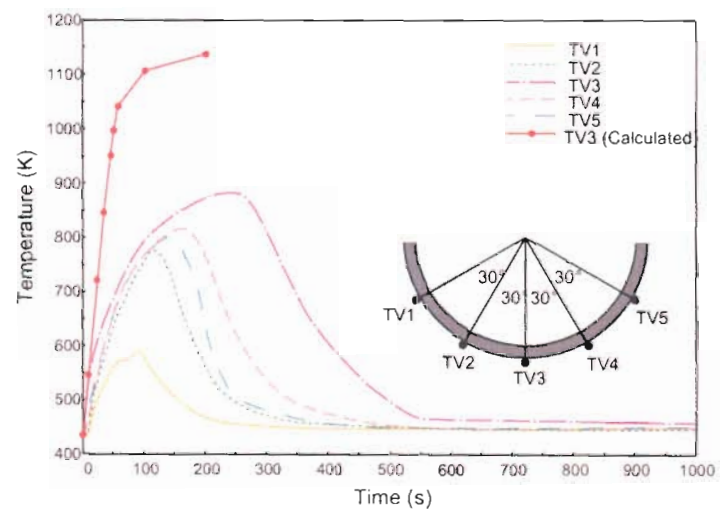

Figure 12. ALPHA test results demonstrating impact of gap cooling. 
As discussed in Section 4.2, it is important to recognize that there are key differences between the properties of simulant and prototypic materials. Although it is much easier and less expensive to use simulant materials, experimental results must be validated with data from tests with prototypic materials. As recently concluded by Reineke, et al., ${ }^{63}$ additional investigations with prototypic materials are needed to quantify the crack and gap formation and cooling phenomena observed in TMI-2. Although additional prototypic data are needed to quantify this cooling, it is recommended that sensitivity studies be completed to assess the impact of various possibilities for USEPR design certification.

\section{Vessel Failure}

The timing and mode of vessel failure significantly affects subsequent accident progression phenomena, such as the potential for phenomena such as molten core concrete interactions, ex-vessel steam explosions, or direct containment heating. This section describes various modes of vessel failure for which models have been developed and sources of data to which these models have been applied.

\subsection{Failure Modes and Models}

The TMI-2 accident, which occurred on March 28, 1979, significantly changed the nuclear industry's thoughts about the potential for vessel failure. Investigations after the accident concluded that at least $45 \%$ of the core had melted and $19,000 \mathrm{~kg}$ of the core material had relocated to the lower head. As discussed in Section 6, post-accident examinations indicate that about half of that material formed a solid layer near the TMI-2 vessel lower head (see Figure 13). Above this solid layer, was a layer of fragmented rubble. ${ }^{55}$

Post accident analyses of the TMI- 2 accident led to the identification of several potential failure mechanisms. There was concern about the potential for an in-vessel steam explosion (as discussed in Section 5). In addition, there was concern about the four vessel lower head failure mechanisms shown in Figure 14. Ex-vessel tube rupture occurs if the pressure and temperature loads in the tube below the vessel causes the stress in the tube to exceed its ultimate strength (this mechanism isn't applicable to the USEPR). Global vessel failure occurs if elevated system pressure, in conjunction with sustained heating of relocated debris in the vessel head, causes vessel material to experience high stresses. Tube weld failure and subsequent tube ejection occurs when the weld that holds the tube to the vessel fails due to temperature and the pressure load acting downward on the tube exceeds the frictional forces between the tube and the vessel (this mechanism also isn't applicable to the USEPR). Localized vessel failure occurs when there are thermal loads due to non-uniform heat sources in relocated debris or a coherent jet impinges on the lower head in conjunction with mechanical loads caused by high system pressure. In the NRCsponsored lower head failure program, ${ }^{64}$ models were developed and applied to estimate the 


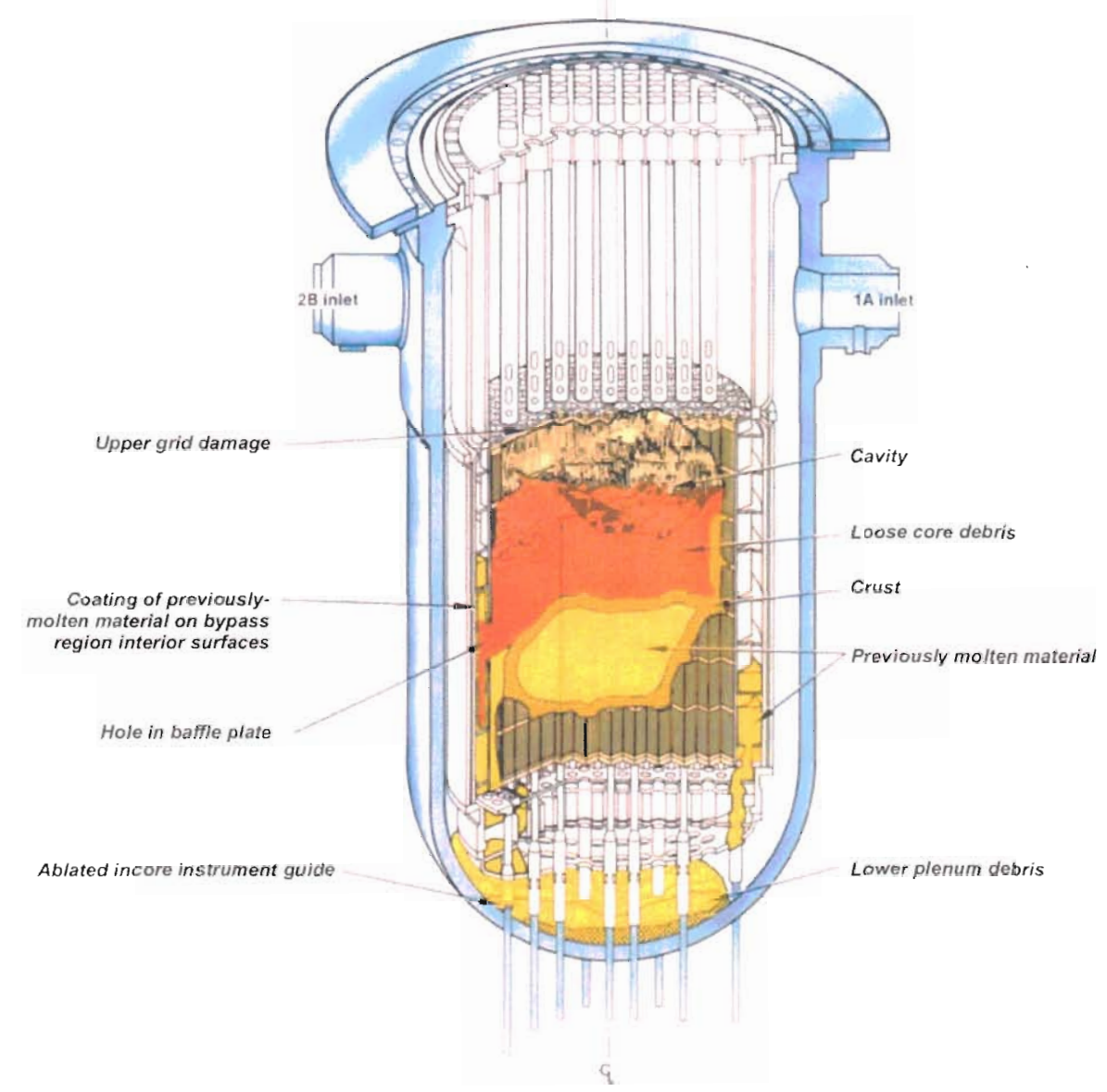

Figure 13. TMI-2 postulated endstate.

potential for each of these mechanisms to occur during a severe accident for a range of accident conditions and reactor designs.

\subsection{Model Development and Assessment}

Table 9 lists two data types of interest in assessing the potential for vessel failure--- high temperature material property data that should be incorporated into models and boundary condition data for assessing the potential of vessel failure. This section provides additional insights about both data types. 

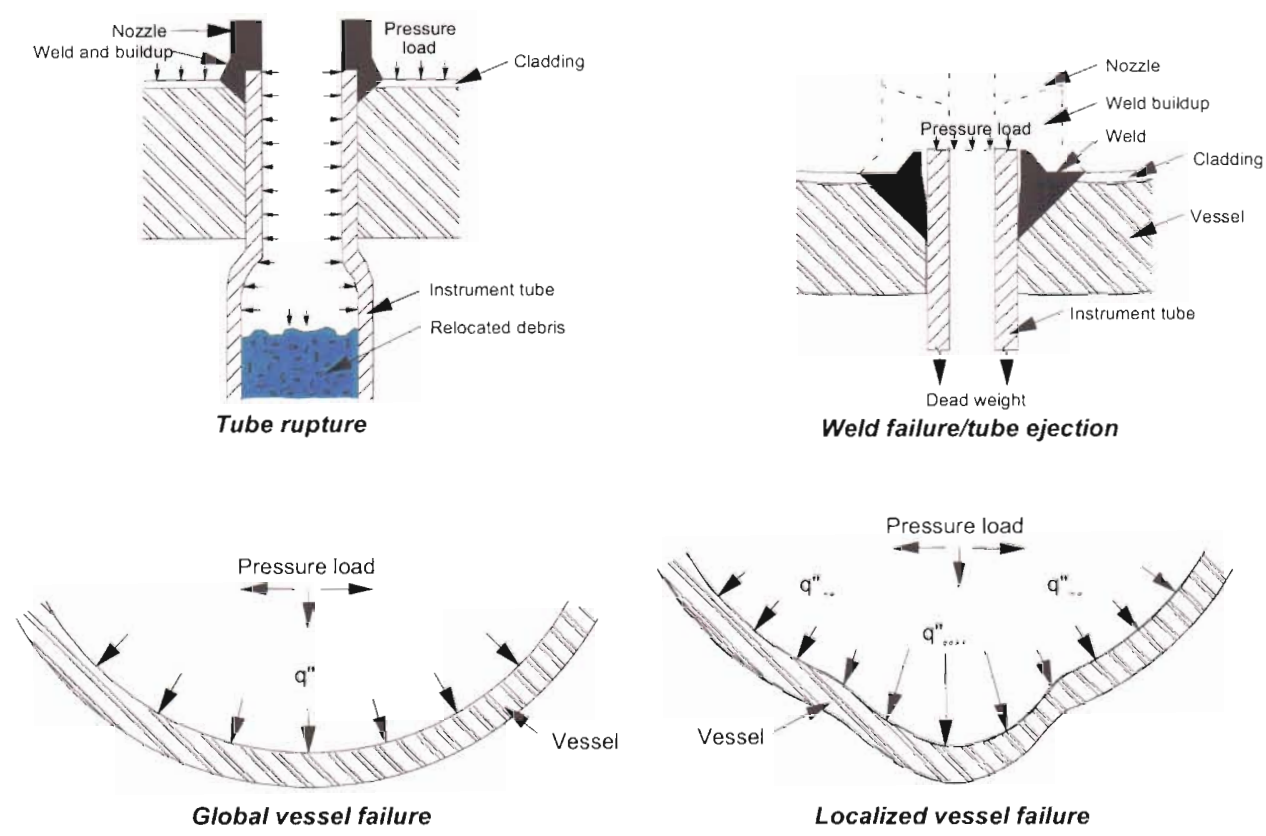

Figure 14. Vessel failure mechanisms.

Table 9. Data for benchmarking vessel failure.

\begin{tabular}{|c|c|}
\hline Data Source [Reference] & Description \\
\hline $\begin{array}{l}\text { NRC Sponsored Lower Head } \\
\text { Failure Program [64] }\end{array}$ & $\begin{array}{l}\text { High temperature creep and tensile data for SA533, SA } 105 / 106, \text { SS304 } \\
\text { and Inconel. Models and data available for incorporation into severe } \\
\text { accident codes (similar to what is used in MAAP; could be incorporated } \\
\text { into MELCOR) }\end{array}$ \\
\hline $\begin{array}{l}\text { INL SCWR Material Property } \\
\text { Evaluations }[65,66]\end{array}$ & High temperature thermal diffusivity data for SA533 and SS304. \\
\hline $\begin{array}{l}\text { OECD-sponsored TMI-2 } \\
\text { Vessel Investigation Project } \\
{[57,67]}\end{array}$ & $\begin{array}{l}\text { Data for assessing the potential for melt penetration through a vessel } \\
\text { penetration and for assessing the potential for tube rupture, tube } \\
\text { ejection, localized and global vessel failure modes. }\end{array}$ \\
\hline SNL LHF [68] & $\begin{array}{l}\text { One-fifth scale data for predicting vessel failure for a well-defined heat } \\
\text { load and pressure history. Data available for benchmarking severe } \\
\text { accident code models }\end{array}$ \\
\hline
\end{tabular}

High temperature creep and tensile data for vessel and penetration materials were obtained in the NRC lower head failure program, up to the $1250-1300 \mathrm{~K}$ range. Higher temperature data are particularly important for vessel lower head materials, such as the SA533B1 steel, because this material undergoes a phase transition, going from ferritic to austenitic steel, at $1000 \mathrm{~K}$. Although it is known that the strength of these materials is inversely proportional to temperature, data were needed to determine exactly how much strength remained in these materials at the 
elevated temperatures possible during severe accidents. Hence, this INL program obtained creep and tensile data for these materials up to $1250 \mathrm{~K}$. Specifically, INL obtained higher temperature creep and tensile data for the SS304 steel used for BWR control rod and instrument tube penetrations, the SA106 material used for BWR drain line penetrations, the Inconel used for PWR instrument tube penetrations, and the SA 533B1 carbon steel used in LWR vessels. Higher temperature data are particularly important for materials, such as the SA533B1 steel, because this material undergoes a phase transition, going from ferritic to austenitic steel, at $1000 \mathrm{~K}$. Hence, this new data allow analysts to estimate this material's strength at temperatures above the point where it undergoes this transition.

High temperature thermal material property data are also limited. In fact, most severe accident codes typically rely on the NRC-developed MATerials PROperty (MATPRO) package associated with the SCDAP/RELAP5 code. ${ }^{69}$ Data for predicting thermal properties in MATPRO are limited, if non-existent, above $1300 \mathrm{~K}$ for these materials. References 65 and 66 present high temperature thermal material property data that were recently obtained for SS304 and SA533B1 using a FL5000 thermal properties material analyzer at INL's High Temperature Test Laboratory. Data were obtained for temperatures up to $1650 \mathrm{~K}$. As documented in References 65 and 66, low temperature results (less than $1300 \mathrm{~K}$ ) indicate that the measured diffusivity data behavior is similar to data available in the literature for all of the materials tested (at least for those materials where data were available in the literature). Diffusivity values for the SA533B1 experienced a minimum at around $1000 \mathrm{~K}$, which corresponds to where a phase transition occurs in this material. High temperature diffusivity data obtained for stainless steel in References 65 and 66 differed from values reported in the literature (although it should be noted that literature values were extrapolated for temperatures above $1300 \mathrm{~K}$ ). It is recommended that this new data be incorporated into severe accident analyses codes.

In the OECD-sponsored TMI-2 Vessel Investigation Project (VIP), samples of the vessel steel, several instrument nozzles, and the debris were examined. Metallographic examination of the vessel steel or "boat" samples indicated that there was an elliptical region $(0.8$ by $1.0 \mathrm{~m})$ that experienced peak temperatures of around $1400 \mathrm{~K}$ for 30 minutes before it rapidly cooled (at a rate of 10 to $100{ }^{\circ} \mathrm{C} / \mathrm{min}$ ). Note that this peak temperature was well above the steel's transition temperature of $727^{\circ} \mathrm{C}$, where its ultimate strength is significantly reduced (it goes from ferritic to austenitic steel). Although there are no penetrations in the USEPR vessel lower head, some of the insights gained from these exams are of interest. Nozzle exams indicate that the most severe damage occurred in the "hot spot" region. It is interesting to note that this damage was not related to the embedded debris height [Nozzle L6 (see Figure 15) was submerged in debris, but it suffered significantly less damage than Nozzle H8 that was located in the hot spot region]. Last, exams indicate that lower portions of the nozzles were protected by crust formation.

Models developed in the NRC-sponsored Lower Head Failure Program were applied to determine the failure margin remaining in the vessel during the TMI-2 accident using available plant and VIP examination data. Analysis results provided several key insights about the potential for vessel failure. First, results indicate that there was a large margin-to-failure for tube rupture 

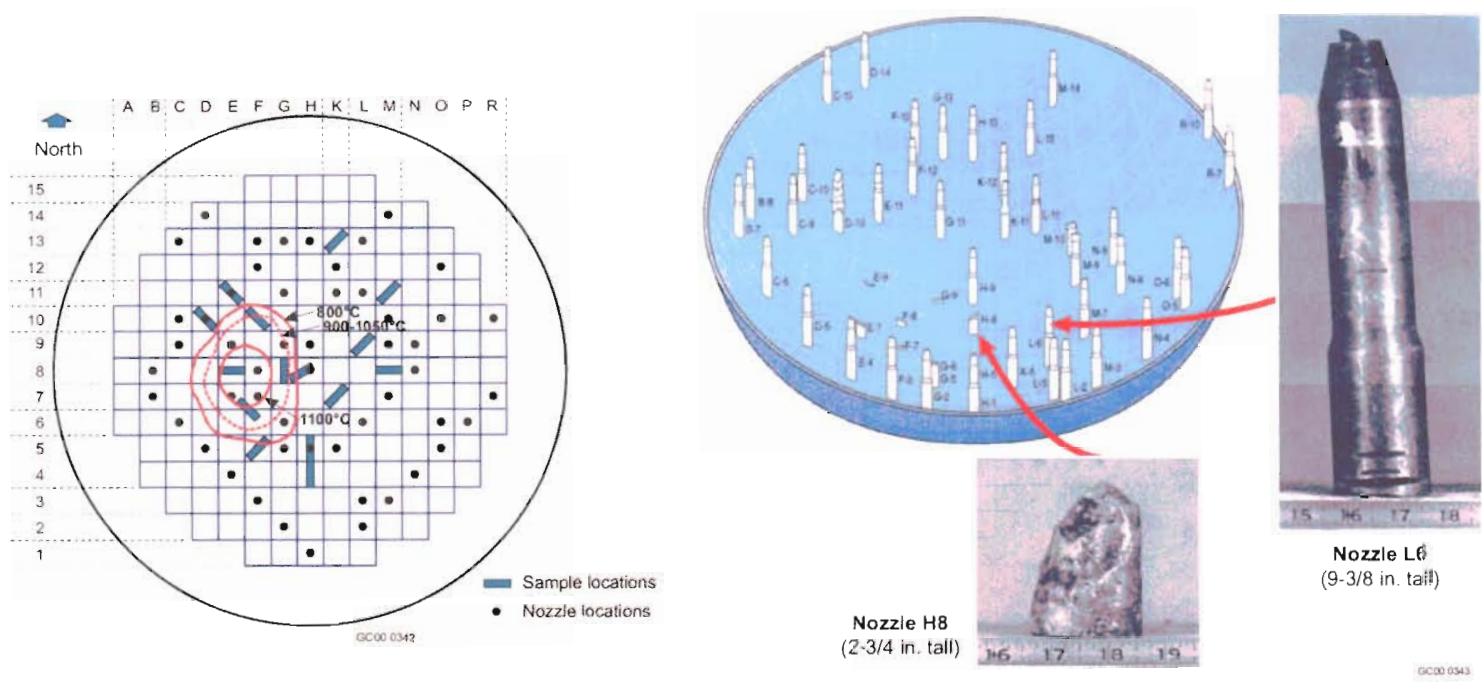

Figure 15. Location of nozzles and boat samples examined in the TMI-2 VIP.

and tube ejection failure modes. Melt traveling below the lower head was insufficient to heat the tube, and the thermal and pressure loads on the lower head were insufficient to fail the weld that joins the tube to the vessel. Second, results indicate that the localized "hot spot" was not due to jet impingement --- RCS pressure instrumentation suggest that peak temperatures from jet impingement were sustained for on the order of 1 minute, which is much less that the 30 minute duration inferred from vessel steel examinations. Third, analyses indicated that global or localized creep rupture was the failure mode with the least margin for TMI-2 scenario. Last, calculations indicate that additional margin, not currently considered in severe accident analyses codes, existed in the vessel lower head during the TMI-2 accident.

To clarify this last point, it is useful to review the TMI-2 vessel pressure history. As indicated in Figure 16, the peak RCS pressure occurred at 3.7 hours after scram due to a major relocation of core materials. At approximately 5 hours, the RCS pressure began to rise because the pressurizer block valve closed. The pressure rose to $15 \mathrm{MPa}$, and the RCS was sustained at this pressure for several hours. Initial TMI-2 VIP calculations performed to investigate global vessel creep rupture suggest that this high system pressure in conjunction with predicted vessel temperatures would result in vessel failure. Hence, it was postulated that additional cooling, not evident from companion sample exams, occurred prior to the time that the vessel was repressurized. This "additional cooling" is postulated to be due to water flowing between cracks within the debris and gaps between the vessel and the debris. As discussed in Reference 67 , several sources of data suggest the existence of this cooling and its importance. As observed in Section 6, recent publications from Magallon, et al., ${ }^{49}$ and Reineke, et al, ${ }^{63}$ continue to stress the importance of these mechanisms and the need for additional tests with protoypic materials to quantify cooling that occurs from these gaps and cracks. 


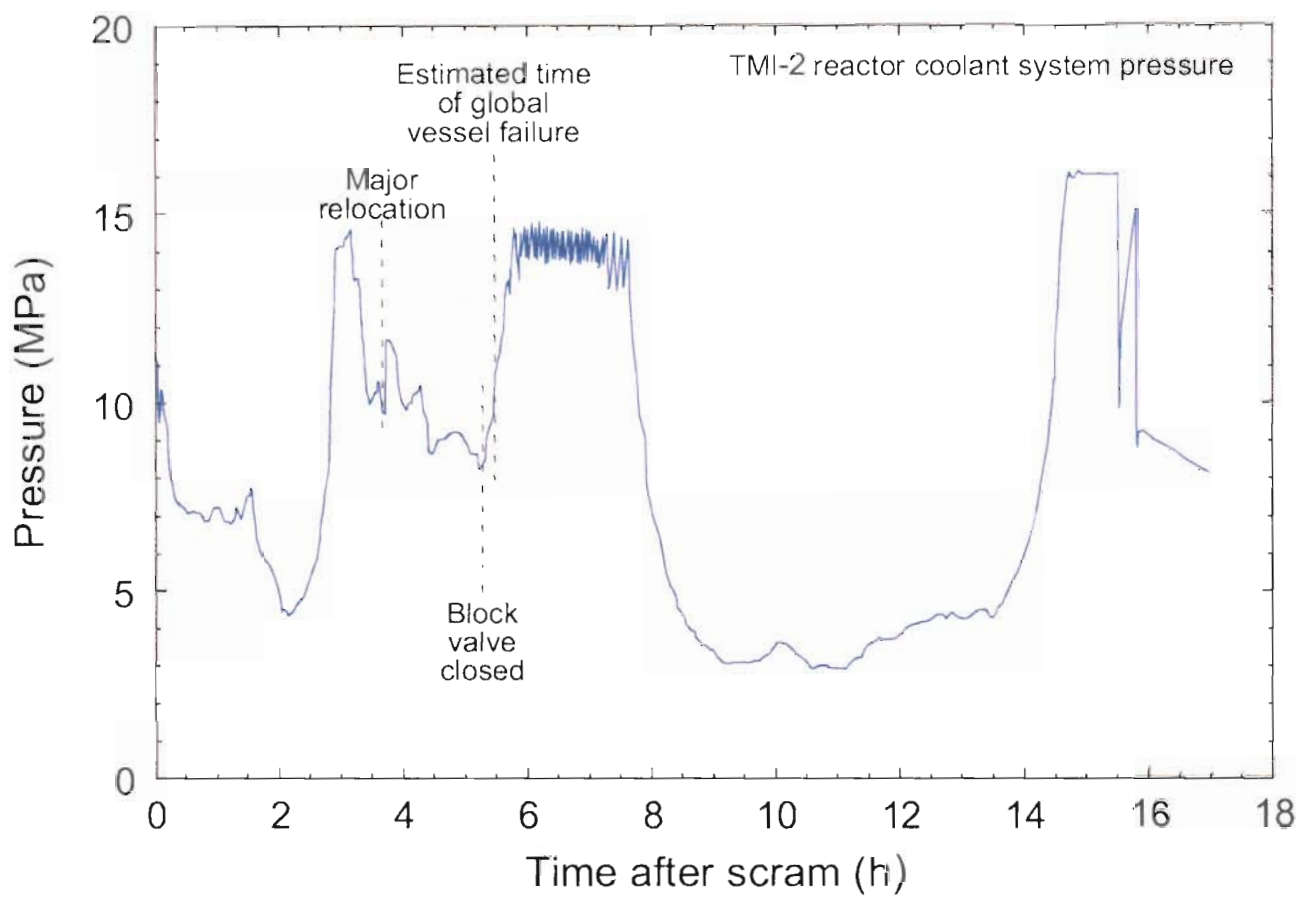

Figure 16. TMI-2 reactor pressure history indicated predicted timing of vessel failure.

Reference 68 describes lower head failure tests that were conducted in a one-fifth scale, SA533B1 carbon steel vessel to assess and make recommendations for reactor pressure vessel creep rupture models and identify the effects of heat flux distribution, pressure, penetrations, and weldments on vessel failure. The eight tests performed under the initial NRC-sponsored Lower Head Failure (LHF) program considered a range of pressures ( 5 to $10 \mathrm{MPa}$ ), heat flux distributions (uniformed and peaked) and the effects of penetrations. The LHF tests provide unique data and insights about vessel failure.

Figure 17 includes several photos from these tests to illustrate some of these insights. For example, photos from the LHF-5 and LHF-3 tests were are included because they provide insights about global vessel failure. In reality, "global" vessel failure may be very localized because heat fluxes aren't perfectly axisymmetric or because of non-uniformities in the vessel thickness during manufacture. Hence, a "global" vessel failure may initiate as a "tear" that may or may not "unzip" prior to depressurization. Obviously, these two different types of failures significantly differ in their impact on subsequent accident progression. Both types of failures were observed in LHF tests with "top-peaked" heat flux distributions (e.g., with heat fluxes that are larger in magnitude near the top of the vessel where the hemisphere is attached to the cylindrical portion of the vessel). The LHF-5 test differed because of an unplanned pressure transient during testing (the pressure went from 10 to $7 \mathrm{MPa}$ ), whereas the LHF-3 test remained at $10 \mathrm{MPa}$.

LHF tests were also conducted to gain insights about the impact of heat flux distribution. However, results illustrated the importance of manufacturing tolerances. Failures were observed 
to occur at the same location in the LHF-1 and LHF-6 tests, but for different reasons. Post-test exams indicate that the LHF-1 test vessel had a thinner wall at the observed failure location (although the thickness was within the allowed manufacturing tolerances). In the case of the LHF6 test, an unplanned hot spot occurred.

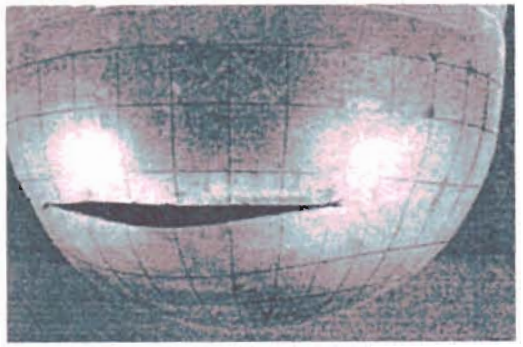

LHF-3

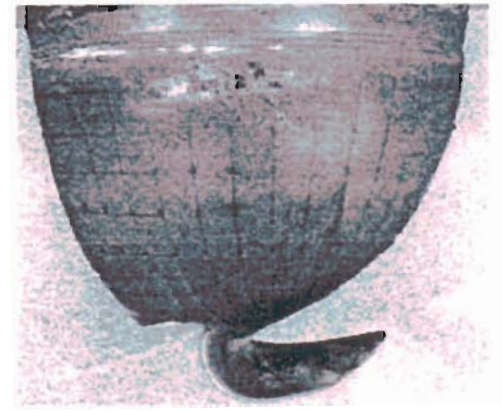

LHF-1

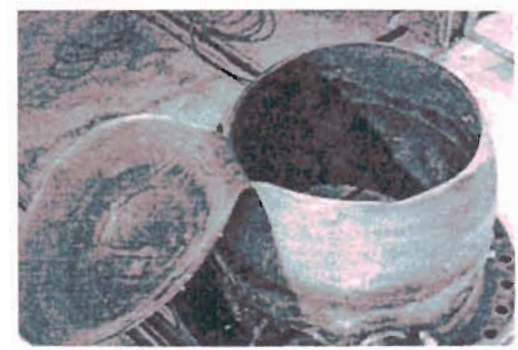

LHF-5

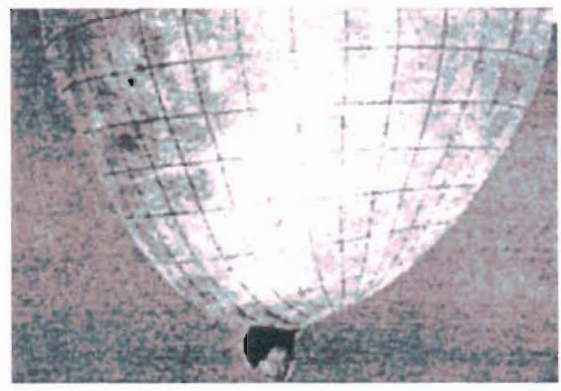

LHF-6

Figure 17. Representative LHF test results.

In summary, it is recommended that AREVA NP confirms the adequacy of high temperature material property data included in models used to predict vessel failure models, considering insights from recently obtained high temperature material property data. In addition, it is important for AREVA NP analysts to note some of the limitations of existing modeling capabilities (e.g., axisymmetric assumptions and unplanned differences in manufacturing capabilities).

\section{8. $\mathrm{MCCl}$ and Reactor Cavity Plug Failure}

The USEPR melt stabilization concept includes an ex-vessel corium spreading compartment for long-term melt stabilization. If this device were placed beneath the reactor pressure vessel, it would have to be protected from or designed to withstand the loads from vessel failure. To avoid such loads, this spreading area was placed in a separate lateral compartment (see Figure 18). The transfer channel between the reactor vessel cavity and the lateral compartment is closed during reactor operation (although it can be removed to allow inspections). USEPR melt 
stabilization requires a period of temporary melt retention and "melt conditioning" in the reactor cavity. This is facilitated by the cavity's sacrificial and protective layers and followed by failure of a sacrificial melt plug at the bottom of the reactor cavity that acts a predefined "weak point" in the cavity. Then, melt travels through the horizontal transfer channel to the lateral compartment or melt spreading area.

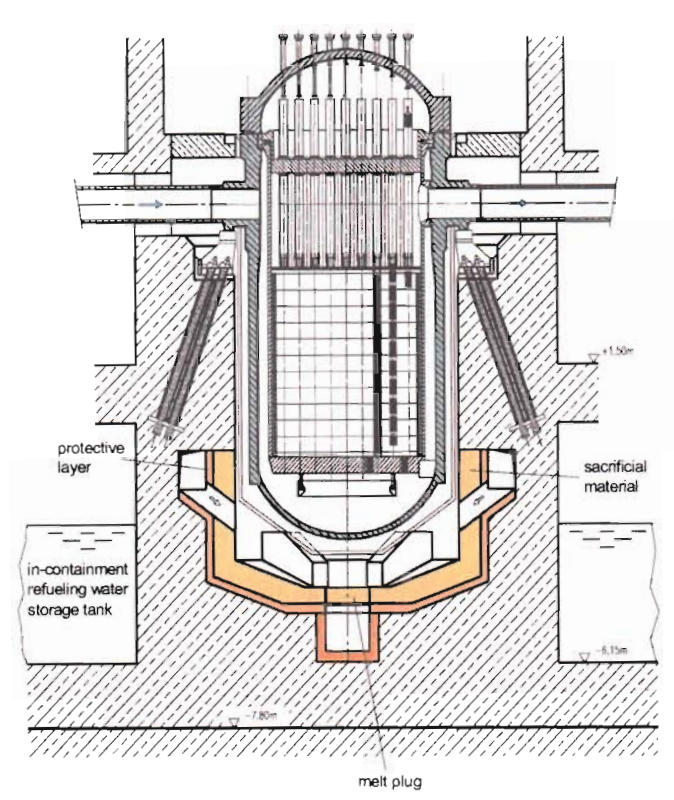

(a) Reactor Cavity

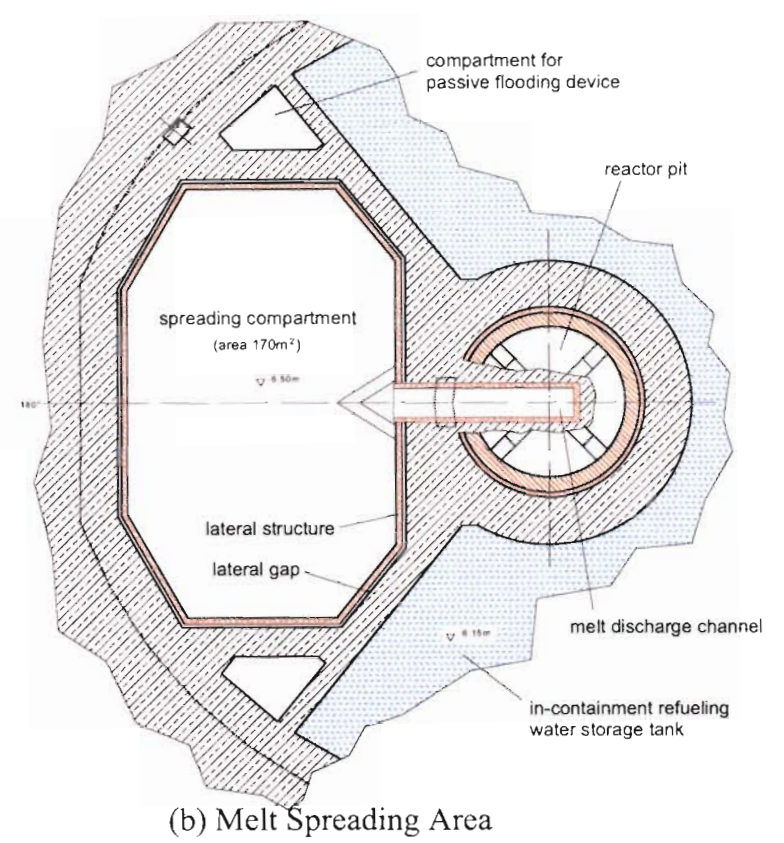

(b) Melt Spreading Area

Figure 18. USEPR melt stabilization components.

As shown in Figure 19, the sacrificial melt plug consists of a metallic support structure (an aluminum plate reinforced by a top-mounted steel grid that is fully embedded in concrete). Aided by four concrete walls that form a virtual pedestal supporting a failed lower head, this structure is designed to absorb the loads associated with reactor pressure vessel failure under high pressure. Per Reference 70 , the cell size of the grid $(42 \times 49 \mathrm{~cm})$ is designed to be significantly larger than the predicted minimum open cross-section required for a "fast melt release of about $0.07 \mathrm{~m}^{2 \text { " }}$. Hence, the grid (which provides most of the mechanical stability of the plug) won't constrict the melt flow. The melt plug has a cover which is composed of sacrificial concrete. The time needed to erode the sacrificial concrete determines the melt retention time in the reactor cavity. The steel support frame can absorb and distribute the mechanical forces acting on the gate into the surrounding protective layer (up to the design pit pressure of 20 bar). During severe accidents, it is estimated that the weight of the melt will produce much smaller mechanical loads (although it is designed to resist any thermal weakening of the support structure due to heat conduction from relocating melt). The plug is locked against the frame by an array of simultaneously operated steel bolts. The aluminum underneath the grid has a low melting point $\left(660.4^{\circ} \mathrm{C}\right)$. It is predicted to fail when it is in contact with $>2000{ }^{\circ} \mathrm{C}$ melt (either metallic or ceramic). If, for some unforeseen reason, the gate does not open, the steel plug support structure which sits on top of the protective 
layer (see Figure 20) is predicted to fail and drop-out under the pressure imposed by the melt. Hence, there are redundant and diverse opening mechanisms included in the USEPR design to ensure that the gate cross-section is open for melt release.

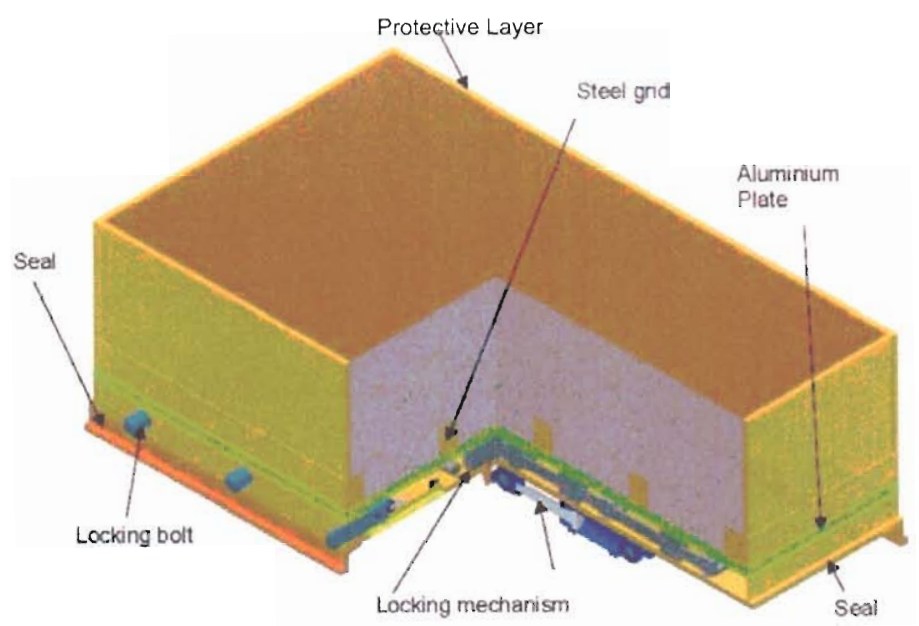

Figure 19. Proposed melt plug design.

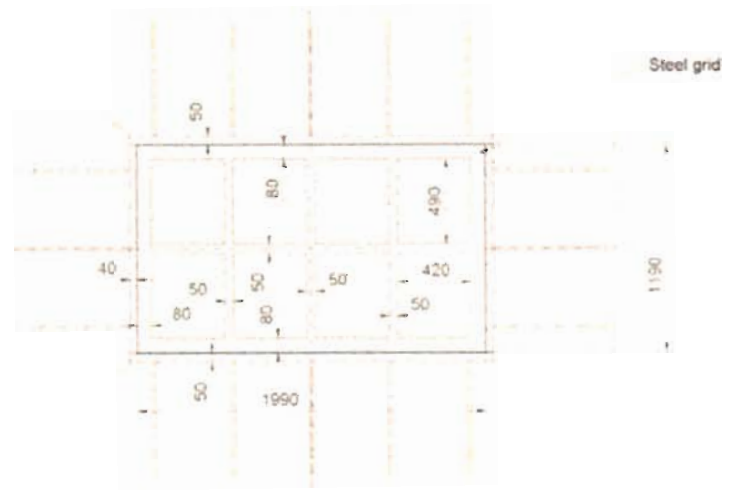

Figure 20. Preliminary design for melt plug support structure.

The proposed melt plug design is unique to the USEPR. In reviewing the design and supporting information provided in Reference 70, it is recommended that the following issues be addressed to confirm the viability of this design:

- Issue I-Will relocated debris yield a heat load that will erode the sacrificial concrete and subsequently fail the gate (and/or) support structure? Resolution of this issue should consider various vessel failure modes, debris relocation scenarios, and corium endstates.

- Issue 2 - Will sufficient heat loads be present in relocated corium (after ablation of the sacrificial concrete) to fail the aluminum plate and/or the steel support structure? Resolution of this issue should consider various debris compositions and masses and any materials 
interactions that would preclude failure of the aluminum plate or the steel support structure (e.g., the formation of aluminum oxide to form on the aluminum plate).

- Issue 3 - After plug or steel support structure failure, will the corium flow toward the spreading area without plugging the transfer channel? Resolution of this issue should consider various debris compositions and masses (and the resulting material after concrete interactions).

References 71 through 74 address Issue 1 by describing "self -adjusting" properties of relocating melt that undergoes $\mathrm{MCCI}$. The authors claim that smaller initial relocating melt masses or delayed melt relocations will have lower decay heats, lower heat fluxes, and lower ablation rates. Hence, these smaller or delayed pours will extend the time window available for the pit to be available to retain later, larger, pours that will ablate through the sacrificial concrete and fail the vessel. Reference 72 notes that parametric studies demonstrate that all of the scenarios that they've considered ultimately lead to gross failure of the vessel lower head (with large melt pours). These sensitivity studies, which considered melt relocation masses ranging from 40 to $80 \%$ of the total oxidic and metallic melt inventory, predict that the reactor vessel failure will occur between 3 hours and 1 day. Scenarios characterized in these references describe phenomena, such as impact of thermal radiation from an ex-vessel pool to the reactor vessel lower head. Subsequently, associated analyses have been performed with models and codes that may be different from those being used for the USEPR severe accident engineering activities; hence, issue closure depends on demonstrating equivalent code development and analysis as part of the USEPR effort.

Reference 70 addresses Issue 2 by noting that several types of debris endstate configurations were considered in evaluating the attack on the gate from relocated debris:

- A 3-layer system, with heavy oxide at the bottom, metal above, and slag layer on top

- A 2-layer system, with metal at the bottom, and an oxide/slag layer above

- A completely mixed melt with metal dispersed within a lighter oxide.

Reference 70 indicates that, irrespective of the debris configuration, the low-melting point of the aluminum causes a hole to form in the gate that subsequently enlarges due to melt flowing through it. An uncertainty not considered in Reference 70 is the potential for a protective layer of alumina to form on the aluminum plate and prohibit gate failure. As such, further evaluation of this phenomena is recommended.

References 70 and 72 address Issue 3 by summarizing results from parametric studies evaluating possible melt compositions after gate failure. Reference 72 also reports the corresponding corium liquidus temperature, melt temperature, resulting volumetric solid fraction (which affects melt viscosity and spreading) from these studies. Results indicate that for all of the cases considered, the melt temperature is always predicted to be at least $2050^{\circ} \mathrm{C}$, which is well above the predicted immobilization temperature of the melt $\left(1500^{\circ} \mathrm{C}\right)$. However, the analyses described in these references assume a large gate failure area (which, in turn, is based on a large global vessel failure area). 
References 70 and 73 identify experiments yielding insights for analyzing the melt plug design. These tests and their insights are summarized in Table 10. It should be noted that the only test with prototypic corium materials is the MET- 1 test, ${ }^{81}$ which was conducted in the MACE facility. As noted in Reference 70, no large scale prototypic test has been conducted because of difficulties with heating the melt without heating the gate. Future testing in this area should consider recent innovations in resistance heater design. (Reference 75)

Table 10. Relevant data for melt plug failure analyses.

\begin{tabular}{|c|c|c|}
\hline Data Source [Reference] & Phenomena & Insights/Key Results \\
\hline KAPOOL $[76,77]$ & $\begin{array}{l}\text { Attack on smaller thickness of } \\
\text { aluminum plates ( } 1 \text { to } 4 \mathrm{~cm} \text { ) by } \\
\text { alumina and metallic melts } \\
\text { (iron/alumina thermite with no } \\
\text { heat sources). }\end{array}$ & $\begin{array}{l}\text { Melt oxide crusts temporarily delayed plate } \\
\text { failure, but eventually underlying aluminum } \\
\text { plate heated up and failed. }\end{array}$ \\
\hline $\begin{array}{l}\text { COrium Interaction with } \\
\text { REfractory and SAcrificial Layers } \\
\text { (CORESA) including COMAS } \\
{[78,79,80]}\end{array}$ & $\begin{array}{l}\text { Melt spreading tests that involve } \\
\text { the contact of metallic and oxidic } \\
\text { corium flows with metallic plate. }\end{array}$ & $\begin{array}{l}\text { Emissivity of the molten corium-con- } \\
\text { crete mixture and radiation heat transfer } \\
\text { to the vessel lower head. } \\
\text { Heat transfer from melt to a metallic } \\
\text { substrate. }\end{array}$ \\
\hline MET-1 $[81]$ & $\begin{array}{l}\text { Attack on aluminum plate by } \\
\text { prototypic oxide corium melt. }\end{array}$ & $\begin{array}{l}\text { Smaller thickness plate of aluminum }(2 \mathrm{~cm} \\
\text { thick }) \text { failed due to oxidic corium attack } \\
\text { without any delay. }\end{array}$ \\
\hline HTCM [78] & $\begin{array}{l}\text { Attack of molten oxidic corium on } \\
\text { metallic structures (submerged } \\
\text { cylindrical metallic samples into } \\
\text { pools of molten oxidic corium). }\end{array}$ & Heat fluxes into steel from corium. \\
\hline MVI $[82,83]$ & $\begin{array}{l}\text { Steel ablation by corium outflow } \\
\text { through predefined holes. }\end{array}$ & $\begin{array}{l}\text { Steel ablation rate and heat transfer } \\
\text { correlations due to melt outflow (hole } \\
\text { widening effects of melt flows). }\end{array}$ \\
\hline KAJET $[84]$ & $\begin{array}{l}\text { Influence of melt impingement on } \\
\text { concrete. Iron/alumina thermite } \\
\text { with concrete added was used to } \\
\text { simulate the "conditioned" } \\
\text { corium. }\end{array}$ & $\begin{array}{l}\text { Ablation rates of various types of concrete } \\
\text { when exposed to various corium } \\
\text { compositions. }\end{array}$ \\
\hline
\end{tabular}

In summary, it is recommended that additional details regarding melt plug failure be provided to address the following:

- Demonstrate that the effectiveness of the retention phase to various corium pour sequences.

- Demonstrate that the aluminum gate won't form a protective alumina crust that prevents failure.

- Incorporate into analyses uncertainties associated with the impact of thermal radiation from an ex-vessel corium pool to the reactor vessel lower head. 
The gate's failure and subsequent melt relocation are key to providing reliable inputs to PRA Level 2 and Level 3 analysis. Hence, it is suggested that the basis for the assumed melt plug failure be well-documented with as much data as possible.

\section{Melt Spreading and Coolability}

As indicated in Figure 18, the USEPR melt stabilization concept includes a melt spreading compartment that is located lateral to the reactor cavity. Once the gate is thermally destroyed, the melt is guided through a horizontal melt transfer channel into the spreading compartment. Due to its large cross-section $\left(>1 \mathrm{~m}^{2}\right.$ ) and its inert, temperature resistant walls, the transfer channel is not expected to retard melt flow. The spreading room is a "dead-end" compartment (see Figure 21). It is initially "dry" in the sense that (1) there is no inflow of water from any part of the containment and (2) the potential height of the condensate at the floor remains sufficiently low. As noted in Section 8 , the position of the melt spreading area from the reactor cavity protects the cavity from any loads from the vessel head or from corium jets during vessel failure. In addition, its lateral position from the reactor vessel eliminates any safety concerns connected with an unintentional flooding of the melt spreading compartment during power operation. ${ }^{73,74}$

\subsection{USEPR Design}

Long term cooling of the melt and heat removal occurs, by design, in the spreading

compartment (area $170 \mathrm{~m}^{2}$ ), which consists of a sacrificial concrete layer supported by a finned metallic bottom cooling plate. Cooling channels at the lower part of the cooling plate permit corium heat removal through the plate, in particular when the sacrificial layer is eroded. The spreading compartment is formed by cast iron elements, which are flexibly connected to avoid problems resulting from thermal deformation. Water leak-tightness of the connections is not required as a wetting of the concrete is acceptable. Melt arrival triggers the opening of two redundant spring-loaded flooding valves that initiate gravity-driven overflow of water from the in-containment refueling water storage tank (IRWST). The fill-up process will complete within a few minutes (for the specified initial flooding rate of $100 \mathrm{~kg} / \mathrm{s}$, the fill-up process takes 5 minutes). The water first fills the central supply duct underneath the spreading compartment, which connects the triangular compartments shown in Figure 21(a). From there, the water enters parallel, horizontal channels, formed by the fins at the bottom of the cooling elements. shown in Figure 21(b). After the vertical space behind the sidewall structure is filled (see Figure 21(b)), water will start to pour onto the melt from the circumference of the melt spreading area.

Several enhanced features of the USEPR spreading area suggest that it is more robust than concepts implemented in other evolutionary or advanced LWR designs. First, the USEPR melt spreading area is larger than that used in the ABWR $\left(88 \mathrm{~m}^{2}\right)$ or the System $80+\left(64.4 \mathrm{~m}^{2}\right)$, and it yields a value much lower than the EPRI requirement of $0.02 \mathrm{~m}^{2} / \mathrm{MWt}$. USEPR. Designers have included this large area for spreading to provide a reliable cooling surface. In the case of the 


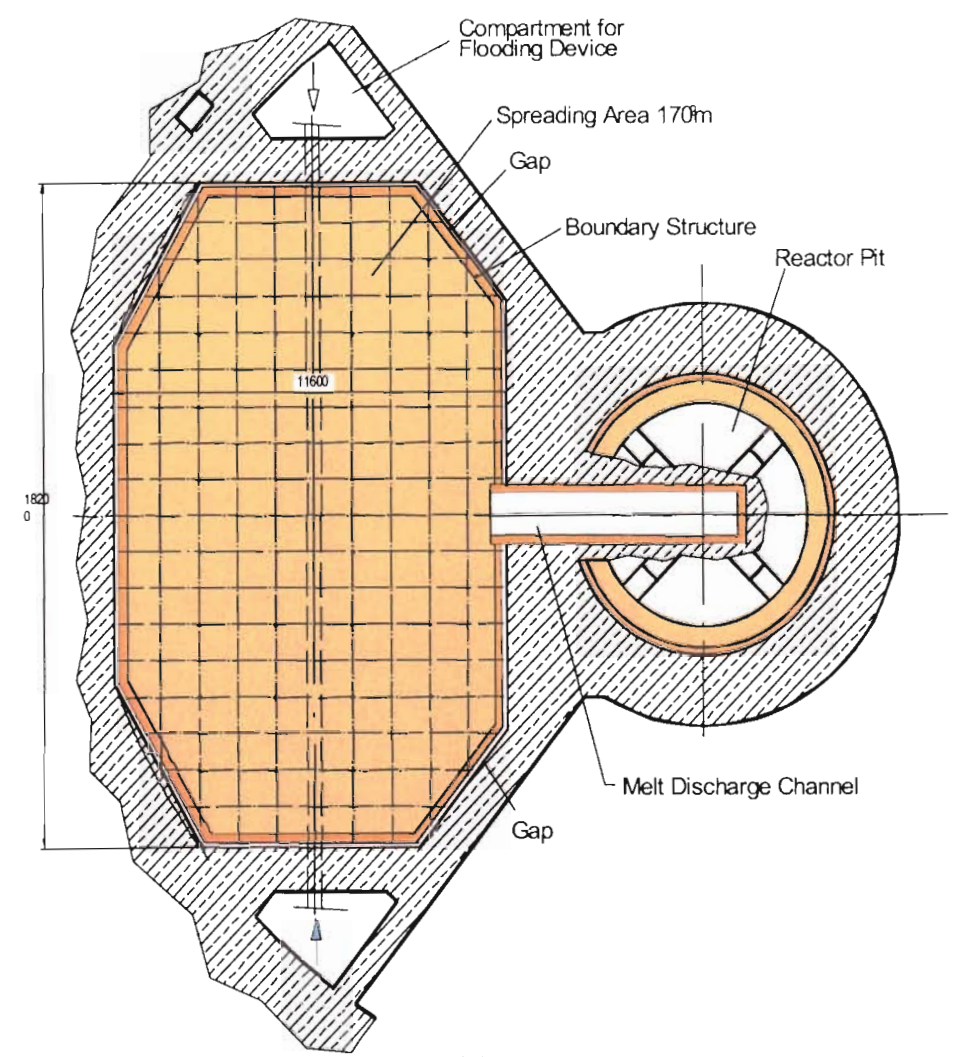

(a)

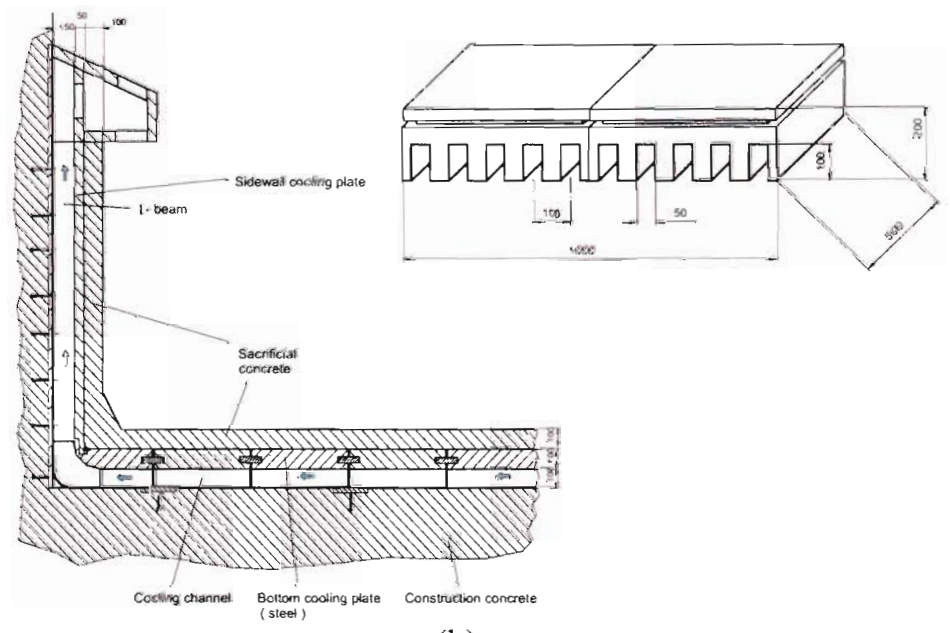

(b)

Figure 21. Melt spreading area and cooling structure.

USEPR, corium that enters the spreading area has a better defined viscosity because of the addition of sacrificial concrete from the reactor pit and from initial contact in the melt spreading compartment. The USEPR melt spreading concept also precludes ex-vessel steam explosions in the melt spreading area. It is initially dry when melt enters the spreading area. The melt has been conditioned with silica-rich sacrificial material that is added to it prior to flooding; and water is 
added in a slow and passively controlled manner to the top of the melt after spreading. Last, it is anticipated that the proposed design will preclude "stable crust formation" observed in MCCI tests. The addition of silica to "conditioned" corium is anticipated to yield a lighter oxidic layer on top of the spread melt with a superheated metallic melt underneath. This superheated metallic melt will cause high concrete erosion and gas generation rates that will promote crust breakup. Experimental tests have also shown that the inclusion of concrete into the melt will reduce the

liquidus temperature of the melt, reduce the melt viscosity, and increase the capacity of the melt to retain fission products. ${ }^{73}$

\subsection{Model Development and Evaluation}

Table 11 summarizes data available for validating various aspects of the proposed USEPR melt stabilization design. As indicated in this table, data are required to determine the heat removal rate from the spreading area cooling channels, to ensure that the melt transfer channel doesn't plug, and to demonstrate MCCI phenomena related to concrete erosion rates, zirconia protective layer stability, ex-vessel steam explosions, melt segregation, and gas generation rate.

Although predicted heat fluxes from relocated melt to the cooling channels were lower than heat removal rates inferred from the SULTAN facility, ${ }^{85}$ cooling tests on a full-scale horizontal cooling channel were performed using the Benson loop. ${ }^{86,87}$ Two water supply modes were investigated, co-current and counter-current flow, reflecting different cooling conditions: water flowing in the same direction as steam in the channel (inflow from the IRWST) or in counter-current flow (passive feeding of the channels from the saturated pool on top of the melt). Results indicate that this system adequately removes heat, even for heat fluxes that significantly exceed expected values. 
Table 11. Relevant data for melt stabilization analyses.

\begin{tabular}{|c|c|c|}
\hline Data Source & Phenomena & Insights \\
\hline BENSON $[86,87]$ & $\begin{array}{l}\text { Heat transfer from representative spreading } \\
\text { area cooling channels. }\end{array}$ & $\begin{array}{l}\text { Adequate heat removed from vertical and horizontal } \\
\text { channels in counter-current passive and co-current } \\
\text { active flow conditions. }\end{array}$ \\
\hline $\begin{array}{l}\text { COrium Interaction with } \\
\text { REfractory and SAcrificial } \\
\text { Layers (CORESA) } \\
\text { including COMAS and } \\
\text { COMAS-EU [78, 79, } 80, \\
88]\end{array}$ & $\begin{array}{l}\text { Melt spreading tests with metallic, oxide, } \\
\text { and mixed corium flows contacting metallic } \\
\text { plates and various types of concrete. } \\
\text { COMAS included 1D/2D large-scale tests in } \\
\text { dry conditions. }\end{array}$ & $\begin{array}{ll}\text { - } & \text { No melt plugging observed in transfer channel. } \\
\text { - } & \text { Stability of zirconia protective layer. } \\
\text { - } & \text { Melt spreading distances. } \\
\text { - } & \text { Melt stratification. }\end{array}$ \\
\hline KATS $[89]$ & $\begin{array}{l}\text { i } \mathrm{D} / 2 \mathrm{D} \text { spreading tests using simulant melts } \\
\text { (metal/oxide) under dry and wet conditions. }\end{array}$ & $\begin{array}{l}\text { - } \quad \text { Lo melt plugging observed in transfer channel. } \\
\text { - Spreseading not influenced by pre-existing thin } \\
\text { water layer. }\end{array}$ \\
\hline ECOKATS [90] & $\begin{array}{l}\text { 2D demonstration test using } 3 \text { tons of high- } \\
\text { temperature simulant (metal and oxide) with } \\
\text { flooding. }\end{array}$ & Demonstration of USEPR melt stabilization. \\
\hline ACE $[91]$ & $\begin{array}{l}\text { Heated } 1 \mathrm{D}-\mathrm{MCCI} \text { tests with prototypic oxide } \\
\text { melts and various types of concrete. }\end{array}$ & \multirow{3}{*}{$\begin{array}{l}\text { - High initial heat transfer from corium (related } \\
\text { to power supplied to the melt). } \\
\text { Significantly lower heat removal after crust } \\
\text { forms on upper surface. } \\
\text { Homogenous flux distribution along the pool } \\
\text { boundary. } \\
\text { Voiding in corium region beneath crust } \\
\text { Pool swelling followed by eruptions enhances } \\
\text { heat removal. } \\
\text { More non-condensable gases (e.g., } \mathrm{CO}_{2} \text { ) from } \\
\text { limestone-common sand concrete. } \\
\text { Fe } \mathrm{O}_{3} \text { promotes oxidation of } \mathrm{U} \text { and } \mathrm{Zr} \text { in relo- } \\
\text { cated corium and ensures melt spreading (low- } \\
\text { ers melting temperature to } 1100^{\circ} \mathrm{C} \text {, and } \\
\text { diminishes radiant heat losses. } \\
\text { Concrete erosion and gas generation rates (mul- } \\
\text { tiple types of concrete). }\end{array}$} \\
\hline $\begin{array}{l}\text { Melt Attack and Coolability } \\
\text { Experiments (MACE) }[92, \\
93,94,95]\end{array}$ & $\begin{array}{l}\text { Heated } 1 \mathrm{D} / 2 \mathrm{D}-\mathrm{MCC} \text { large-scale tests with } \\
\text { prototypic oxidic melts and various types of } \\
\text { concrete (primarily under top-flooded } \\
\text { conditions). } 100 \text { to } 2000 \mathrm{~kg} \text { scale }(30 \mathrm{~cm} \times \\
30 \mathrm{~cm} \text { to } 120 \mathrm{~cm} \times 120 \mathrm{~cm} \text { concrete basemat } \\
\text { area) }\end{array}$ & \\
\hline$\widehat{\mathrm{OECD}-\mathrm{MCCI}}[96,97]$ & $\begin{array}{l}\text { Heated 2D-MCCI tests with prototypic } \\
\text { oxidic melts and various types of concrete } \\
\text { partially under flooded conditions. }\end{array}$ & \\
\hline $\begin{array}{l}\text { Coolability of MEIT } \\
\text { (COMET) }[98,99]\end{array}$ & $\begin{array}{l}\text { Large-scale MCCI test with heated metallic } \\
\text { melt and bottom water injection. }\end{array}$ & $\begin{array}{l}\text { Concrete erosion rates and velocities by superheated } \\
\text { metallic flows. }\end{array}$ \\
\hline BALISE[100] & $\begin{array}{l}\text { Gas-driven mixing of density stratified non- } \\
\text { freezing liquids. }\end{array}$ & $\begin{array}{l}\text { Correlations for predicting if oxide and metallic melt } \\
\text { fractions become mixed. }\end{array}$ \\
\hline$\overline{B A L I}[101]$ & $\begin{array}{l}\text { Heat flux distribution in a volumetrically } \\
\text { heated, bubble agitated fluid with cold } \\
\text { sidewalls. }\end{array}$ & $\begin{array}{l}\text { Heat flux to the top, which envelops that to the side, } \\
\text { is about the same as to the bottom over a wide range } \\
\text { of gas rates and heat fluxes. }\end{array}$ \\
\hline BETA [102] & $\begin{array}{l}\text { 2D-interaction of various concrete types } \\
\text { with heated metallic melts }\left(\mathrm{Fe}_{2} \mathrm{O}_{3} / \mathrm{Al}-\right. \\
\text { thermite) }\end{array}$ & $\begin{array}{l}\text { Directional concrete erosion rates and gas generation } \\
\text { rates. }\end{array}$ \\
\hline $\begin{array}{l}\text { Small-Scale Water } \\
\text { Ingression and Crust } \\
\text { Strength (SSWICS) } \\
\text { Facility[103] }\end{array}$ & $\begin{array}{l}\text { Heated } 2 \mathrm{D} \text { tests designed to quantify cooling } \\
\text { rate of prototypic oxide melts and various } \\
\text { amounts of concrete under flooded } \\
\text { conditions }\end{array}$ & $\begin{array}{l}\text { Cooling rate exceeded conduction rate for corium } \\
\text { with } 8 \mathrm{wt} / \% \text { concrete. Less cooling observed with } \\
\text { coriums containing larger fractions of concrete. }\end{array}$ \\
\hline COTELS [104] & $\begin{array}{l}\text { Heated } 2 \mathrm{D} \text { tests to quantify concrete ablation } \\
\text { using prototypic melts with and without } \\
\text { water addition. }\end{array}$ & $\begin{array}{l}\text { Ablation rate for basaltic concrete was significantly } \\
\text { smaller compared to mortar without coarse } \\
\text { aggregates. }\end{array}$ \\
\hline
\end{tabular}


The Melt Attack and Coolability and Experiment (MACE) program focused on "top flooding" phenomena by collecting molten corium in the reactor cavity and flooding it with

water. ${ }^{92-95}$ Results showed that flooding leads to an initial cooling stage with efficient melt/water heat transfer, followed by the formation of a crust that inhibits further quenching. Four major tests were conducted in this program for a range of increasing larger scale facilities (e.g., from 100 to $2000 \mathrm{~kg} / 30 \mathrm{~cm} \times 30 \mathrm{~cm}$ to $120 \mathrm{~cm} \times 120 \mathrm{~cm}$ spreading area). Although some cooling mechanisms to counter the formation of a stable crust were observed, such as crust cracking followed by water ingression, "volcanic" eruptions due to concrete decomposition gases passing through or mechanical breach of a suspended crust, the stability of the crust due to attachment to the test facility sidewalls precluded long term melt coolability being observed in these tests (even in larger tests). Later tests performed at ANL in the Small-Scale Water Ingression and Crust Strength (SSWICS) facility indicate that the coolability due to crack formation was associated with the fraction of concrete in the corium. Results indicate that the cooling rate of melts containing 23 $w t \%$ concrete approached that similar to conduction-rate cooling; whereas the cooling measured in melts with lower fractions of concrete (e.g., $8 \mathrm{wt} \%$ ) were significantly higher than the conduction-limited rate. ${ }^{103}$ Furthermore, MACE tests indicate that energetic steam explosions will not occur under these conditions.

In summary, the USEPR melt spreading design appears to be much more robust than designs included in other evolutionary plant designs or existing reactor containments. In addition to the much larger spreading area, the design has included several aspects that should further promote debris coolability and melt stabilization (e.g., the inclusion of silica materials, the use of cooling channels beneath the spreading compartment, etc.). Data appear to be available for evaluating most of the relevant phenomena associated with this concept. There are some exceptions. For example, there have not been tests to demonstrate MCCI phenomena with heated oxide and metallic melts present so that the integral behavior of stratification and mixing phenomena could be evaluated. However, no additional data are recommended because of the robustness of the proposed design and because sensitivity calculations can be used to address existing uncertainties (e.g., with stratified and uniformly mixed corium materials). Nevertheless, some code development and associated verification and validation is necessary to consider phenomena unique to the USEPR (e.g., material properties for corium with silica materials, the cooling channel configuration and heat transfer rates, and the concrete erosion and gas generation rates associated with superheated metallic melts).

\section{Hydrogen Control}

A key LWR containment challenge that must be evaluated during a severe accident is the pressure produced during hydrogen combustion. Combustion of hydrogen occurs according to the following exothermic reaction:

$2 \mathrm{H}_{2}+\mathrm{O}_{2} \rightarrow 2 \mathrm{H}_{2} \mathrm{O}+57.8 \mathrm{kcal} / \mathrm{gm}-$ mole $\mathrm{H}_{2}$ consumed

Of interest in assessing the effects of $\mathrm{H}_{2}$ combustion are: 
- Under what conditions will hydrogen combustion occur?

- Are pressure and temperature loads associated with hydrogen combustion sufficient to threaten containment integrity or damage key equipment?

As shown in Figure 22, hydrogen combustion increased the TMI-2 containment pressure by 28 psig. During core heatup, between 270 to $370 \mathrm{~kg}$ hydrogen released through PORVs ( $40 \%$ of zirconium oxidized). This pressure rise corresponds to complete combustion of an approximately $8 \%$ hydrogen atmosphere. This rise led to concerns about the integrity of containments with smaller net free volumes, such as a Mark I containment, that might be exposed to similar threats.

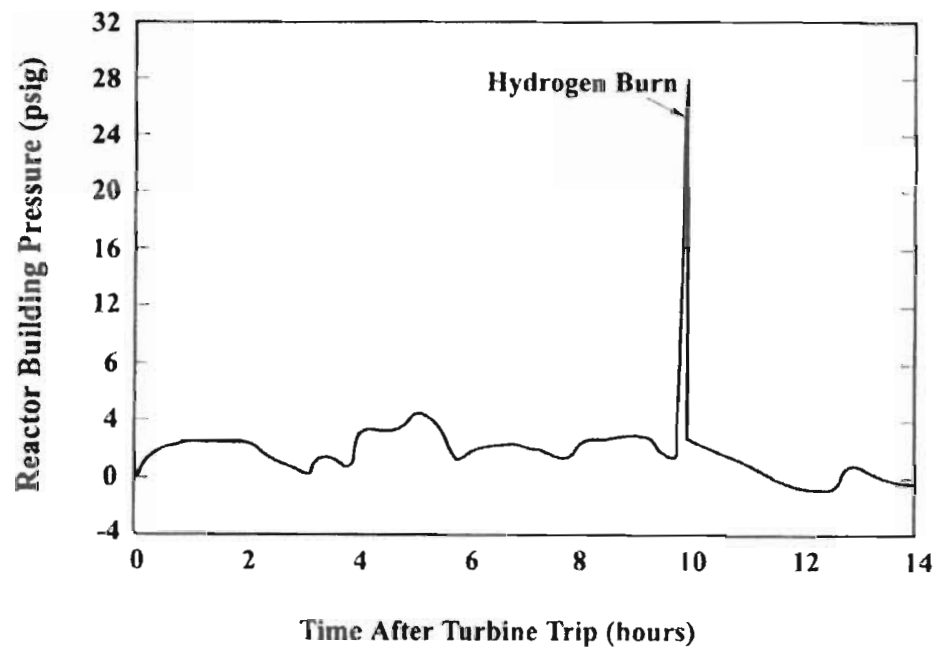

Figure 22. TMI-2 containment pressure history.

Combustion waves are divided into two classifications: deflagration and detonation. Deflagration waves travel subsonicallly to produce quasi-static (near steady state) containment loads. Detonation waves are combustion waves in which heating of the unburned gases is due to compression from shock waves. Detonation waves ravel supersonically $(>2200 \mathrm{~m} / \mathrm{s})$ and produce dynamic or impulsive containment loads in addition to static loads. In addition, analysts must consider if there are any "high energy" ignition sources or any localized high concentrations of hydrogen that could allow detonation to occur. Higher concentrations of hydrogen may occur near release points, under ceilings or domes (due to density stratification) or near steam removal locations, such as ice condensers, suppression pools, and fan coolers. In assessing the potential for hydrogen ignition, analysts consider the following:

- Equipment more susceptible to high pressures or temperatures

- Compartments with smaller volumes

- Structures or regions at higher temperature or with more ignition sources 
Generally, in order for substantial combustion to occur, the gaseous mixture must be flammable and an ignition source must be present. Flammability limits for hydrogen: air: steam mixtures are often depicted in tools, such as the Shapiro and Moffette diagram ${ }^{106}$ shown in Figure 23. In this figure, the closer one is to the center of this diagram, the smaller amount of energy that's needed for the atmosphere to be flammable. For example, less than $60 \%$ steam (e.g., $40 \%$ steam, $40 \%$ air, and $60 \% \mathrm{H}_{2}$ ) will yield a flammable mixture; greater than $60 \%$ steam will inert the containment. However, it should be noted that the limits vary with pressure, temperature, and the presence of steam or other diluents.

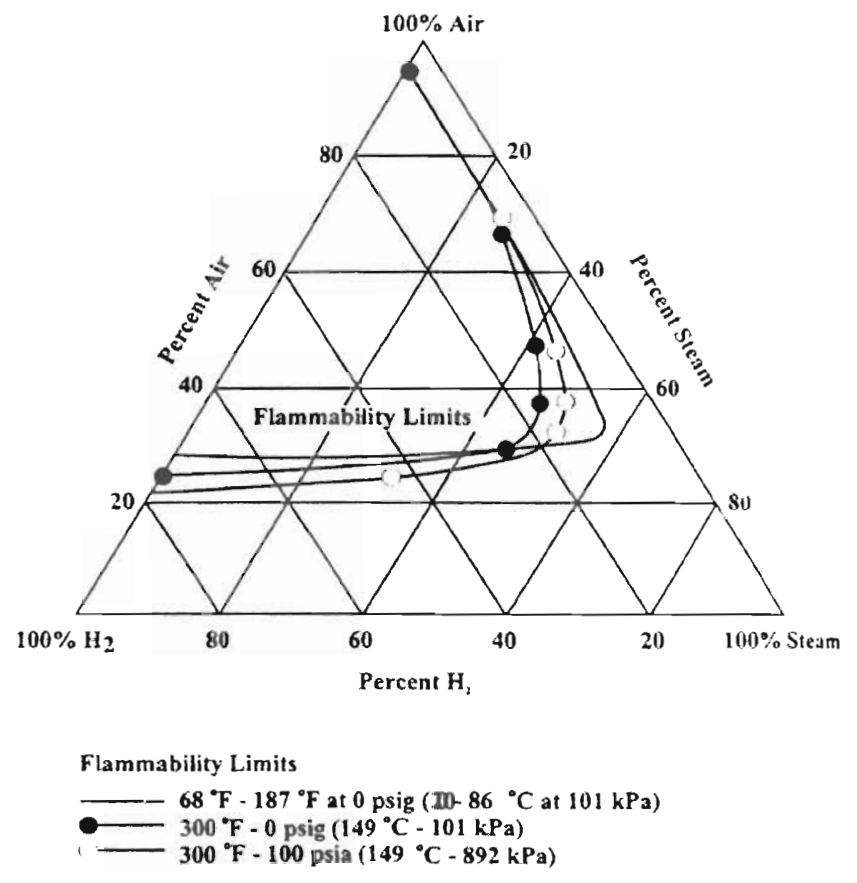

Figure 23. Flammability limits of hydrogen: air: steam mixtures.

Combustion risk is often quantified using the " $\sigma$ " and the " $7 \lambda$ " experimentally-developed criteria. ${ }^{107}$ The $\sigma$ criterion is used to estimate the risk of flame acceleration (or fast deflagration). This criterion relates the expansion ratio $\sigma$ (density of the gas before divided by the density after non-isochoric combustion) to an experimentally-based limit (primarily form tests performed in tubes). As long as the ratio of the expansion ratio, $\sigma$, to this experimentally-based limit is less than 1 , there is no risk of flame acceleration. If fast deflagration cannot be excluded, another criterion, the $7 \lambda$ criterion, is used to assess the non-occurrence of deflagration-to-detonation (DDT). This criterion compares the mixture quality, in terms of detonation cell width $\lambda$, with a characteristic length, L, of the compartment or of a group of compartments. The detonation cell width is determined by interpolation of experimentally found cell widths with hydrogen-steam 
concentration, temperatures, and pressure as parameters. Experimental data suggests that as long as the ratio of $L$ to $\lambda$ remains greater than 7 , there is no risk of DDT.

In the USEPR, hydrogen is controlled by ensuring that concentrations do not reach detonation limits. ${ }^{105}$ This is accomplished with a large containment volume $\left(80,000 \mathrm{~m}^{3}\right)$ and the distribution of nearly 50 auto passive autocatalytic recombiners (PARs) throughout the containment. When hydrogen is released from the primary system, it is also released with sufficient steam to ensure a low detonation risk. In addition, the PARs are designed to maintain the average hydrogen concentration inside the containment below $10 \%$ by volume. Rupture disks and flaps are also used to passively transform the two-room containment into a single convective volume following a pressure increase. Analyses are performed to ensure that any potential combustion doesn't yield Adiabatic Isochoric Complete Combustion (AICC) pressures above the containment design pressure. ${ }^{108}$

\subsection{In-Vessel and Ex-Vessel Hydrogen Generation}

In-vessel hydrogen generation evaluations must consider production during fuel heatup, during reflooding (if it occurs), and during melt/water interactions that occur during core slumping. After vessel failure, hydrogen production evaluations should consider any addition oxidation of zirconium in the melt and hydrogen production during MCCI. Several large scale tests have been completed to verify calculations method predictions for in-vessel hydrogen production, such as CORA, PHEBUS, LOFT, QUENCH, PBF, and TMI-2 (see Sections 2 and 3). Although there are some uncertainties related to the increase in hydrogen production due to reflooding and later stages of core melt progression, it is believed that hydrogen production during reflood is calculated conservatively and that later stages of melt progression do not significantly contribute to hydrogen production. Hence, no additional research is recommended. Likewise, as discussed in Section 9, hydrogen production during core-concrete interactions has been quantified using results from large-scale test facilities, such as the MACE program; and no additional research is recommended.

Calculation results presented in Reference 109 indicate that the following amounts of hydrogen can be produced during a severe accident before and after reactor vessel failure:

- Within the RPV, where the maximum conceivable amount is given by the amount of easily oxidizing metal, such as zirconium: $100 \% \mathrm{Zr}$ oxidation would lead to $1680 \mathrm{~kg} \mathrm{H}_{2}$.

- In case of RPV failure in the reactor pit and in the spreading compartment, the amount of hydrogen is limited by the water content of the sacrificial material: $700 \mathrm{~kg}$.

Also, additional hydrogen production could occur due to oxidation of zirconium released from the reactor vessel at high pressure. However, USEPR design features have been implemented to reduce the likelihood of high pressure releases. 


\subsection{Hydrogen Ignition and Recombiner Performance}

Table 12 summarizes representative sources of data available for assessing the potential for hydrogen combustion and the performance of PARs. As evidenced from this table, a considerable amount of work has been done to provide adequate data for validating computational tools. Recent evaluations suggest that Computational Fluid Dynamics (CFD) codes should be used in conjunction with traditional lumped parameter severe accident analysis tools, such as MELCOR and MAAP. The combined computational approach allows one to assess the "goodness" of the lumped parameter tools and limit the computational requirements associated with CFD tools.

At this time, no additional data are required. However, it is suggested that analysis tools (both CFD and lumped parameter models) be applied to predict results from tests evaluating the performance of multiple recombiners in multi-room and single-room configurations. In addition, the effects of fission product aerosols, steam, and concentration gradients on recombiners should be evaluated.

Table 12. Relevant data sources for assessing ex-vessel hydrogen behavior.

\begin{tabular}{|c|c|}
\hline Data Source & Facility Size and Phenomena Evaluated \\
\hline $\begin{array}{l}\text { HDR T31.5 and E11.2 [110, } 111 \\
112]\end{array}$ & $\begin{array}{l}\text { Large-scale }\left(11,300 \mathrm{~m}^{3}\right) \text { multi-compartment facility for evaluating } \\
\text { hydrogen distribution, stratification, and mixing. }\end{array}$ \\
\hline $\begin{array}{l}\text { Battelle Model Containment } \\
\text { (KfK) GX7, RX4, RX5, } \\
\text { VANAM, and HYJET }[113 \\
114,115,116]\end{array}$ & $\begin{array}{l}\text { Large-scale, multi-compartment facility tests to evaluate hydrogen } \\
\text { distribution with respect to transport, steam inertion, and gas mixing }\end{array}$ \\
\hline $\begin{array}{l}\text { NUPEC Large-Scale Test Facility } \\
(\mathrm{M}-7-1 \text { and M-8-1 Tests) }[117 \\
118,119]\end{array}$ & $\begin{array}{l}\text { One-forth scale }\left(1300 \mathrm{~m}^{3}\right) \text {, multi-compartment simulated containment } \\
\text { facility. Tests evaluated the impact of temperature and pressure on } \\
\text { hydrogen distribution and combustion. Analyses documented for } \\
\text { MELCOR [3] }\end{array}$ \\
\hline TOSQAN [120] & $\begin{array}{l}\text { Small scale }\left(7 \mathrm{~m}^{3}\right) \text { vessel for investigating the effects of condensation } \\
\text { on spray droplets. }\end{array}$ \\
\hline MISTRA [120] & Large scale $\left(100 \mathrm{~m}^{3}\right)$ facility to investigate the impact of sprays. \\
\hline ThAI [120] & $\begin{array}{l}\text { Medium scale }\left(60 \mathrm{~m}^{3}\right) \text { facility to investigate hydrogen distribution and } \\
\text { iodine chemistry. }\end{array}$ \\
\hline $\begin{array}{l}\text { RUT (Kurchatov Institute } \\
\text { Moscow) [121, 122] }\end{array}$ & $\begin{array}{l}\text { Large scale }\left(480 \mathrm{~m}^{3}\right) \text { facility to investigate hydrogen distribution and } \\
\text { ignition (with respect to placement of igniters). }\end{array}$ \\
\hline KALI $[123,124]$ & $\begin{array}{l}\text { Smaller scale }\left(16 \mathrm{~m}^{3}\right) \text { facility tests to qualify recombiners and } \\
\text { investigate effects of hydrogen concentration and containment spray on } \\
\text { recombiners. }\end{array}$ \\
\hline H2PAR [125] & $\begin{array}{l}\text { Smaller scale }\left(8 \mathrm{~m}^{3}\right) \text { facility to test evaluate the performance of } \\
\text { recombiners and investigate the effects of various conditions that may } \\
\text { occur in a containment (e.g., the presence of nuclear aerosols, etc.) on } \\
\text { their performance. }\end{array}$ \\
\hline
\end{tabular}




\section{Summary}

This document summarizes data that can be used for assessing various models embodied in severe accident analysis codes. Phenomena discussed in this document, which were limited to those anticipated to be of interest in assessing severe accidents in the USEPR developed by AREVA NP, include:

- Fuel Heatup and Melt Progression

- Reactor Coolant System (RCS) Thermal Hydraulics

- In-Vessel Molten Pool Formation and Heat Transfer

- Fuel/Coolant Interactions during Relocation

- Debris Heat Loads to the Vessel

- Vessel Failure

- Molten Core Concrete Interaction (MCCI) and Reactor Cavity Plug Failure

- Melt Spreading and Coolability

- Hydrogen Control

A section is devoted to describing each of these phenomena and identifying available modeling data. As noted in this document, models for many of these phenomena differ in US accident analysis codes (MAAP, MELCOR, and SCDAP/RELAP5). Where possible, this report notes if previous assessments are available that illustrate the impact of these modeling differences on predicting various phenomena.

Table 13 summarizes the recommendations noted for each of the phenomena reviewed. As indicated in this table, no additional data are needed for most of the phenomena considered. In most cases, the response of the USEPR can be predicted with models in existing codes because the data supporting these models are considered adequate. However, there are a few exceptions where it is recommended that models be reviewed to ensure appropriate applicability and validation. In cases where such applicability and validation cannot be ensured, it is recommended that new models be developed, validated and incorporated to simulate the required phenomena. For example, models and material property data in MAAP and MELCOR must be modified to simulate phenomena associated with melt stabilization in the spreading compartment. Another exception is the basis for predicting phenomena associated with the failure of the melt plug. As indicated in Table 13 (and in Section 8), limited data were identified to support the conclusion that vessel failure and subsequent melt pours will guarantee melt plug failure. The failure of this plug is essential for successfully mitigating the consequences of severe accidents in the USEPR. Hence, additional information is required to demonstrate several aspects associated with the response of this melt plug. In addition, models in severe accident codes must be modified to incorporate the feedback effects required to simulate the melt plug response.

As noted in Section 12, over 100 references were cited in completing this review. For cases where the USEPR response is similar to that of existing LWRs, the basis of this review is well-established. In cases where the USEPR design deviates from other evolutionary and existing LWR designs, it should be recognized that this is a preliminary review. All of the information 
available to AREVA NP designers was not available for preparing this document. Yet, unless additional information is provided to NRC reviewers, it is suspected that they may also request similar information.

Table 13. Summary recommendations for phenomena evaluated.

\begin{tabular}{|c|c|}
\hline Phenomena & Recommendation Summary \\
\hline Fuel Heatup and Melt Progression & $\begin{array}{l}\text { No additional data needed to verify the ability of severe accident codes to } \\
\text { model USEPR fuel heatup and melt progression phenomena. }\end{array}$ \\
\hline RCS Thermal Hydraulics & $\begin{array}{l}\text { No additional data needed to verify that severe accident codes adequately } \\
\text { model USEPR transient system thermal hydraulic response. }\end{array}$ \\
\hline $\begin{array}{l}\text { Molten Pool Formation and Heat } \\
\text { Transfer }\end{array}$ & $\begin{array}{l}\text { Simulant data adequate for verifying ability to predict natural convection } \\
\text { in pools with volumetric heating. Prototypic data not suitable for } \\
\text { validating code predictions. However, severe accident analysis should } \\
\text { consider key insights were gained from prototypic tests. }\end{array}$ \\
\hline $\begin{array}{l}\text { Fuel/Coolant Interactions during } \\
\text { Relocation }\end{array}$ & $\begin{array}{l}\text { No additional data required. Existing data deemed adequate to } \\
\text { demonstrate that the potential for an energetic in-vessel steam explosion is } \\
\text { negligible. }\end{array}$ \\
\hline Debris Heat Loads to the Vessel & $\begin{array}{l}\text { Although additional prototypic data are needed to quantify cooling that } \\
\text { may occur with various debris configurations, geometries, and } \\
\text { compositions, it is recommended that sensitivity studies be completed to } \\
\text { assess the impact of various possibilities. }\end{array}$ \\
\hline Vessel Failure & $\begin{array}{l}\text { No additional data required. However, code models should be checked to } \\
\text { verify that recently-obtained high-temperature material property data are } \\
\text { included for predicting vessel failure. }\end{array}$ \\
\hline Reactor Cavity Plug Failure & $\begin{array}{l}\text { Additional information needed to demonstrate that protective crust } \\
\text { formation (from multiple relocations or aluminum oxide formation) won't } \\
\text { prohibit melt plug failure. Integral tests are suggested to validate } \\
\text { combined effects of radiation heat transfer from upper surface of } \mathrm{MCCI} \\
\text { pool on vessel heatup and failure. }\end{array}$ \\
\hline Melt Spreading and Coolability & $\begin{array}{l}\text { No additional data required, but sensitivity calculations should be } \\
\text { performed to address existing uncertainties (e.g., with stratified and } \\
\text { uniformly mixed corium materials). In addition, computational models } \\
\text { must consider appropriate phenomena (e.g., material properties for corium } \\
\text { with silica materials, the cooling channel configuration and heat transfer } \\
\text { rates, and the concrete erosion and gas generation rates associated with } \\
\text { superheated metallic melts). }\end{array}$ \\
\hline Hydrogen Control & $\begin{array}{l}\text { No additional data required, but it is suggested that analysis tools (both } \\
\text { CFD and lumped parameter models) be applied to assess their ability to } \\
\text { predict results from on-going multiple-recombiner performance tests. }\end{array}$ \\
\hline
\end{tabular}




\section{References}

1. L. J. Siefken, E. W. Coryell, E. A. Harvego, and J. K. Hohorst, SCDAP/RELAP5/MOD3.3 Code Manual, Volume5: Assessment of Modeling of Reactor Core Behavior during Severe Accidents, NUREG/CR-6150, Vol. 5, Rev. 2, INEL-96/0422, January 2001.

2. Fauske and Associates, Inc., MAAP4-Modular Accident Analysis Program for LWR Power Plants, Vol. 3, Benchmarking, prepared for Electric Power Research Institute, May 1994.

3. R. O. Gauntt, et al., MELCOR Computer Code Manuals, Volume 3: Demonstration Problems, Version 1.8.5, NUREG/CR-6119, Vol. 3, Rev. 0, April 2001.

4. C. M. Allison, J. L. Rempe, and S. A. Chàvez, Design Report on SCDAP/RELAP5 Model Improvements - Debris Bed and Molten Pool Behavior, INEL-94/0174, November 1994.

5. R. W. Brower L. J. Fackrell, D. W. Golden, M. L. Harris, and C. L. Olaveson, ICBC Version 3.I, TMI-2 Initial and Boundary Conditions Data Base, GEND-INF-078, January 1988.

6. Y. Nomura, PORV Discharge Flow During the TMI-2 Accident, EGG-TMI-7825, July 1987.

7. D. Coleman, "As-Built Design and Material Characteristics of the TMI-2 Core," Part III in TMI-2 Accident Core Heatup Analysis, A Supplement, NSAC-25, June 1981.

8. J. L. Anderson, TMI-2 Once Through Steam Generator Secondary Level Analysis, EGG--TMI7359, January 1987.

9. J. L. Anderson, Recommended HPI Rates for the TMI-2 Analysis Exercise (0 - 300 Minutes), EGG-TMI-7833, September 1987.

10. Chan Y. Paik, "MAAP4 TMI-2 Benchmarks, MAAP4 Training Course Lecture 14," January 22$25,2002$.

11. ROSA Benchmarks for AP600 Summary Report, Proprietary Westinghouse Document.

12. S. M. Sloan and Y. Hassan, "Study of RELAP5/MOD2 and RELAP5/MOD3 predictions of a small-break loss-of-coolant accident simulation conducted at the ROSA-IV Large-Scale Test Facility," Nuclear Technology, 102, October 1992, pp 111-124.

13. D. L. Knudson, Analysis of 3BE Transients in AP600 using SCDAP/RELAP5, Revision 1, Idaho National Engineering Laboratory, 1995.

14. S. M. Jensen, D. W. Akers, and B. A. Pregger, "Postirradiation Examination Data and Analyses for OECD LOFT Fission Product Experiment LP-FP-2," OECD-LOFT-T-3810-V1 and V2, 1989.

15. C. L. Nalezny, Summary of Nuclear Regulatory Commission's LOFT Program Experiments, NUREG/CR-3214, EGG-2248, Idaho National Engineering Laboratory, 1983.

16. L. N. Kmetyk, MELCOR 1.8.1 Assessment: LOFT Integral Test LP-FP-2, SAND92-1373, Sandia National Laboratories, December 1992. 
17. A. Sharon, R. E. Henry, and M. A. Kenton, MAAP 3.0 Simulation of OECD LOFT Experiments LP-FP-2, EPRI Report NP-6178-L (1989).

18. W. A. Stewart et al., Natural Circulation Experiments for PWR Degraded Core Accidents, EPRI Report NP-6324-D, Westinghouse Electric Corporation, 1989.

19. W. A. Stewart et al., Natural Circulation Experiments for PWR High Pressure Accidents, EPRI Project RP2177-5 Final Report, Westinghouse Electric Corporation, 1992.

20. K. Almenas et al., Natural Circulation Induced Heating of Primary System Components: Final Report, University of Maryland at College Park, 1994.

21. P. D. Bayless et al., Severe Accident Natural Circulation Studies at the INEL, NUREG/CR-6285, Idaho National Engineering Laboratory, 1995.

22. D. L. Knudson, L. S. Ghan, and C. A. Dobbe, SCDAP/RELAP5 Evaluation of the Potential for Steam Generator Tube Ruptures as a Result of Severe Accidents in Operating Pressurized Water Reactors, INEEL/EXT-98-00286, Revision 1, 1998.

23. MELCOR Project Staff, "Severe Accident Natural Circulation Modeling using MELCOR," MELCOR User Group Meeting, Bethesda, MD, May 10-15, 2001.

24. K. M. Kelkar, R. C. Schmidt, and S. V. Patankar, "Numerical Analysis of Laminar Natural Convection for an Internally Heated Fluid in a Hemispherical Cavity," ANS Proceedings of the 1992 National Heat Transfer Conference, Volume 6, San Diego, CA, August 1992, pp. 355-364.

25. F. A. Kulacki, Review and Evaluation of 'Examination of Thermohydraulic Processes and Heat Transfer in a Core Melt, ' by Mayinger, Jahn, Reineke, and Steinbrenner, Letter report prepared for the U.S. N.R.C under contract AT(49-24)-0149, March 31, 1976.

26. B. D. Turland and J. Morgan (eds.) "Compendium of Post Accident Heat Removal Models for Liquid Metal Cooled Fast Breeder Reactors," European Applied Research Reports, Vol. 6, No. 5, April 1985.

27. F. A. Kulacki and D. E. Richards, "Natural Convection in Plane Layers and Cavities with Volumetric Energy Sources," Natural Convection, Fundamentals and Applications, Edited by S. Kakaç, W. Aung, and R. Viskanta, Washington, D. C.: Hemisphere Publishing Corporation, 1985.

28. U. Müller and T. Schulenberg, Post-Accident Heat Removal Research: A State of the Art Review, KfK 3601, November, 1983.

29. F. Mayinger, M. Jahn, H. H. Reineke, and V. Steinbrenner, Examination of Thermohydraulic Processes and Heat Transfer in a Core Melt, BMFT RS 48/1, Institut für Verfahrenstecknik der T. U., Hanover FRG (in German), 1976.

30. M. Jahn and H. H. Reineke, "Free Convection Heat Transfer with Internal Heat Sources," 5th Int. Heat Transfer Conference, Paper NC2.8, Tokyo, Japan, 1974. 
31. U. Steinberner and H. H. Reineke, "Turbulent Buoyancy Convection Heat Transfer with Internal Heat Sources," Proc. 6th Int. Heat Transfer Conf., Vol. 2, Toronto, Canada, August 1978, Paper NC-21, pp. 305-310.

32. O. Kymäläinen, H. Tuomisto, O. Hongisto, and T. G. Theofanous, "Heat Flux Distribution from a Volumetrically Heated Pool with High Rayleigh Number," NURETH-6 Meeting, Grenoble, France, October 1993.

33. J. D. Gabor, J. C. Cassulo, and P. C. Ellison, "Heat Transfer from Internally Heated Hemispherical Pools," ASME Paper 80-HAT-16, Presented at the 19th National Heat Transfer Conference, Orlando, FL, July 1980.

34. B. Frantz and V. Dhir, "Experimental Investigation of Natural Convection in Spherical Segments of Volumetrically Heated Pools" ASME Proceedings of the 1992 National Heat Transfer Conference, HTD-Vol. 192, Thermal Hydraulics of Severe Accidents, San Diego, CA, August 1992.

35. F. J. Asfia and V. K. Dhir, "Natural Convection Heat Transfer in Volumetrically Heated Spherical Pools," CSNI Workshop on Large Molten Pool Heat Transfer, Grenoble, France, March 1994.

36. J.H. Min and F. A. Kulacki, Steady and Transient Natural Convection with Volumetric Energy Sources in a Fluid Layer Bounded from Below by a Segment of a Sphere - Annual Report 6, July 1976-September 1977, NUREG/CR-0006, February, 1978.

37. J. L. Rempe, et al., Potential for AP600 In-Vessel Retention through Ex-Vessel Flooding, INEEL/EXT-97-00779, December 1997.

38. RASPLAV Final Report, Attachment B, Facilities: Components \& Instrumentation, July 2000.

39. J. L. Rempe, MASCA and RASPLAV Test Program - Description, Status, and Implications, INEEL/EXT-03-00224, February 2003.

40. U.S. Nuclear Regulatory Commission, "Reactor Safety Study," WASH 1400, NUREG/75-0114, October 1975.

41. M. L. Corradini, "Vapor Explosions: A Review of Experiments for Accident Analysis," Nuclear Safety, 32, No. 3, July - September 1991.

42. D. F. Fletcher, "Steam Explosion Triggering: A Review of Theoretical and Experimental Investigations," Nuclear Engineering and Design, 155, 1995.

43. Corradini, M. L., Kim, B. J. and Oh, M. D., "Vapor Explosions in Light Water Reactors: A Review of Theory and Modeling," Progress in Nuclear Energy, 22, No.1, pp.1-117, 1988.

44. Steam Explosion Review Group, A Review of Current Understanding of the Potential for Containment Failure Arising from In-Vessel Steam Explosions, Nuclear Regulatory Commission Report, NUREG-1116, February 1985.

45. S. Basu and T. P. Speis, "An Overview of Fuel-Coolant Interactions (FCI) Research at NRC," presented at the 23rd Water Reactor Safety Information Meeting, NUREG/CP-0149, Vol. 2, October 23-25, 1995, Bethesda, Maryland. 
46. S. Basu and T. Ginsberg, A Reassessment of the Potential for an Alpha-Model Containment Failure and a Review of the Current Understanding of Broader Fuel-Coolant Interaction Issues, Report of the Second Steam Explosion Review Group (SERG-2), NUREG-1524, 1996.

47. Magallon, D., Huhtiniemi, I., and Hohmann, H., "Lessons Learnt from FARO/TERMOS Corium Melt Quenching Experiments," Nuclear Engineering and Design, 189, pp.223-238, 1999.

48. Magallon, D. and Huhtiniemi, I., "Corium Melt Quenching Tests at Low Pressure and Subcooled Water in FARO, Nuclear Engineering and Design," 204, pp.369-376, 2001.

49. Magallon, D., "Characteristics of Corium Debris Bed Generated in Large-scale Fuel-Coolant Interaction Experiments," Nuclear Engineering and Design, 236, pp. 1998-2009, 2006.

50. Huhtiniemi, I., Magallon, D., and Hohmann, H., 1999, Results of Recent KROTOS FCI Tests: Alumina versus Corium Melts, Nuclear Engineering and Design, 189, pp.379-389.

51. Huhtiniemi, I. and Magallon, D., 2001, Insight into Steam Explosions with Corium Melts in KROTOS, Nuclear Engineering and Design, 204, pp.391-400.

52. J. H. Kim, et al., "A Study on Intermediate Scale Steam Explosion Experiments with Zirconia and Corium Melts," Transactions of the International Congress on Advanced Nuclear Power Plants (ICAPP), June 9-13, 2002, Hollywood, FL, USA.

53. Kim, J. H., Park, I. K., Min, B. T., Hong, S. W., Kim, H. Y., Song, J. H. and Kim, H. D., "Triggered Steam Explosions in the TROI Facility, " Proceedings of the Fifth International Conference on Advanced Power Plants (ICAPP5), Seoul, Korea, May 15-19, 2005.

54. J. H. Song, J. H. Kim, B. T. Min, and S. W. Hong, "The Effect of Composition on the Mechanism of Prototypic Steam Explosion," Eleventh Topical Meeting on Nuclear Reactor Thermal-Hydraulics (NURETH-11), Pope's Palace Conference Center, Avignon, France, October 2-6, 2005.

55. J. R. Wolf and J. L. Rempe, TMI-2 Vessel Investigation Project Integration Report, TMI V(93) EG10, October 1993.

56. T.Theofanous, C. Liu, S. Additon, S. Angelini, O. Kymäläinen, and T. Salmassi, In-Vessel Coolability and Retention of Core Melt, DOE/ID-10460, October 1996.

57. J. Rempe, et. al., "Margin-to-Failure Calculations for the TMI-2 Vessel," Nuclear Safety, Vol. 35, No. 2, July-December 1994, p 313.

58. Kang, K. H., Kim, J. H, Kim S. B., Hong, J. H., and Kim, H. D. KIM., "Experimental Investigations on In-Vessel Debris Coolability through Inherent Cooling Mechanisms: LAVA," OECD/CSNI Workshop on In-Vessel Debris Retention and Coolability, Garching, Germany, 1998.

59. Maruyama, Y., et al., "Analysis of Debris Coolability Experiments in ALPHA Program with CAMP Code," Ninth International Topical Meeting on Nuclear Reactor Thermal Hydraulics (NURETH-9), San Francisco, California, October 3-8, 1999.

60. Fauske and Associates, Inc., Experiments to Address Lower Plenum Response under Severe Accident Conditions, EPRI TR-1033890V1, Project 3130-02, Final Report, April 1994. 
61. B.R.Sehgal, R.R. Nourgaliev, T.N. Dinh, A. Karbojian, V.A. Bui, and J.A.Green, "FOREVER Experiment on Thermal and Mechanical Behavior of a Reactor Vessel during a Severe Accident," Proceedings of the OECD/CSNI Workshop on 'In-Vessel Core Debris Retention and Coolability', Garching, Germany, 3-6 March, 1998.

62. B. R. Sehgal, A. Giri, U. Chikkanagoudar, and A. Karbojian, "Experiments on In-vessel Melt Coolability in the EC-FOREVER, Program," Nuclear Engineering and Design, 236, 2006, 2199 2210.

63. Reinke, N., Drath, T., Berlepsch, T., Unger, H., and Koch, M., "Formation, Characterization, and Cooling of Debris Scenario Discussion with Emphasis on TMI-2," Nuclear Engineering and Design, 236, pp. 1955-1964, 2006.

64. J. L. Rempe, et al., Light Water Reactor Lower Head Failure Analysis, NUREG/CR-5642, EGG2618, October 1993.

65. J. L. Rempe, K. G. Condie, and D. L. Knudson, Thermal Properties for Candidate SCWR Materials, INL/EXT-05-01030, December 2005.

66. J. L. Rempe and D. L. Knudson, "High temperature Thermal Properties for Metals used in LWR Vessels," accepted for publication by the Journal of Nuclear Materials, March 2007.

67. L. A. Stickler, J. L. Rempe, S. A. Chàvez, G. L. Thinnes, S. D. Snow, R. J. Witt., M. L. Corradini, and J. A. Kos, Calculations to Estimate the Margin-to-Failure in the TMI-2 Vessel, OECD-NEATMI-2 Vessel Investigation Project, TMI V(93) EG01, September 1993 (Also issued as NUREG/CR-6196, EGG-2733, February 1994).

68. T. Y. Chu, M. M. Pilch, J. H. Bentz, J. S. Ludwigsen, Y-Y Lu, and L. L. Humphries, "Lower Head Failure Experiments and ANalyses, NUREG/CR-5582 (SAND98-2047), February 1999A. L. Camp, et al., Light Water Reactor Hydrogen Manual, NUREG/CR-2726, SAND92-1137, August 1983.

69. Idaho National Engineering and Environmental Laboratory, SCDAP/RELAP5-3D ${ }^{\complement}$ Code Manuals - Volume 4 - MATPRO-A Library of Materials Properties for Light-Water-Reactor Accident Analysis, INEEL/EXT-02-00589, Idaho National Engineering and Environmental Laboratory, May 2002.

70. M. Fischer and W. Schmidt, "Description and Validation of the Improved Gate Design," AREVA NP GmbH Document NGPS4/2005/en/1026, July 7, 2005 (proprietary).

71. M. Fischer, "Long-term melt stabilization as part of the severe accident mitigation strategy of the European Pressurized Reactor (EPR)," Proceedings of the 2005 International Congress on Advances in Nuclear Power Plants (ICAPP '05), May 15-19, 2005, Seoul, South Korea.

72. M. Nie and M. Fischer, "Use of Molten Core Concrete Interactions in the Melt Stabilization Strategy of the EPR," Proceedings of the 2006 International Congress on Advances in Nuclear Power Plants (ICAPP '06), June 4-8, 2006, Reno, NV, USA. 
73. M. Fischer, "Description and R\&D-Background of the Core Melt Stabilization Concept of the EPR," AREVA NP GmbH Document NGPS4/2003/en/0196, Rev. E, July 20, 2004 (proprietary).

74. J. Eyink, M. Fischer, and M. Nie, $R \& D$ in Support of Core Melt Stabilization and Hydrogen Control, AREVA Document, April 27, 2006 (unreleased proprietary report).

75. J. L. Rempe, et al., In-Vessel Retention Strategy for High Power Reactors, Final Report, INEEL/EXT-04-02561, January 2005.

76. B. Eppinger, et al., "Investigations on the Melt Gate Ablation by Ex-vessel Core Melts in the KAPOOL Experiments," Proceedings of the Tenth International Conference on Nuclear Engineering (ICONE10), Arlington, VA, April 14-18, 2002.

77. B. Eppinger, et al., "KAPOOL Experiments on Melt-Through of a Metal Plate by an Overlying Melt Pool," Forschungszentrum Karlsruhe, FZKA 7024, August 2004.

78. W. Steinwarz, et al., "Investigations on the Phenomenology of Ex-vessel Core Behavior, Final Report, EU 4th FWP, EXV-COMAS(99) D-27, 1999.

79. W. Steinwarz, et al., "Experimental Investigations on Corium Interaction with Refractory and Sacrificial Layers (CORESA)," - BMWI project 1401212, Final Report, November 2002, Seimpelkamp Nukleartechnik GmbH, SNT-AB-2002-01.

80. W. Häfner, "Experimental Investigations on Corium Interaction with Refractory and Sacrificial Layers (CORESA) BMWI Project 1501210, Final Report, October 2001, Battelle Ingenieurtechnik GmbH, BF-40.092-8, 2001.

81. M. Farmer, "Melt Eruption Test (MET-1) Results," presentation at the 6th Program Review Meeting of the MCCI-OECD Project, Madrid, Spain, April 2005.

82. B. R. Sehgal, et al., "Experimental Investigations on Vessel Hole Ablation during Severe Accidents," SKI Report 97:44, Swedish Nuclear Power Inspectorate, Sweden, December 1997.

83. B. R. Sehgal, et al., "Experimental and Analytical Investigations of VEssel-Hole Ablation during Severe Accidents," Proceedings of the Fifth International Topical Meeting in Nuclear Thermal Hydraulics, Operations, and Safety (NUTHOS-5)," Beijing, China, April 1997.

84. G. Albrecht, at al., "KAJET Experiments on Pressure Driven Melt Jets and their Interaction with Concrete," Technical Report, FZKA 7002, Forschungzentrum, Karlsruhe, Germany, February 2005.

85. S. Rouge, I Dor, and G. Greffraye, "Reactor Vessel External Cooling for Corium Retention SULTAN Experimental Program and Modeling with CATHARE Code", OECD WOrkshop on In-Vessel Debris Retention and Coolability, Garching, Germany, March 3-6, 1998.

86. D. Lange and D. Bitterman, "The R\&D Performed in Support to the EPR," Thirteenth International Conference on Nuclear Engineering (ICONE13), Paper 50432, Beijing, China, May 16-20, 2005. 
87. M. Fischer, O. Herbst, and H. Schmidt, "Demonstration of the Heat Removing Capabilities of the EPR Core Catcher," Proceedings of the 3rd International Symposium on Two-Phase Flow Modeling and Experimentation, Pisa, Italy, September 22-24, 2004.

88. W. Steinwarz, et al., "Experimental Investigations on Corium Interaction with Refractory and Sacrificial Layers (CORESA)," BMWI Project 150211, Final Report, November 2002.

89. B. Eppinger, et al., "Simulationexperimente zum Ausbreitungsverhalten von Kernschmelze: KATS 8-17," Forschungszentrum, Karlsruh, FZKA 6589, März 2001.

90. H. Alsmeyer, et al., "Ex-vessel Core-Melt Stabilization Research (ECOSTAR)," Proceedings of FISA 2003, Luxemborg, November 2003.

91. D. G. Thompson, et al., Compilation, Analysis and Interpretation of ACE Phase C and MACE Experimental Data - MCCI Thermohydraulic Results, ACEX TR-C14, Vol. 1; Argonne National Laboratory, November 1997.

92. B. W. Spencer, et al., MACE Scoping Test, MACE-TR-D03, June 1991.

93. M. T. Farmer, et al., MACE Test M3b, Data Report, MACE-TR-D13, Volumes 1 and 2, November 1997.

94. M. T. Farmer, et al., MACE Test M4, Data Report, MACE-TR-D16, August 1999.

95. M. T. Farmer and B. W. Spencer, "A Review of the Database pertaining to Ex-Vessel Debris Coolability," ACEX-TR-C34, Argonne National Laboratory, Argonne, IL, 2000.

96. M. T. Farmer, S. Lomperski, and S. Basu, "Results of Reactor Material Experiments Investigating 2-D Core-Concrete Interaction and Debris Coolability," Proceedings of the 2004 International Congress on Advances in Nuclear Power Plants (ICAPP '04), Pittsburgh, PA, June 13-17, 2004.

97. M. T. Farmer, S. Lomperski, and S. Basu, "Status of the Melt Coolability and Concrete Interaction Program (MCCI) at Argonne National Laboratory," Proceedings of the 2005 International Congress on Advances in Nuclear Power Plants (ICAPP '05), May 15-19, 2005, Seoul, South Korea.

98. H. Alsmeyer and W. Tromm, The COMET Concept for Cooling Core Melts: Evaluation of the Experimental Studies and Use in the EPR, FZKA 6186, EXV-CSC(99)D036, Forschungszentrum Karlsruhe, 1999.

99. H. Alsmeyer, et al., "The COMET Concept for Cooling of Ex-vessel Corium Melts," Proceedings from the Sixth International Conference on Nuclear Engineering (ICONE6), San Diego, May 10$15,1998$.

100. B. Touniaire and J. Seiler, "Study of the Mixing of Immiscible Liquids. Results of the BALISE Experiments," proceedings from the Tenth International Topical Meeting on Nuclear Reactor THermal Hydraulics (NURETH10), Seoul, Korea, October 5-9, 2003.

101. J. M. Bonnet, "Thermal Hydraulic Phenomena in Corium Pools for Ex-vessel Situations; The BALI Experiment," OECD Workshop on Ex-vessel Coolability," Karlsruhe, Germany, 1999, FZKA 64753. 
102. H. Alsmeyer, et al., "BETA Experimental Results on Melt/Concrete Interaction," CSNI Specialist's Meeting on Core-Debris-Concrete Interaction, EPRI-NP-5054-5R, pp 2-2 through 2-17, February, 1987.

103. S. Lomperski, M. T. Farmer, and S. Basu, "Experimental Investigation of Corium Quenching at Elevated Pressure," Nuclear Engineering and Design, 236, pp. 2271-2280, 2006.

104. Y. Maruyama, Y. Kojima, M. Tahara, H. Nagasaka, M. Kato, A. Kolodeshnikov, V. Zhdanov, and Y. Vassiliev, "A Study on Concrete Degradation during Molten Core/Concrete Interactions," Nuclear Engineering and Design, 236, pp. 2237-2244, 2006.

105. F. Bouteille, et al., "The EPR Overall Approach for Severe Accident Mitigation," Nuclear Engineering and Design, 236, August 2006, pp 1464-1470.

106. Z.M. Shapiro and T. R. Moffette, "Hydrogen Flammability Data and Applicability to PWR Lossof-Coolant Accident,"WAPD-SC-545, Bettis Plant, September 1957.

107. W. Breitung, et al., Flame Acceleration and Deflagration to Detonation Transition in Nuclear Safety, OECD Nuclear Energy Agency Report NEA/CSNI/R(2000)7, August 2000.

108. J. Eyink, The EPR Hydrogen Mitigation Concept, AREVA NP GmbH Document NGPS4/2003/EN0192, Rev. D, July 20, 2004 (proprietary).

109. J. Eyink, PSA Level 2: 4. Description of the Phenomena, AREVA NP GmbH Document NGPS4/2003/en/029, January 29, 2004 (proprietary).

110. L. Wolf, et al., "Detailed Assessment of the HDR Mixing Experiments," Proceedings of the International Conference, New Trends in Nuclear System Thermohydraulic, Pisa, Italy, 1994.

111. L. Wolf, H. Holzbauer, and T. Cron, "Detailed assessment of the HDR H2 mixing experiments E11, Battelle-HDR," Nuclear Technology, Vol 125, pp 119-135. February 1999.

112. L. Wolf, A. Rastogi A, D. Wennerberg, T. Cron, and E. Hansjosten, "Detailed assessment of the HDR $\mathrm{H}_{2}$ Deflagration Experiments E12," Battelle-HDR. Nuclear Technology, Vol 125, pp 136154. February 1999.

113. T. Kanzleiter, "Multiple Hydrogen-Recombiner Experiments Performed in the Batelle Model Containment: Multi-Reco Experiment Zx08," Technical Report BF-V68.405-01, CONTVOASM(97)-P001, Battelle Ingenieurtecnik, Eschborn, Germany, April 1997.

114. T. Kanzleiter, "Multiple Hydrogen-Recombiner Experiments Performed in the Battelle Model Containment: Multi-Reco Experiment Zx02 and Zx05," Technical Report BF-R40.084-01, CONT-HYMI(97)-P004, Battelle Ingenieurtecnik, Eschborn, Germany, March 1997.

115. T. Kanzleiter, "Experimental Investigation on Recombiner Efficiency in the Batelle Model Containment," International Workshop on Hydrogen Research for Reactor Safety, Munich, September 1994. 
116. G. Langer, et al., "Experimental Investigation of the Hydrogen Distribution in the Containment of a Light Water Reactor following a Coolant Loss Accident," Battelle Report BF-R-63.363.3, NRC Translation 801 (1980).

117. Organization for Economic Cooperation and Development, "Final Comparison Report on ISP-35: NUPEC $\mathrm{H}_{2}$ Mixing and Distribution test (Test M-7-1)," NEA/CSNI/R(94)29, OECD/GD(95)29, December 1994.

118. Nuclear Power Engineering Corporation (NUPEC), System Safety Department, "Specification of ISP-35-NUPEC's Hydrogen Mixing and Distribution Test- Test M-5-5 ISP35-027, Rev. 1, NUPEC, November 3-4, 1993.

119. M. A. Jiménez, J. M. Martín-Valdepeñas, and F. Martín-Fuertes, "MELCOR 1.8.3 application to NUPEC M-7-1 Test (ISP-35) and two hydrogen severe accident scenarios in a typical PWR plant," OECD/NEA/CSNI Workshop on the Implementation of Hydrogen Mitigation Techniques, Winnipeg, Manitoba, 1996 May 13-15, AECL-11762, NEA/CSNI/R(96)8. March 1997.

120. J. Vendel, et al., "ISP 47 "Containment thermal-hydraulics" Computer codes exercise based on TOSQAN, MISTRA and THAI experiments," presented at the Eurosafe Forum for Nuclear Safety, November 4-5, 2002, Berlin, Germany.

121. M A Jiménez, "Deliverable D27: A Methodology for Combustion Risk Assessment," NNC Report CTN-04/03, C69101, December 2003.

122. S. B. Dorofeev, et al., Recent Experimental and Analytical Results on Hydrogen Combustion at RRC "Kurchatov Institute," presented at the 23rd Water Reactor Safety Information Meeting, October 23-25, 1995, Bethesda, Maryland.

123. O. Braillard, et al., "Test of Passive Catalytic Recombiners (PARs) for Combustible Gas Control in Nuclear Power Plants," Proc. 2nd Int. Top. Meeting. on Advanced Reactor Safety ARS'97, Orlando, Florida, June 1997, 541-548.

124. G. Avakian, et al., "Validation of a Catalytic Recombiner Model for KALI Experiments", Experimental Heat Transfer, Fluid Mechanics and Thermodynamics, 1997.

125. E. Studer, M. Durin, M. Petit, P. Rongier, J. Vendel, D. Leteinturier, and S. Dorofeev, "Assessment of Hydrogen Risk in PWR," IPSN/GRS Eurosafe Meeting, Paris, France, November 18-19, 1999. 